\title{
A translation control module coordinates germline stem cell differentiation with ribosome biogenesis during Drosophila oogenesis
}

\author{
Elliot T. Martin ${ }^{1 *}$, Patrick Blatt ${ }^{1 *}$, Elaine Ngyuen ${ }^{2}$, Roni Lahr $^{2}$, Sangeetha Selvam ${ }^{1}$, Hyun Ah M. \\ Yoon $^{1,3}$, Tyler Pocchiari ${ }^{1,4}$, Shamsi Emtenani ${ }^{5}$, Daria E. Siekhaus ${ }^{5}$, Andrea Berman ${ }^{2}$, Gabriele \\ Fuchs $^{1 \dagger}$ and Prashanth Rangan ${ }^{1 \dagger}$ \\ ${ }^{1}$ Department of Biological Sciences/RNA Institute, University at Albany SUNY, Albany, NY \\ 12202
}

${ }^{2}$ Department of Biological Sciences, University of Pittsburgh, Pittsburgh, PA 15260

${ }^{3}$ Albany Medical College, Albany, NY 12208

${ }^{4}$ SUNY Upstate Medical University, Syracuse, NY 13210-2375

${ }^{5}$ Institute of Science and Technology Austria, Klosterneuburg, Austria

*These authors contributed equally to this work

\author{
${ }^{\dagger}$ Co-corresponding authors \\ Email: gfuchs@albany.edu, prangan@albany.edu
}

Summary: Ribosomal defects perturb stem cell differentiation, causing diseases called ribosomopathies. How ribosome levels control stem cell differentiation is not fully known. Here, we discovered three RNA helicases are required for ribosome biogenesis and for Drosophila oogenesis. Loss of these helicases, which we named Aramis, Athos and Porthos, lead to aberrant stabilization of p53, cell cycle arrest and stalled GSC differentiation. Unexpectedly, Aramis is required for efficient translation of a cohort of mRNAs containing a 5'-Terminal-Oligo-Pyrimidine (TOP)-motif, including mRNAs that encode ribosomal proteins and a conserved p53 inhibitor, Novel Nucleolar protein 1 (Non1). The TOP-motif co-regulates the translation of growth-related mRNAs in mammals. As in mammals, the La-related protein co-regulates the translation of TOPmotif containing RNAs during Drosophila oogenesis. Thus, a previously unappreciated TOP-motif in Drosophila responds to reduced ribosome biogenesis to co-regulate the translation of ribosomal proteins and a p53 repressor, thus coupling ribosome biogenesis to GSC differentiation.

\section{Introduction}

All life depends on the ability of ribosomes to translate mRNAs into proteins. Despite this universal requirement, ribosome biogenesis is not universally equivalent. Stem cells, the unique cell type that underlies the generation and expansion of tissues, in particular have a distinct ribosomal requirement (Gabut et al., 2020; Sanchez et al., 2016; Woolnough et al., 2016; Zahradkal et al., 1991; Zhang et al., 2014). Ribosome production and levels are dynamically regulated to maintain higher amounts in stem cells (Fichelson et al., 2009; Gabut et al., 2020; Sanchez et al., 2016; Woolnough et al., 2016; Zahradkal et al., 1991; Zhang et al., 2014). For example, ribosome biogenesis components are often differentially expressed, as observed during differentiation of embryonic stem cells, osteoblasts, and myotubes (Gabut et al., 2020; Watanabe-Susaki et al., 2014; Zahradkal et al., 1991). In some cases, such as during Drosophila germline stem cell (GSC) division, ribosome biogenesis factors asymmetrically segregate during asymmetric cell division, such that a higher pool of ribosome biogenesis factors is maintained in the stem cell compared to the daughter cell (Blatt et al., 2020a; Fichelson et al., 2009; Zhang et al., 2014). Reduction of 
ribosome levels in several stem cells systems can cause differentiation defects (Corsini et al., 2018; Fortier et al., 2015; Khajuria et al., 2018; Zhang et al., 2014). In Drosophila, perturbations that reduce ribosome levels in the GSCs result in differentiation defects causing infertility (Sanchez et al., 2016). Similarly, humans with reduced ribosome levels are afflicted with clinically distinct diseases known as ribosomopathies, such as Diamond-Blackfan anemia, that often result from loss of proper differentiation of tissue-specific progenitor cells (Armistead and Triggs-Raine, 2014; Barlow et al., 2010; Brooks et al., 2014; Higa-Nakamine et al., 2012; Lipton et al., 1986; Mills and Green, 2017). However, the mechanisms by which ribosome biogenesis is coupled to proper stem cell differentiation remain incompletely understood.

Ribosome production requires the transcription of ribosomal RNAs (rRNAs) and of mRNAs encoding ribosomal proteins (Bousquet-Antonelli et al., 2000; de la Cruz et al., 2015; Granneman et al., 2011, 2006; Tafforeau et al., 2013; Venema et al., 1997). Several factors, such as helicases and endonucleases, transiently associate with maturing rRNAs to facilitate rRNA processing, modification, and folding (Granneman et al., 2011; Sloan et al., 2017; Tafforeau et al., 2013; Watkins and Bohnsack, 2012). Ribosomal proteins are imported into the nucleus, where they assemble with rRNA to form the small $40 \mathrm{~S}$ and large 60S ribosome subunits, which are then exported to the cytoplasm (Baxter-Roshek et al., 2007; Decatur and Fournier, 2002; Granneman et al., 2011, 2006; Koš and Tollervey, 2010; Nerurkar et al., 2015; Tafforeau et al., 2013; Zemp and Kutay, 2007). Loss of RNA Polymerase I transcription factors, helicases, exonucleases, large or small subunit ribosomal proteins, or other processing factors all compromise ribosome biogenesis and trigger diverse stem cell-related phenotypes (Brooks et al., 2014; Calo et al., 2018; Mills and Green, 2017; Sanchez et al., 2016; Yelick and Trainor, 2015; Zhang et al., 2014).

Nutrient availability influences the demand for de novo protein synthesis and thus ribosome biogenesis (Anthony et al., 2000; Hong et al., 2012; Mayer and Grummt, 2006; Shu et al., 2020). In mammals, nearly all of the mRNAs that encode the ribosomal proteins contain a Terminal Oligo Pyrimidine (TOP) motif within their 5' untranslated region (UTR), which regulates their translation in response to nutrient levels (Fonseca et al., 2015; Hong et al., 2017; Lahr et al., 2017; Tcherkezian et al., 2014). Under growth-limiting conditions, La related protein 1 (Larp1) binds to the TOP sequences and to mRNA caps to inhibit translation of ribosomal proteins (Fonseca et al., 2015; Jia et al., 2021; Lahr et al., 2017; Philippe et al., 2018). When growth conditions are suitable, Larp1 is phosphorylated by the nutrient/redox/energy sensor mammalian Target of rapamycin (mTOR) complex 1 (mTORC1), and does not efficiently bind the TOP sequence, thus allowing for efficient translation of ribosomal proteins (Fonseca et al., 2018, 2015; Hong et al., 2017; Jia et al., 2021). In some instances, Larp1 binding can also stabilize TOP-containing mRNAs (Aoki et al., 2013; Berman et al., 2020; Gentilella et al., 2017; Ogami et al., 2020), linking mRNA translation with mRNA stability to promote ribosome biogenesis (Aoki et al., 2013; Berman et al., 2020; Fonseca et al., 2018, 2015; Hong et al., 2017; Lahr et al., 2017; Ogami et al., 2020; Philippe et al., 2018). Cellular nutrient levels are known to affect stem cell differentiation and oogenesis in Drosophila (Hsu et al., 2008), however whether TOP motifs exist in Drosophila to coordinate ribosome protein synthesis is unclear. The Drosophila ortholog of Larp1, La related protein (Larp) is required for proper cytokinesis and meiosis in Drosophila testis as well as for female fertility, but its targets remain undetermined (Blagden et al., 2009; Ichihara et al., 2007).

83 Germline depletion of ribosome biogenesis factors manifests as a stereotypical GSC 84 differentiation defect during Drosophila oogenesis (Sanchez et al., 2016). Female Drosophila 85 maintain 2-3 GSCs in the germarium (Figure 1A) (Kai et al., 2005; Twombly et al., 1996; Xie, 86 2000; Xie and Li, 2007; Xie and Spradling, 1998). Asymmetric cell division of GSCs produces a 87 self-renewing daughter GSC, and a differentiating daughter, called the cystoblast (CB) (Chen and 88 McKearin, 2003; McKearin and Ohlstein, 1995). This asymmetric division is unusual: following 


\section{Results}

mitosis, the abscission of the GSC and CB is not completed until the following G2 phase (Figure 1A') (De Cuevas and Spradling, 1998; Hsu et al., 2008). The GSC is marked by a round structure called the spectrosome, which elongates and eventually bridges the GSC and CB, similar to the fusomes that connect differentiated cysts (Figure 1A'). During abscission the extended spectrosome structure is severed and a round spectrosome is established in the GSC and the CB (De Cuevas and Spradling, 1998; Hsu et al., 2008). Ribosome biogenesis defects result in failed GSC-CB abscission, causing cells to accumulate as interconnected cysts marked by a fusome-like structure called "stem cysts" (Figure 1A') (Mathieu et al., 2013; Sanchez et al., 2016). In contrast with differentiated cysts (McKearin and Ohlstein, 1995; McKearin and Spradling, 1990; Ohlstein and McKearin, 1997), these stem cysts lack expression of the differentiation factor Bag of Marbles (Bam), do not differentiate, and typically die, resulting in sterility (Sanchez et al., 2016). How proper ribosome biogenesis promotes GSC abscission and differentiation is not known.

By characterizing three RNA helicases that promote ribosome biogenesis, we identified a translational control module that is sensitive to proper ribosome biogenesis and coordinates ribosome levels with GSC differentiation. When ribosome biogenesis is optimal, ribosomal proteins and a p53 repressor are both efficiently translated allowing for proper GSC cell cycle progression and its differentiation. However, when ribosome biogenesis is perturbed, we observe diminished translation of both ribosomal proteins and the p53 repressor. As a consequence, p53 is stabilized, cell cycle progression is blocked and GSC differentiation is stalled. Thus, our work reveals an elegant tuning mechanism that links ribosome biogenesis with a cell cycle progression checkpoint and thus stem cell differentiation. Given that ribosome biogenesis defects in humans result in ribosomopathies, which often result from stem cell differentiation defects, our data lay the foundation for understanding the etiology of developmental defects that arise due to ribosomopathies.

Three conserved RNA helicases are required in the germline for GSC differentiation We performed a screen to identify RNA helicases that are required for female fertility in Drosophila, and identified three predicted RNA helicases with previously uncharacterized functions, CG5589, CG4901, and CG9253 (Figure 1B-C) (Supplemental Table 1) (Blatt et al., 2020b). We named these candidate genes aramis, athos, and porthos, respectively, after Alexandre Dumas' three musketeers who fought in service of their queen. To further investigate how these helicases promote fertility, we depleted aramis, athos, and porthos in the germline using the germline-driver nanos-GAL4 (nosGAL4) in combination with RNAi lines. We detected the germline and spectrosomes/fusomes in ovaries by immunostaining for Vasa and 1B1, respectively. In contrast to controls, aramis, athos, and porthos germline RNAi flies lacked spectrosome-containing cells, and instead displayed cells with fusome-like structures proximal to the self-renewal niche (Figure 1D-H; Figure S1A-A"'). The cells in this cyst-like structure contained ring canals, a marker of cytoplasmic bridges, suggesting that they are indeed interconnected (Figure S1B-B"') (Zhang et al., 2014). In addition to forming cysts in an aberrant location, the aramis, athos, and porthos germline RNAi ovaries failed to form egg chambers (Figure 1D-H).

Aberrant cyst formation proximal to the niche could reflect stem cysts with GSCs that divide to give rise to CBs but fail to undergo cytokinesis or differentiated cysts that initiate differentiation but cannot progress further to form egg chambers. To discern between these possibilities, first we examined the expression of a marker of GSCs, phosphorylated Mothers against decapentaplegic (pMad). We observed pMad expression in the cells closest to the niche, but not elsewhere in the germline cysts of aramis, athos, and porthos germline RNAi flies (Figure S1C- 
F') (Kai and Spradling, 2003). Additionally, none of the cells connected to the GSCs in aramis, athos, and porthos germline RNAi flies expressed the differentiation reporter bamGFP (Figure 1D-G') (McKearin and Ohlstein, 1995). Thus, loss of aramis, athos, or porthos in the germline results in the formation of stem cysts, however with variable severity. This variability could be due to a differential requirement for these genes or different RNAi efficiencies. Overall, we infer that Aramis, Athos, and Porthos are required for proper GSC cytokinesis to produce a stem cell and differentiating daughter.

\section{Athos, Aramis, and Porthos are required for ribosome biogenesis}

We found that Aramis, Athos, and Porthos are conserved from yeast to humans (Figure 1B). The closest orthologs of Aramis, Athos, and Porthos are Rok1, Dhr2, and Rrp3 in yeast and DExDBox Helicase 52 (DDX52), DEAH-Box Helicase 33 (DHX33), and DEAD-Box Helicase 47 (DDX47) in humans, respectively (Hu et al., 2011). Both the yeast and human orthologs have been implicated in rRNA biogenesis (Bohnsack et al., 2008; Khoshnevis et al., 2016; Martin et al., 2014; O 'day et al., 1996; Sekiguchi et al., 2006; Tafforeau et al., 2013; Venema et al., 1997; Venema and Tollervey, 1995; Vincent et al., 2017; Zhang et al., 2011). In addition, the GSCcytokinesis defect that we observed in aramis, athos, and porthos RNAi flies is a hallmark of reduced ribosome biogenesis in the germline (Sanchez et al., 2016). Based on these observations, we hypothesized that Aramis, Athos, and Porthos could enhance ribosome biogenesis to promote proper GSC differentiation.

Many factors involved in rRNA biogenesis localize to the nucleolus and interact with rRNA (Arabi et al., 2005; Grandori et al., 2005; Henras et al., 2008; Karpen et al., 1988). To detect the subcellular localization of Aramis and Athos, we used available lines that express Aramis::GFP::FLAG or Athos::GFP::FLAG fusion proteins under endogenous control. For Porthos, we expressed a Porthos::FLAG::HA fusion under the control of UASt promoter in the germline using a previously described approach (DeLuca and Spradling, 2018). We found that in the germline, Aramis, Athos and Porthos colocalized with Fibrillarin, which marks the nucleolus, the site of rRNA synthesis (Figure 2A-C"') (Ochs et al., 1985). Aramis was also in the cytoplasm of the germline and somatic cells of the gonad. To determine if Aramis, Athos, and Porthos directly interact with rRNA, we performed immunoprecipitation (IP) followed by RNA-seq. We found that rRNA immunopurified with Aramis, Athos, and Porthos (Figure 2D-D", Figure S2A-A'). Thus, Aramis, Athos, and Porthos are present in the nucleolus and interact with rRNA, suggesting that they might regulate rRNA biogenesis.

Nucleolar size, and in particular nucleolar hypotrophy, is associated with reduced ribosome biogenesis and nucleolar stress (Neumüller et al., 2008; Zhang et al., 2011). If Aramis, Athos, and Porthos promote ribosome biogenesis, then their loss would be expected to cause nucleolar stress and a reduction in mature ribosomes. Indeed, immunostaining for Fibrillarin revealed hypotrophy of the nucleolus in aramis, athos, and porthos germline RNAi flies compared to in control flies, consistent with nucleolar stress (Figure S2B-C). Next, we used polysome profile analysis to evaluate the ribosomal subunit ratio and translation status of ribosomes in S2 cells depleted of aramis, athos, or porthos (Boamah et al., 2012; Õunap et al., 2013). We found that upon the depletion of all three helicases, the heights of the polysome peaks were reduced (Figure 2E-E'). We found that depletion of aramis and porthos diminished the height of the 40S subunit peak compared to the 60S subunit peak, characteristic of defective $40 \mathrm{~S}$ ribosomal subunit biogenesis (Figure 2E, E', Figure S2D) (Cheng et al., 2019), whereas athos depletion diminished the height of the $60 \mathrm{~S}$ subunit peak compared to the $80 \mathrm{~S}$ peaks, characteristic of a $60 \mathrm{~S}$ ribosomal subunit biogenesis defect (Figure 2E', Figure S2D') (Cheng et al., 2019). RNAimediated depletion of the orthologs of these helicases in HeLa cells similarly affected the 
184

185

186

187

188

189

190

191

192

193

194

195

196

197

198

199

200

201

202

203

204

205

206

207

208

209

210

211

212

213

214

215

216

217

218

219

220

221

222

223

224

225

226

227

228

229

230

231

232

polysome profiles (Figure 2F'-F', Figure S2E-G). Taken together our findings indicate that these helicases promote ribosome biogenesis in Drosophila and mammalian cells.

\section{Aramis promotes cell cycle progression via $\mathrm{p} 53$ repression}

Our data so far indicate that Aramis, Athos and Porthos promote ribosome biogenesis, which is known to be required for GSC abscission (Sanchez et al., 2016). Yet the connections between ribosome biogenesis and GSC abscission are poorly understood. To explore the connection, we further examined the aramis germline RNAi line, as its defect was highly penetrant but maintained sufficient germline for analysis (Figure 1E, H). First, we compared the mRNA profiles of aramis germline RNAi ovaries to bam germline RNAi to determine if genes that are known to be involved in GSC abscission have altered expression. We used germline bam depletion as a control because it leads to the accumulation of CBs with no abscission defects (Flora et al., 2018a; Gilboa et al., 2003; McKearin and Ohlstein, 1995; Ohlstein and McKearin, 1997), whereas loss of aramis resulted in accumulation of CBs that do not abscise from the GSCs.

We performed RNA-seq and found that 607 RNAs were downregulated and 673 RNAs were upregulated in aramis germline RNAi versus bam germline RNAi (cut-offs for differential gene expression were $\log _{2}$ (foldchange) $>|1.5|$, FDR < 0.05) (Figure S3A, Supplemental Table 2). Gene Ontology (GO) analysis for biological processes on these genes encoding these differentially expressed mRNAs (Thomas et al., 2003) revealed that the genes that were downregulated upon aramis germline depletion were enriched for $\mathrm{GO}$ terms related to the cell cycle, whereas the upregulated genes were enriched for $\mathrm{GO}$ terms related to stress response (Figure 3A, Figure S3B). The downregulated genes included Cyclin $A$, which is required for cell cycle progression, Cyclin $B(C y c B)$ and aurora $B$, which are required for both cell cycle progression and cytokinesis; in contrast the housekeeping gene Actin $5 \mathrm{C}$ was unaffected (Figure 3B-C, Figure S3C-C') (Mathieu et al., 2013; Matias et al., 2015). We confirmed that CycB was reduced in the ovaries of aramis germline RNAi flies compared to bam germline RNAi flies by immunofluorescence (Figure 3D-F). These results suggest that aramis is required for the proper expression of key regulators of GSC abscission.

CycB is expressed during G2 phase after asymmetric cell division to promote GSC abscission (Flora et al., 2018a; Mathieu et al., 2013). To test if the loss of germline aramis leads to GSC abscission defects due to diminished expression of $\mathrm{CycB}$, we attempted to express a functional CycB::GFP fusion protein in the germline under the control of a UAS/GAL4 system (Figure S3DD') (Mathieu et al., 2013). Unexpectedly, the CycB::GFP fusion protein was not expressed in the aramis-depleted germline, unlike the wild type (WT) germline (Figure S3E-E') (Glotzer et al., 1991; Mathieu et al., 2013; Zielke et al., 2014). We considered the possibility that progression into $\mathrm{G} 2$ is blocked in the absence of aramis, precluding expression of CycB. To monitor the cell cycle, we used the Fluorescence Ubiquitin-based Cell Cycle Indicator (FUCCI) system. Drosophila FUCCl utilizes a GFP-tagged degron from E2f1 to mark G2, M, and G1 phases and an RFPtagged degron from $\mathrm{CycB}$ to mark S, G2, and M phases (Zielke et al., 2014). We observed cells in different cell cycle stages in both WT and bam-depleted germaria, but the aramis-depleted germaria expressed neither GFP nor RFP (Figure S3F-H'). Double negative reporter expression is thought to indicate early $S$ phase, when expression of E2f1 is low and CycB is not expressed (Hinnant et al., 2017). The inability to express FPs is not due to a defect in translation as aramisdepleted germline can express GFP that is not tagged with the degron (Figure S3I-I'). Taken together, we infer that loss of aramis blocks cell cycle progression around late G1 phase/early $\mathrm{S}$ phase and prevents progression to G2 phase, when GSCs abscise from CBs.

In mammals, cells defective for ribosome biogenesis stabilize p53, which is known to impede the G1 to S transition (Agarwal et al., 1995; Senturk and Manfredi, 2013). Therefore, we hypothesized 
that the reduced ribosome biogenesis in the aramis-depleted germline leads to p53 stabilization in undifferentiated cells, driving cell cycle arrest and GSC abscission defects. To test this hypothesis, we detected p53 and Vasa in the germline by immunostaining. A hybrid dysgenic cross that expresses p53 in undifferentiated cells was utilized as a positive control, and p53 null flies were used as negative controls (Figure S3J-K) (Moon et al., 2018). In WT, we observed p53 expression in the meiotic stages of germline but p53 expression in GSCs and CBs was attenuated as previously reported (Figure 3G-G") (Lu et al., 2010). However, compared to WT GSCs/CBs, we observed p53 expression in the stem cysts of the aramis-depleted germline (Figure 3G-I). Similarly, we observed p53 expression in the stem cysts of athos-and porthos-depleted germlines (Figure S3L-M), further supporting that reduced ribosome biogenesis stabilizes p53. To determine if p53 stabilization is required for the cell cycle arrest in aramis-depleted germline cysts, we depleted aramis in the germline of p53 mutants. We observed a partial but significant alleviation of the cyst phenotype, such that spectrosomes were restored (Figure $3 \mathbf{J}-\mathbf{L}$ ). This finding indicates that p53 contributes to cytokinesis failure upon loss of aramis, but that additional factors are also involved. Taken together, we find that aramis-depleted germ cells display reduced ribosome biogenesis, aberrant expression of p53 protein and a block in cell cycle progression. Reducing p53 partially alleviates the cell cycle block and GSC cytokinesis defect.

\section{Aramis promotes translation of Non1, a negative regulator of p53, linking ribosome biogenesis to the cell cycle}

Although p53 protein levels were elevated upon loss of aramis in the germline, p53 mRNA levels were not significantly altered ( $\log _{2}$ fold change: -0.49 ; FDR: 0.49 ). Given that ribosome biogenesis is affected, we considered that translation of p53 or one of its regulators was altered in aramisdepleted germlines. To test this hypothesis, we performed polysome-seq of gonads enriched for GSCs or CBs as developmental controls, as well as gonads depleted for aramis in the germline (Flora et al., 2018b). We plotted the ratios of polysome-associated RNAs to total RNAs (Figure 4A-A", Supplemental Table 3) and identified 87 mRNAs with a reduced ratio upon depletion of aramis, suggesting that they were translated less efficiently compared to developmental controls. Loss of aramis reduced the levels of these 87 downregulated transcripts in polysomes, without significantly affecting their total mRNA levels (Figure 4B, Figure S4A-A'). These 87 transcripts encode proteins mostly associated with translation including ribosomal proteins (Figure 4C). To validate that Aramis regulates translation of these target mRNAs, we utilized a reporter line for the Aramis-regulated transcript encoding Ribosomal protein S2 (RpS2) that is expressed in the context of the endogenous promoter and regulatory sequences (Buszczak et al., 2007; Zhang et al., 2014). We observed reduced levels of RpS2::GFP in germlines depleted of aramis but not in those depleted of bam (Figure 4D-F). To ensure that reduced RpS2::GFP levels did not reflect a global decrease in translation, we visualized nascent translation using O-propargyl-puromycin (OPP). OPP is incorporated into nascent polypeptides and can be detected using click-chemistry (Sanchez et al., 2016). We observed that global translation in the germlines of ovaries depleted of aramis was not reduced compared to bam (Figure $\mathbf{4 G - I ) . ~ T h u s , ~ l o s s ~ o f ~ a r a m i s ~ r e s u l t s ~ i n ~}$ reduced translation of a subset of transcripts.

None of these 87 translational targets have been implicated in directly controlling abscission (Mathieu et al., 2013; Matias et al., 2015). However, we noticed that the mRNA encoding Novel Nucleolar protein 1 (Non1/CG8801) was reduced in polysomes upon loss of aramis in the germline (Figure 4C). The human ortholog of Non1 is GTP Binding Protein 4 (GTPBP4), and these proteins are known to physically interact with p53 in both Drosophila and human cells and have been implicated in repressing p53 (mentioned as CG8801 in Lunardi et al.) (Li et al., 2018; Lunardi et al., 2010). To determine if translation of Non1 is reduced upon depletion of aramis, we monitored the abundance of Non1::GFP, a transgene that is under endogenous control (Sarov et al., 2016), and found that Non1::GFP was expressed in the undifferentiated GSCs and CBs 
(Figure 5A-A"). Non1::GFP levels were reduced in the aramis-depleted stem cysts compared to the CBs that accumulated upon bam-depletion (Figure 5B-D), suggesting that Aramis and ribosome biogenesis promote efficient translation of Non1.

During normal oogenesis, p53 protein is expressed in cyst stages in response to recombinationinduced double strand breaks (Lu et al., 2010). We found that Non1 was highly expressed at undifferentiated stages and in two- and four-cell cysts when p53 protein levels were low, whereas its expression was attenuated at eight- and 16-cell cyst stages when p53 protein levels were high (Figure 5A-A', Figure S5A-B'). Non1 was highly expressed in egg chambers, which express low levels of p53 protein suggesting that Non1 could regulate p53 protein levels. To determine if Non1 regulates GSC differentiation and p53, we depleted Non1 in the germline. We found that germline-depletion of Non1 results in stem cyst formation and loss of later stages, as well as increased p53 expression, phenocopying germline-depletion of aramis, athos, and porthos (Figure 5E-F, H, Figure S5C-E). In addition, we found that loss of p53 from Non1-depleted

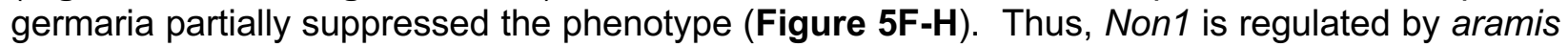
and is required for p53 suppression, cell cycle progression, and GSC abscission.

To determine if Aramis promotes GSC differentiation via translation of Non1, we restored Non1 expression in germ cells depleted of aramis. Briefly, we cloned Non1 with heterologous UTR elements under the control of the UAS/GAL4 system (see Methods) (Rørth, 1998). We found that restoring Non 1 expression in the aramis-depleted germline significantly attenuated the stem cysts and increased the number of cells with spectrosomes (Figure 5I-K). Taken together, we conclude that Non 1 can partially suppress the cytokinesis defect caused by germline aramis depletion.

\section{Aramis-regulated targets contain a TOP motif in their 5'UTR}

We next asked how aramis and efficient ribosome biogenesis promote the translation of a subset of mRNAs, including Non1, to regulate GSC differentiation. We hypothesized that the 87 mRNA targets share a property that make them sensitive to rRNA and ribosome levels. To identify shared characteristics, we performed de novo motif discovery of target genes compared to non-target genes (Heinz et al., 2010) and identified a polypyrimidine motif in the 5'UTRs of most target genes (UCUUU; E-value: $6.6 \mathrm{e}^{-094}$ ). This motif resembles the previously described TOP motif at the 5 ' end of mammalian transcripts (Philippe et al., 2018; Thoreen et al., 2012). Although the existence of TOP-containing mRNAs in Drosophila has been speculated, to our knowledge their presence has not been explicitly demonstrated (Chen and Steensel, 2017; Qin et al., 2007). This observation motivated us to precisely determine the 5' end of transcripts, so we analyzed previously published cap analysis of gene expression sequencing (CAGE-seq) data that had determined transcription start sites (TSS) in total mRNA from the ovary (Figure 6A, Figure S6AA') (Boley et al., 2014; Chen et al., 2014; dos Santos et al., 2015). Of the 87 target genes, 76 had sufficient expression in the CAGE-seq dataset to define their TSS. We performed motif discovery using the CAGE-seq data and found that 72 of 76 Aramis-regulated mRNAs have a polypyrimidine motif that starts within the first 50 nt of their TSS (Figure 6B-C). In mammals, it was previously thought that the canonical TOP motif begins with an invariant ' $C$ ' (Meyuhas, 2000; Philippe et al., 2020). However, systematic characterization of the sequence required in order for an mRNA to be regulated as a TOP containing mRNA revealed that TOP mRNAs can start with either a 'C' or a 'U' (Philippe et al., 2020). Thus, mRNAs whose efficient translation is dependent on aramis share a terminal polypyrimidine-rich motif in their 5'UTR that resembles a TOP motif.

In vertebrates, most canonical TOP-regulated mRNAs encode ribosomal proteins and translation initiation factors that are coordinately upregulated in response to growth cues mediated by the Target of Rapamycin (TOR) pathway and the TOR complex 1 (mTORC1) (Hornstein et al., 2001;

328 ladevaia et al., 2014; Kim et al., 2008; Meyuhas and Kahan, 2015; Pallares-Cartes et al., 2012) 
Indeed, 76 of the 87 Aramis targets were ribosomal proteins, and 9 were known or putative translation factors, consistent with TOP-containing RNAs in vertebrates (Figure 4C, Supplemental Table 4). To determine if the putative TOP motifs that we identified are sensitive to TORC1 activity, we designed "TOP reporter" constructs. Specifically, the germline-specific nanos promoter was employed to drive expression of an mRNA with 1) the 5'UTR of the aramis target $R p L 30$, which contains a putative TOP motif, 2) the coding sequence for a GFP-HA fusion protein and 3) a 3'UTR (K10) that is not translationally repressed (Flora et al., 2018b; Serano et al., 1994), referred to as the WT-TOP reporter (Figure S6B). As a control, we created a construct in which the polypyrimidine sequence was mutated to a polypurine sequence referred to as the Mut-TOP reporter (Figure S6B).

In Drosophila, TORC1 activity increases in 8- and 16-cell cysts (Hong et al., 2012; Kim et al., 2017). We found that the WT-TOP reporter displayed peak expression in 8-cell cysts, whereas the Mutant-TOP reporter did not (Figure 6D-E'), suggesting that the WT-TOP reporter is sensitive to TORC1 activity. Moreover, depletion of Nitrogen permease regulator-like 3 (Nprl3), an inhibitor of TORC1 (Wei et al., 2014), led to a significant increase in expression of the WTTOP reporter but not the Mutant-TOP reporter (Figure S6C-G). Additionally, to attenuate TORC1 activity, we depleted raptor, one of the subunits of the TORC1 complex (Hong et al., 2012; Loewith and Hall, 2011). Here we found that the WT-TOP reporter had a significant decrease in reporter expression while the Mutant-TOP reporter did not show a decrease in expression (Figure S6HL). Taken together, our data suggest that Aramis-target transcripts contain TOP motifs that are sensitive to TORC1 activity. However, we note that our TOP reporter did not recapitulate the pattern of Non $1:$ GFP expression, suggesting that Non1 may have additional regulators that modulate its protein levels in the cyst stages.

TOP mRNAs show increased translation in response to TOR signaling, leading to increased ribosome biogenesis (Jefferies et al., 1997; Jia et al., 2021; Powers and Walter, 1999; Thoreen et al., 2012). However, to our knowledge, whether reduced ribosome biogenesis can coordinately diminish the translation of TOP mRNAs to balance and lower ribosome protein production and thus balance the levels of the distinct components needed for full ribosome assembly is not known. To address this question, we crossed the transgenic flies carrying the WT-TOP reporter and Mutant-TOP reporter into bam and aramis germline RNAi backgrounds. We found that the expression from the WT-TOP reporter was reduced by 2.9 -fold in the germline of aramis RNAi ovaries compared to bam RNAi ovaries (Figure 6F-G, J). In contrast, the Mutant-TOP reporter was only reduced by 1.6 -fold in the germline of aramis RNAi ovaries compared to bam RNAi ovaries (Figure 6H-J). This suggests that the TOP motif-containing mRNAs are sensitive to ribosome biogenesis.

\section{Larp binds TOP sequences in Drosophila}

365

366 In mammalian cells, Larp1 is a critical negative regulator of TOP-containing RNAs during nutrient deprivation (Berman et al., 2020; Fonseca et al., 2015; Hong et al., 2017; Philippe et al., 2020; Tcherkezian et al., 2014). Therefore, we hypothesized that Drosophila Larp reduces the translation of TOP-containing mRNAs when rRNA biogenesis is reduced upon loss of aramis. First, using an available gene-trap line in which endogenous Larp is tagged with GFP and 3xFLAG, we confirmed that Larp was robustly expressed throughout all stages of oogenesis including in GSCs (Figure S7A-A').

375

Next, we performed electrophoretic mobility shift assays (EMSA) to examine protein-RNA interactions with purified Drosophila Larp-DM15, the conserved domain that binds to TOP sequences in vertebrates (Lahr et al., 2017). As probes, we utilized capped 42-nt RNAs 
corresponding to the 5'UTRs of RpL30 and Non1, including their respective TOP sequences. We observed a gel shift with these RNA oligos in the presence of increasing concentrations of LarpDM15 (Figure 7A-A', Figure S7B), and this shift was abrogated when the TOP sequences were mutated to purines (Figure S7C-C'). To determine if Larp interacts with TOP-containing mRNAs in vivo, we immunopurified Larp::GFP::3xFLAG from the ovaries of the gene-trap line and performed RNA-seq (Figure S7D). We uncovered 156 mRNAs that were bound to Larp, and 84 of these were among the 87 aramis translationally regulated targets, including Non1, RpL30, and RpS2 (Figure 7B-C, Supplemental Table 5). Thus, Drosophila Larp binds to TOP sequences in vitro and TOP-containing mRNAs in vivo.

To test our hypothesis that Drosophila Larp inhibits the translation of TOP-containing mRNAs upon loss of aramis, we immunopurified Larp::GFP::3xFLAG from germline bam RNAi ovaries and germline aramis RNAi ovaries. Larp protein is not expressed at higher levels in aramis RNAi compared to developmental control bam RNAi (Figure S7E-G). We found that Larp binding to aramis target mRNAs Non1 and RpL30 was increased in aramis RNAi ovaries compared to bam RNAi ovaries (Figure 7D, Figure S7H). In contrast, a non-target mRNA that does not contain a TOP motif, alpha-tubulin mRNA, did not have a significant increase in binding to Larp in aramis RNAi ovaries compared to bam RNAi ovaries. Overall, these data suggest that reduced rRNA biogenesis upon loss of aramis increases Larp binding to the TOP-containing mRNAs Non1 and RpL30.

If loss of aramis inhibits the translation of TOP-containing mRNAs due to increased Larp binding, then overexpression of Larp would be expected to phenocopy germline depletion of aramis. Unphosphorylated Larp binds to TOP motifs more efficiently, but the precise phosphorylation sites of Drosophila Larp, to our knowledge, are currently unknown (Hong et al., 2017). To circumvent this issue, we overexpressed the DM15 domain of Larp which we showed binds the RpL30 and Non1 TOP motifs in vitro (Figure 7A-A'), and, based on homology to mammalian Larp1, lacks majority of the putative phosphorylation sites (Jia et al., 2021; Lahr et al., 2017; Philippe et al., 2018). We found that overexpression of a Larp-DM15::GFP fusion in the germline resulted in fusome-like structures extending from the niche (Figure 7E-F'). Additionally, ovaries overexpressing Larp-DM15 had 32-cell egg chambers, which were not observed in control ovaries (Figure S7I-l'). The presence of 32-cell egg chambers is emblematic of cytokinesis defects that occur during early oogenesis (Mathieu et al., 2013; Matias et al., 2015; Sanchez et al., 2016). Our findings indicate that these cells are delayed in cytokinesis and that over expression of Larp partially phenocopies depletion of aramis.

\section{Discussion}

During Drosophila oogenesis, efficient ribosome biogenesis is required in the germline for proper GSC cytokinesis and differentiation. The outstanding questions that needed to be addressed were: 1) Why does disrupted ribosome biogenesis impair GSC abscission and differentiation? and 2) How does the GSC monitor and couple ribosome abundance to differentiation? Our results suggest that germline ribosome biogenesis defect stalls the cell cycle, resulting a loss of differentiation and the formation of stem cysts. We discovered that proper ribosome biogenesis is monitored through a translation control module that allows for co-regulation of ribosomal proteins and a p53 repressor. Loss of aramis, athos and porthos reduces ribosome biogenesis and inhibits translation of a p53 repressor, leading to p53 stabilization, cell cycle arrest and loss of stem cell differentiation (Figure 7G).

Aramis, Athos, and Porthos are required for efficient ribosome biogenesis in Drosophila We provide evidence that Aramis, Athos and Porthos play a role in ribosome biogenesis in Drosophila, similar to their orthologs in yeast (Bohnsack et al., 2008; Granneman et al., 2006; 
Khoshnevis et al., 2016; O 'day et al., 1996) and mammals (Sekiguchi et al., 2006; Tafforeau et al., 2013; Zhang et al., 2011). Their role in ribosome biogenesis is likely a direct function of these helicases as they physically interact with precursor rRNA. In yeast, Rok1, the ortholog of Aramis, binds to several sites on pre-rRNA, predominantly in the $18 \mathrm{~S}$ region (Bohnsack et al., 2008; Khoshnevis et al., 2016; Martin et al., 2014). This is consistent with the small subunit ribosome biogenesis defect we observe upon loss of aramis in Drosophila. Rrp3, the yeast ortholog of Porthos, promotes proper cleavage of pre-rRNA and is required for proper $18 \mathrm{~S}$ rRNA production (Granneman et al., 2006; O 'day et al., 1996). DDX47, the mammalian ortholog of Porthos, binds to early rRNA precursors as well as proteins involved in ribosome biogenesis (Sekiguchi et al., 2006). Consistent with these findings, we find that Aramis and Porthos promote $40 \mathrm{~S}$ ribosome biogenesis. DHX33, the mammalian ortholog of Athos, has been implicated in facilitating rRNA synthesis (Zhang et al., 2011). In contrast, we find that Athos promotes 605 ribosome biogenesis by directly interacting with rRNA. However, we cannot rule out that Athos also affects transcription of rRNA in Drosophila as it does in mammals (Zhang et al., 2011). Overall, we find that each mammalian ortholog of Aramis, Athos, and Porthos has consistent ribosome subunit defects, suggesting that the function of these helicases is conserved from flies to mammals. Intriguingly, DDX52 (Aramis) is one of the 15 genes deleted in 17q12 syndrome (Hendrix et al., 2012). 17q12 syndrome results in delayed development, intellectual disability, and, more rarely, underdevelopment of organs such as the uterus (Bernardini et al., 2009; Hendrix et al., 2012). Our finding that Aramis disrupts stem cell differentiation could explain some of the poorly understood defects in 17q12 syndrome.

\section{Ribosome biogenesis defects leads to cell cycle defects mediated by p53}

Here we report that three RNA helicases, aramis, athos, and porthos, that promote proper ribosome biogenesis in Drosophila are required in the germline for fertility. Loss of aramis, athos, and porthos causes formation of a "stem cyst" and loss of later stage oocytes. Stem cysts are a characteristic manifestation of ribosome biogenesis deficiency wherein GSCs are unable to complete cytokinesis and fail to express the differentiation factor Bam, which in GSCs is initiated at G2 of the cell cycle (Sanchez et al., 2016; Zhang et al., 2014). Our RNA seq and cell cycle analysis indicates that depletion of aramis blocks the cell cycle at $\mathrm{G} 1$, and that failure to progress to $\mathrm{G} 2$ prevents abscission and expression of Bam. Thus, our results suggest that ribosome biogenesis defects in the germline stall the cell cycle, resulting in formation of stem cysts and sterility.

In most tissues in Drosophila, p53 primarily activates apoptosis, however, in the germline p53 is activated during meiosis and does not cause cell death (Fan et al., 2010; Lu et al., 2010). Furthermore, p53 activation in the germline is required for germline repopulation and GSC survival after genetic insult, implicating p53 as a potential cell cycle regulator (Ma et al., 2016; Tasnim and Kelleher, 2018). Our observation that reduction of $p 53$ partially rescues a stem cyst defect caused by ribosome deficiency due to germline depletion of aramis indicates that the G1 block in GSCs is, in part, mediated by p53 activation. Thus, in Drosophila GSCs, p53 blocks the GSC cell cycle and is sensitive to rRNA production. The developmental upregulation of p53 during GSC differentiation concomitant with lower ribosome levels parallels observations in disease states, such as ribosomopathies (Calo et al., 2018; Deisenroth and Zhang, 2010; Pereboom et al., 2011; Yelick and Trainor, 2015).

We find that p53 levels in GSCs are regulated by conserved p53 regulator Non1. In mammalian cells, increased free RpS7 protein due to nucleolar stress binds and sequesters MDM2, a repressor of p53, freeing p53, resulting in G1 cell cycle arrest (Deisenroth and Zhang, 2010; Zhang and Lu, 2009). Drosophila have no identified homolog to MDM2. It is not fully known how ribosome levels are monitored in Drosophila in the absence of MDM2 and how this contributes to 
cell cycle progression. In Drosophila, Non1 levels are high in the GSCs and p53 is low, and reciprocally Non 1 levels are low during meiosis, but p53 is expressed. Our finding that loss of Aramis leads to diminished Non1 and elevated p53, and that either loss of p53 or elevated Non1 suppress differentiation defects caused by loss of Aramis, suggests that, in the female germline, Non1 may fulfill the function of Mdm2 by promoting p53 degradation during Drosophila oogenesis. While Non1 has been shown to directly interact with p53, how it regulates p53 levels in both humans and Drosophila is not known (Li et al., 2018; Lunardi et al., 2010). Overall, our data place Non1 downstream of ribosome biogenesis and upstream of p53 in controlling cell cycle progression and GSC differentiation. However, our data do not rule out that Non1 may also act upstream of or in parallel to Aramis.

The vertebrate ortholog of Non1, GTPBP4, also controls p53 levels and is upregulated in some cancers (Li et al., 2018; Lunardi et al., 2010; Yu et al., 2016). This suggests that there may be parallel pathways for monitoring ribosome levels via p53 in different tissue types. Unlike Drosophila Non1, its ortholog, GTPBP4 has not been identified as a TOP mRNA, so if it similarly acts as a mediator between ribosome biogenesis and the cell cycle it is likely activated in a somewhat different manner (Philippe et al., 2020). However, mammalian Larp1 is required for proper cell cycle progression and cytokinesis (Burrows et al., 2010; Tcherkezian et al., 2014). Excitingly several differentiation and cell cycle regulation genes in mammals are TOP mRNAs regulated by Larp1, including Tumor Protein, Translationally-Controlled 1 (TPT1) and Nucleosome Assembly Protein 1 Like 1 (NAP1L1) (Philippe et al., 2020). TPT1 is a cancer associated factor that has been implicated in activating pluripotency (Burrows et al., 2010; Qiao et al., 2018). Similarly, NAP1L1, a nucleosome assembly protein, is required to maintain proper cell cycle control as loss of NAP1L1 results in cell cycle exit and premature differentiation. Overall, although the specific targets of Larp1 in mammals may differ from those in Drosophila, the mechanism by which Larp modulates cell cycle and differentiation may be conserved.

\section{Ribosome biogenesis defects leads to repression of TOP-containing mRNA}

TOP-containing mRNAs are known to be coregulated to coordinate ribosome production in response to nutrition or other environmental cues (Kimball, 2002; Meyuhas and Kahan, 2015; Tang et al., 2001). Surprisingly, our observation that loss of aramis reduces translation of a cohort of TOP-containing mRNAs, including Non1, suggests that the TOP motif also sensitizes their translation to lowered levels of rRNA. This notion is supported by TOP reporter assays demonstrating that reduced translation upon loss of aramis requires the TOP motif. We hypothesize that limiting TOP mRNA translation lowers ribosomal protein production to maintain a balance with reduced rRNA production. This mechanism would prevent the production of excess ribosomal proteins that cannot be integrated into ribosomes and the ensuing harmful aggregates (Tye et al., 2019). Additionally, it would coordinate rRNA production and ribosomal protein translation during normal germline development, where it is known that the level of ribosome biogenesis and of global translation are dynamic (Blatt et al., 2020a; Fichelson et al., 2009; Sanchez et al., 2016; Zhang et al., 2014).

\section{Larp transduces growth status to ribosome biogenesis targets}

Recent work has shown that the translation and stability of TOP-containing mRNAs are mediated by Larp1 and its phosphorylation (Berman et al., 2020; Hong et al., 2017; Jia et al., 2021). We found that perturbing rRNA production and thus ribosome biogenesis, without directly targeting ribosomal proteins, similarly results in dysregulation of TOP mRNAs. Our data show that Drosophila Larp binds the RpL30 and Non1 5'UTR in a TOP-dependent manner in vitro and to nearly all of the translation targets we identified in vivo. Together these data suggest that rRNA production regulates TOP mRNAs via Larp. Furthermore, the cytokinesis defect caused by overexpression of Larp-DM15 in the germline suggests that Larp regulation could maintain the 
560

561

562

563

564

565

566

567

568

569

570

571

572

573

574

575

576

homeostasis of ribosome biogenesis more broadly by balancing the expression of ribosomal protein production with the rate of other aspects of ribosome biogenesis, such as rRNA processing, during development.

Previous studies indicate that unphosphorylated Larp1 binds to and represses its targets more efficiently than phosphorylated Larp1 (Fonseca et al., 2018; Hong et al., 2017; Jia et al., 2021). Thus, although we do not know the identity of the kinase that phosphorylates Larp in Drosophila, we hypothesize that Larp is not phosphorylated upon loss of aramis, athos and porthos, when ribosome biogenesis is perturbed. We propose that until ribosome biogenesis homeostasis is reached, this kinase will remain inactive, continuously increasing the pool of dephosphorylated Larp. In this scenario, as dephosphorylated Larp accumulates, it begins to bind its targets. Initially, it will bind its highest affinity targets, presumably encoding ribosomal proteins and repress their translation to rebalance ribosomal protein production with rRNA production. Consistent with this model, the TOP motif in RpL30 is bound by Larp even more tightly with a nearly 9-fold higher affinity compared to the Non1 TOP site (Figure S7B). We propose that such differences in affinity may allow Larp to repress ribosomal protein translation to facilitate cellular homeostasis without immediately causing cell cycle arrest. However, if homeostasis cannot be achieved and sufficient dephosphorylated Larp accumulates, Larp will also bind and repress the translation of lower affinity targets. Repression of Non1 in this manner would result in cell cycle arrest and block differentiation as occurs upon aramis depletion.

\section{Ribosome biogenesis in stem cell differentiation and ribosomopathies}

Ribosomopathies arise from defects in ribosomal components or ribosome biogenesis and include a number of diseases such as Diamond-Blackfan anemia, Treacher Collins syndrome, Shwachman-Diamond syndrome, and 5q-myelodysplastic syndrome (Armistead and TriggsRaine, 2014; Draptchinskaia et al., 1999; McGowan et al., 2011; Valdez et al., 2004; Warren, 2018). Despite the ubiquitous requirement for ribosomes and translation, ribosomopathies cause tissue-specific disease (Armistead and Triggs-Raine, 2014). The underlying mechanisms of tissue specificity remain unresolved.

In this study we demonstrate that loss of helicases involved in rRNA processing lead to perturbed ribosome biogenesis and, ultimately, cell cycle arrest. Given that Drosophila germ cells undergo an atypical cell cycle program as a normal part of their development it may be that this underlying cellular program in the germline leads to the tissue-specific symptom of aberrant stem cyst formation (McKearin and Spradling, 1990). This model implies that other tissues would likewise exhibit unique tissue-specific manifestations of ribosomopathies due to their underlying cell state and underscores the need to further explore tissue-specific differentiation programs and development to shed light not only on ribosomopathies but on other tissue-specific diseases associated with ubiquitous processes. Although it is also possible that phenotypic differences arise from a common molecular cause, our data suggests two sources of potential tissue specificity: 1) tissues express different cohorts of mRNAs, such as Non1, that are sensitive to ribosome levels. For example, we find that in Drosophila macrophages, RNAs that regulate the metabolic state of macrophages and influence their migration require increased levels of ribosomes for their translation (Emtenani et al., 2021). 2) p53 activation, as has been previously described, is differentially tolerated in different developing tissues (Bowen and Attardi, 2019; Calo et al., 2018; Jones et al., 2008). Together, both mechanisms could begin to explain the tissuespecific nature of ribosomopathies and their link to differentiation.

\section{Acknowledgements}

We are grateful to all members of the Rangan and Fuchs labs for their discussion and comments on the manuscript. We also thanks Dr. Sammons, Dr. Marlow, Life Science Editors, for their 
577 thoughts and comments the manuscript Additionally, we thank the Bloomington Stock Center, the Vienna Drosophila Resource Center, the BDGP Gene Disruption Project, and Flybase for fly stocks, reagents, and other resources. P.R. is funded by the NIH/NIGMS (R01GM111779-06 and RO1GM135628-01), G.F. is funded by NSF MCB-2047629 and NIH RO3 Al144839, D.E.S. was funded by Marie Curie CIG 334077/IRTIM and the Austrian Science Fund (FWF) grant ASI_FWF01_P29638S, and A.B is funded by NIH R01GM116889 and American Cancer Society RSG-17-197-01-RMC.

\section{Author Contributions}

Conceptualization, E.T.M., P.B., G.F., and P.R.; Methodology, E.T.M., P.B., G.F., and P.R.; 587 Investigation, E.T.M., P.B., E.N., R.L., S.S., H.Y., T.P., and S.E.; Writing - Original Draft, E.T.M., 588 D.E.S., and P.R.; Writing - Review \& Editing, E.T.M., P.B., D.E.S, A.B., G.F., and P.R.; Funding Acquisition, G.F. and P.R.; Visualization, E.T.M., E.N.; Supervision, G.F. and P.R. 
A

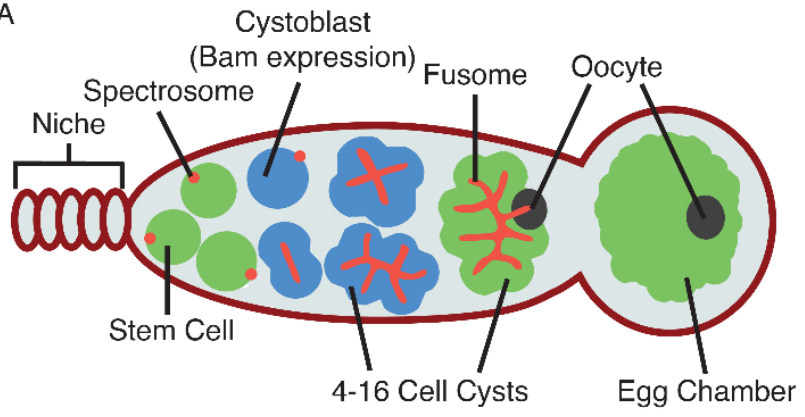

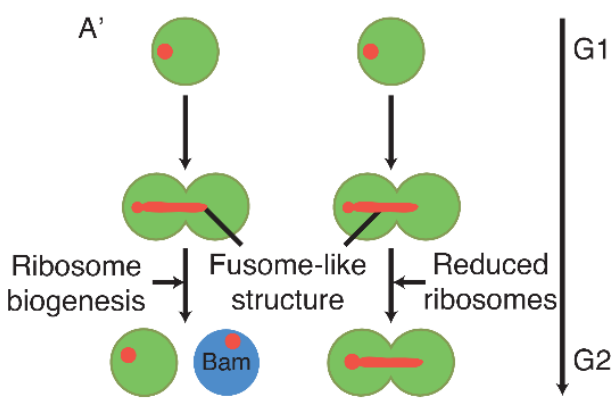

Cell Cycle
B

D. sapiens S. cerevisiae

H. sapiens S. cerevisiae

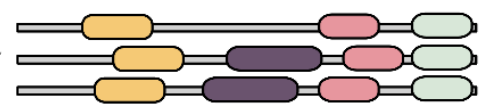

$\mathrm{DHX} 33$ 65\%

Athos (CG4901)

DHR2 55\%

H. sapiens
D. melanogaster
S. cerevisiae
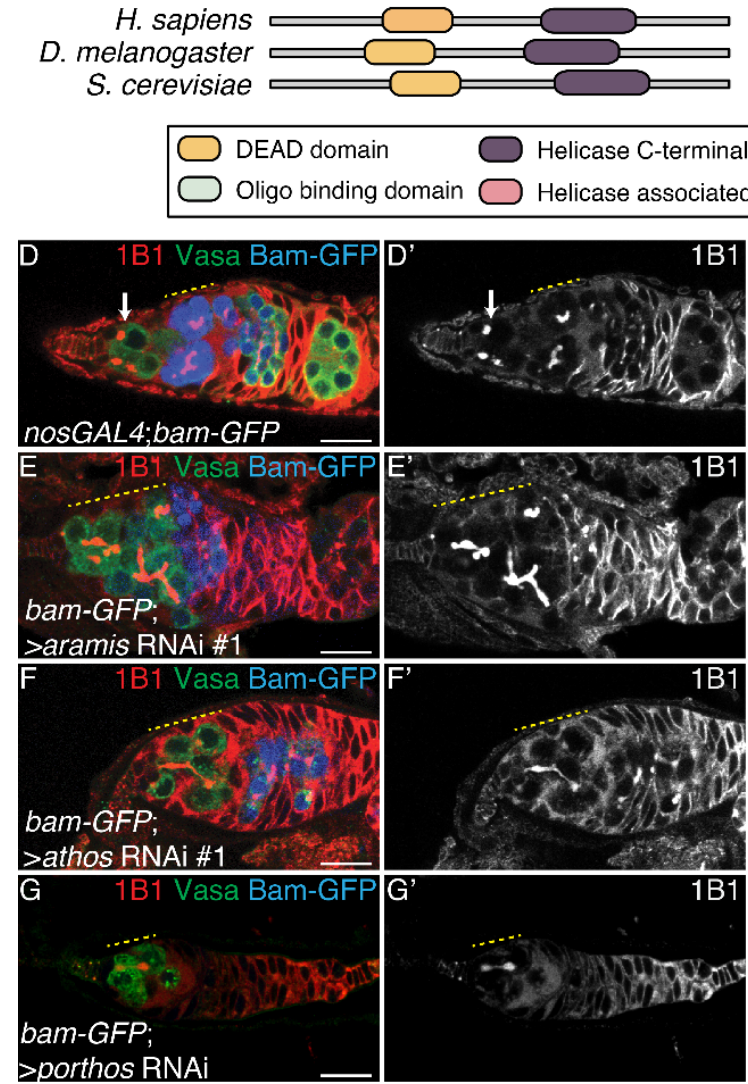

DDX52 64\% ROK1 55\% Aramis (CG5589)
Figure 1: RNA helicases Aramis, Athos and Porthos are required for GSC differentiation. (A) Schematic of Drosophila germarium. Germline stem cells are attached to the somatic niche (dark red). The stem cells divide and give rise to a stem cell and a cystoblast (CB) that expresses the differentiation factor Bag-of-marbles (Bam). GSCs and CBs are marked by spectrosomes. The $\mathrm{CB}$ undergoes four incomplete mitotic divisions giving rise to a 16-cell cyst (blue). Cysts are marked by branched spectrosome structures known as fusomes (red). One cell of the 16-cell cyst is specified as the oocyte. The 16-cell cyst is encapsulated by the surrounding somatic cells giving 
600 rise to an egg chamber. (A') Ribosome biogenesis promotes GSC cytokinesis and differentiation. 601 Disruption of ribosome biogenesis results in undifferentiated stem cyst accumulation. (B) 602 Representation of conserved protein domains for three RNA helicases in Drosophila compared 603 to $H$. sapiens and S. cerevisiae orthologs. Percentage values represent similarity to Drosophila 604 orthologs. (C) Egg laying assay after germline RNAi knockdown of aramis, athos or porthos 605 indicating a loss of fertility compared to nosGAL4, driver control ( $n=3$ trials). ${ }^{* * *}=p<0.001$, 606 Tukey's post-hoc test after one-way ANOVA, $p<0.001$. Error bars represent standard error (SE). 607 (D-G") Confocal micrographs of ovaries from control, UAS-Dcr2;nosGAL4;bam-GFP (D-D") and 608 germline RNAi depletion targeting (E-E') aramis, (F-F') athos or (G-G') porthos stained for 1B1 609 (red, left grayscale), Vasa (green), and Bam-GFP (blue, right grayscale). Depletion of these genes 610 (E-G") results in a characteristic phenotype in which early germ cells are connected marked by a 611 1B1 positive, fusome-like structure highlighted by a yellow dotted line in contrast to the single 612 cells present in (D-D') controls (white arrow) or differentiating cysts (yellow dashed line). Bam 613 expression, if present, is followed by loss of the germline. $(\mathbf{H})$ Phenotype quantification of ovaries 614 depleted of aramis, athos or porthos compared to control ovaries $\left(n=50\right.$ ovarioles, $d f=2,{ }^{* *}=p<$ 615 0.001, Fisher's exact tests with Holm-Bonferroni correction). Scale bars are 15 micron. 

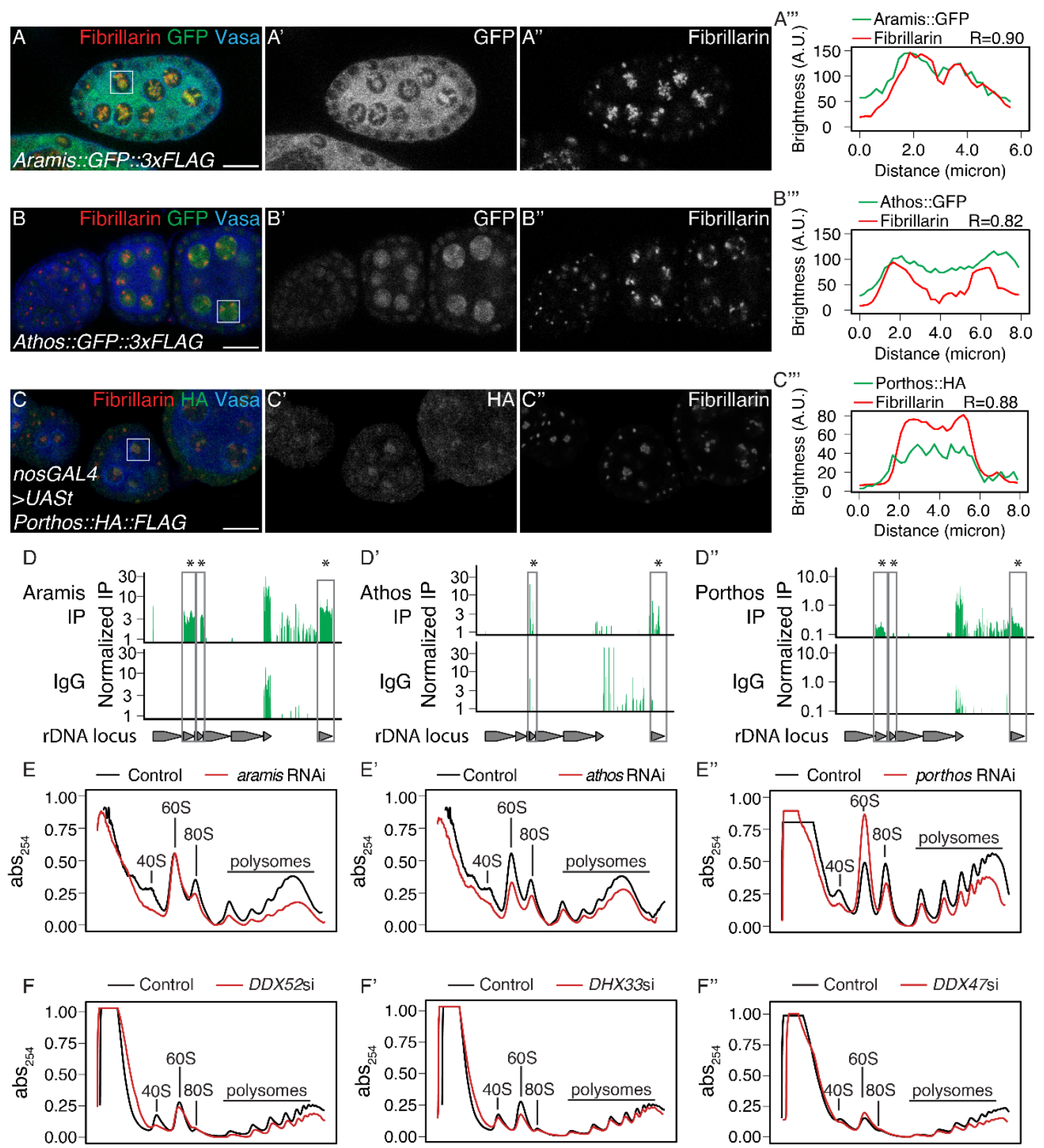

616

Figure 2. Athos, Aramis, and Porthos are required for efficient ribosome biogenesis. (AC") Confocal images of ovariole immunostained for Fibrillarin (red, right grayscale), Vasa (blue), (A-A") Aramis::GFP, (B-B') Athos::GFP and (C-C"') Porthos::HA (green, left grayscale). (A"'C"') Fluorescence intensity plot generated from a box of averaged pixels centered around the punctate of Fibrillarin in the white box. $\mathrm{R}$ values denote Spearman correlation coefficients between GFP and Fibrillarin from plot profiles generated using Fiji, taken from the nucleolus denoted by the white box. Aramis, Athos and Porthos are expressed throughout oogenesis and localize to the nucleolus. Aramis is also present in the cytoplasm. (D-D") RNA IP-seq of (D) Aramis, (D') Athos, and (D') Porthos aligned to rDNA displayed as genome browser tracks. Bar height represents log scaled rRNA reads mapping to rDNA normalized to input and spike-in. Grey boxes outline rRNA precursors that are significantly enriched in the IP compared to the IgG control (bootstrapped paired t-tests, $n=3,{ }^{*}=p$-value < 0.05). (E-E'”) Polysome traces from Drosophila 
bioRxiv preprint doi: https://doi.org/10.1101/2021.04.04.438367; this version posted April 4, 2021. The copyright holder for this preprint (which was not certified by peer review) is the author/funder, who has granted bioRxiv a license to display the preprint in perpetuity. It is made available under aCC-BY-NC-ND 4.0 International license.

629 S2 cells treated with dsRNA targeting (E) aramis, (E') athos, (E') porthos (red line) compared to 630 a mock control (black line). aramis and porthos are required to maintain a proper $40 \mathrm{~S} / 60 \mathrm{~S}$ 631 ribosomal subunit ratio compared to control and have a smaller 40S/60S ratio. athos is required 632 to maintain a proper $40 \mathrm{~S} / 60 \mathrm{~S}$ ribosomal subunit ratio compared to control and has a larger 633 40S/60S ratio. Additionally, aramis, athos, and porthos are required to maintain polysome levels. 634 (F-F') Polysome preparations from HeLa cells depleted of DDX52, DHX33, DDX47, and control 635 siRNA treated cells. DDX52, DHX33, and DDX47 are required to maintain a proper 40S/60S 636 ribosomal subunit ratio. Additionally, all three are required to maintain polysome levels. Scale bar 637 for all images is 15 micron.

638 
A

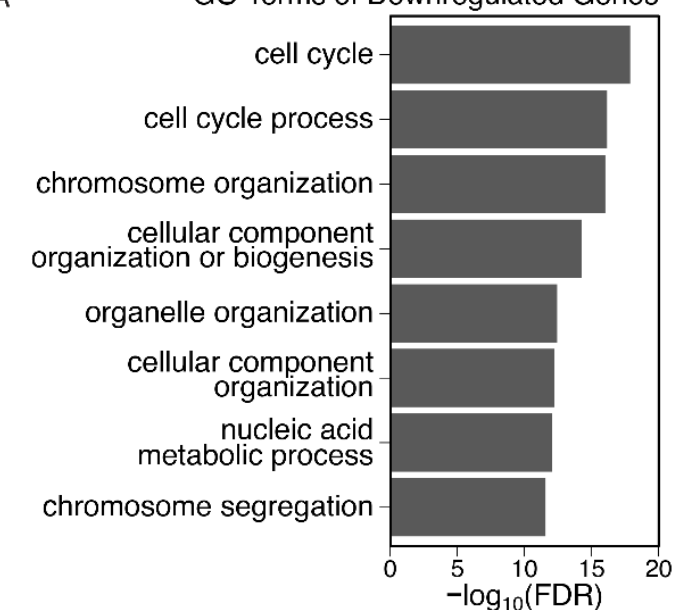

B

C
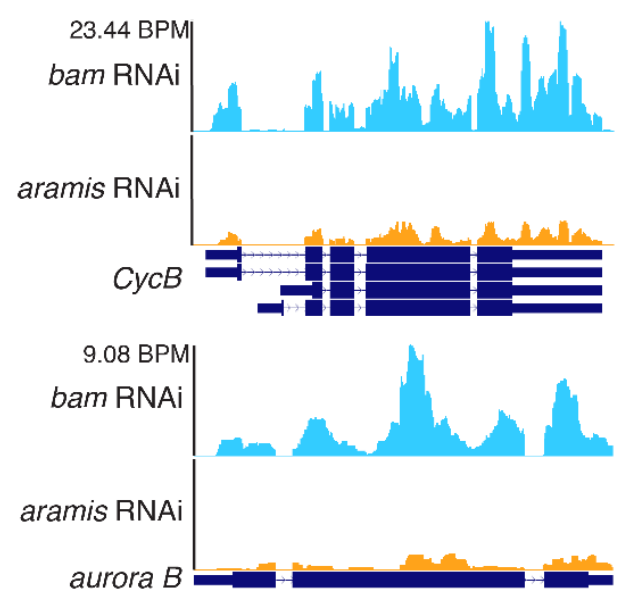
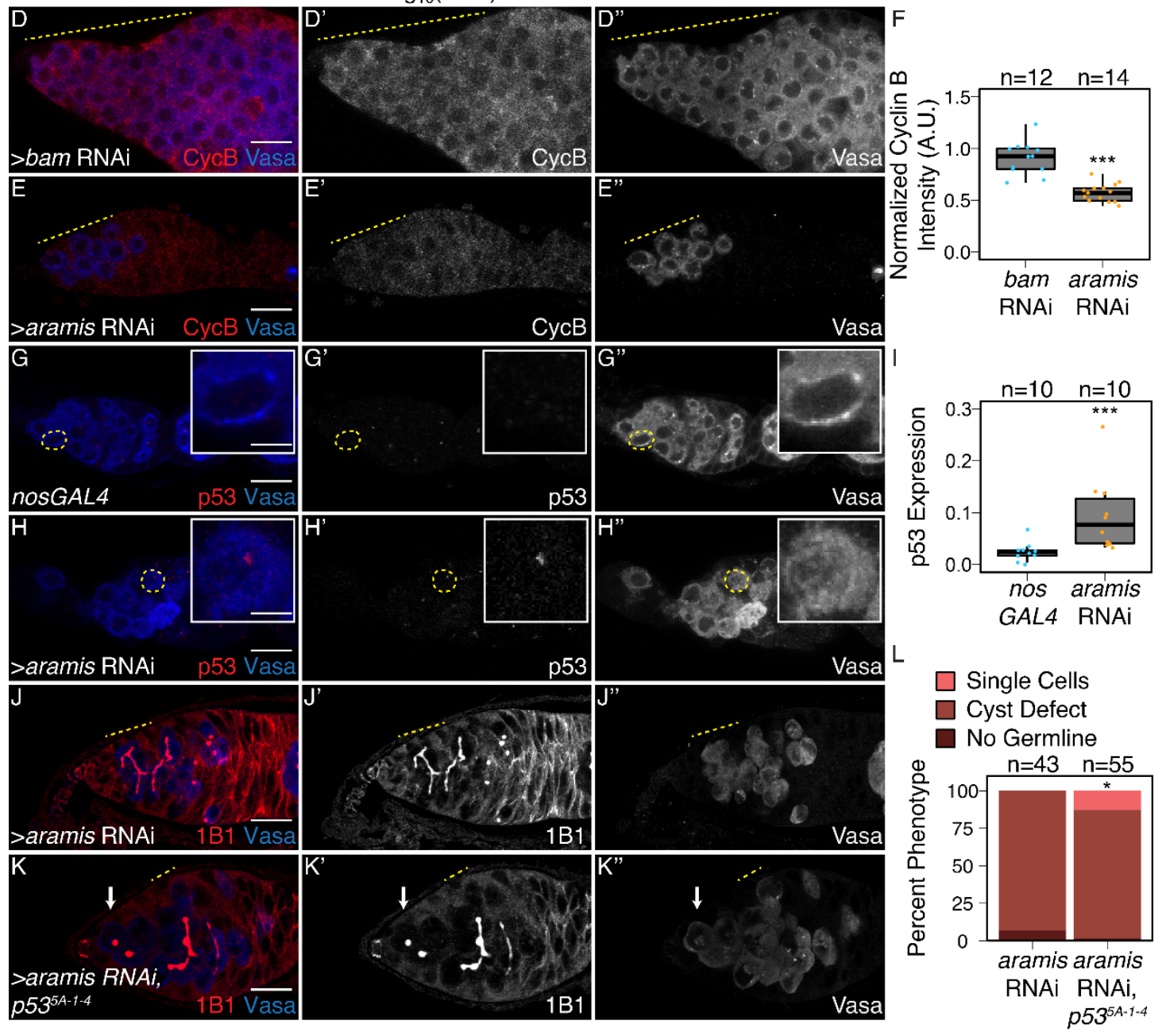

Figure 3. Athos, Aramis, and Porthos are required for cell cycle progression during early oogenesis. (A) Bar plot representing the most significant Biological Process GO terms of downregulated genes in ovaries depleted of aramis compared to bam RNAi control (FDR = False Discovery Rate from p-values using a Fisher's exact test). (B-C) Genome browser tracks representing the gene locus of (B) $C y c B$ and (C) aurora $B$ in ovaries depleted of aramis compared to the developmental control, bam RNAi. Y-axis represents the number of reads mapping to the 
646 locus in bases per million (BPM). (D-E') Confocal images of germaria stained for CycB (red, left 647 grayscale) and Vasa (blue, right grayscale) in (D-D"') bam RNAi control ovaries and (E-E') 648 aramis germline RNAi. (F) Boxplot of CycB intensity in the germline normalized to Cyc B intensity 649 in the soma in bam RNAi and aramis RNAi $\left(n=12-14\right.$ germaria per sample, ${ }^{* * *}=p<0.001$, Welch 650 t-test. (G-H') Confocal images of germaria stained for p53 (red, left grayscale) and Vasa (blue, 651 right grayscale) in (G-G') nosGAL4, driver control ovaries and (H-H') germline depletion of 652 aramis. Cells highlighted by a dashed yellow circle represent cell shown in the inset. Driver control 653 nosGAL4 ovaries exhibit attenuated p53 expression in GSCs and CBs, but higher expression in 654 cyst stages as previously reported, while p53 punctate are visible in the germline of aramis RNAi 655 in the undifferentiated cells. (I) Box plot of percentage of pixel area exceeding the background 656 threshold for p53 in GSCs and CBs in driver control nosGAL4 ovaries and the germline of aramis 657 RNAi indicates p53 expression is elevated in the germline over the GSCs/CBs of control ovaries. 658 ( $n=10$ germaria per sample, ${ }^{* * *}=p<0.001$, Welch's t-test. (J-K') Confocal images of germaria 659 stained for 1B1 (red, left grayscale) and Vasa (blue, right grayscale) in (J-J'") germline aramis 660 RNAi in a wild type background and (K-K') germline aramis RNAi with a mutant, null, p53 ${ }^{5-A-14}$ 661 background showing presence of spectrosomes upon loss of p53. (L) Quantification of stem cyst 662 phenotypes demonstrates a significant rescue upon of loss of $p 53^{5-A-14}$ in aramis germline 663 depletion compared to the wild type control $(n=43-55$ germaria per genotype, $\mathrm{df}=2$, Fisher's exact 664 test $p<0.05$ ). Scale bar for main images is 15 micron, scale bar for insets is 3.75 micron. 


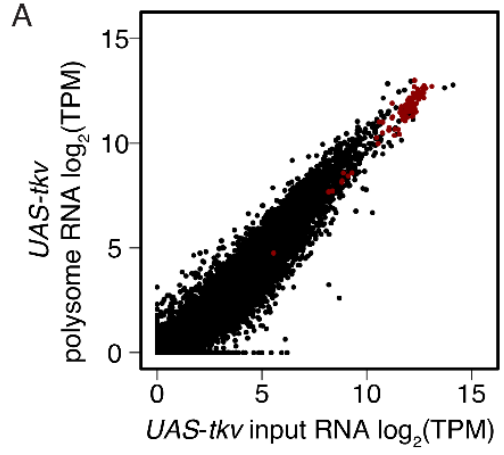

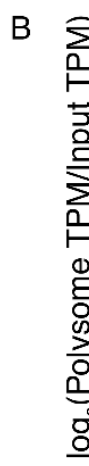
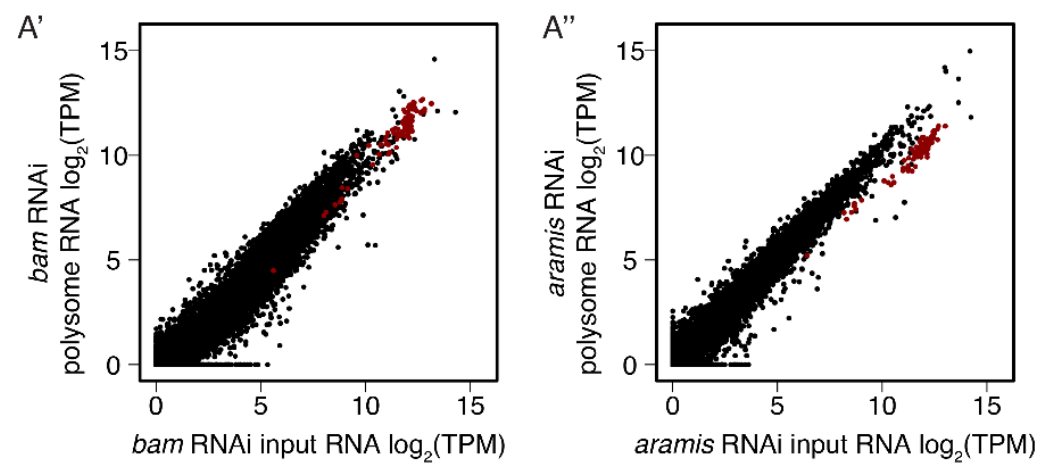

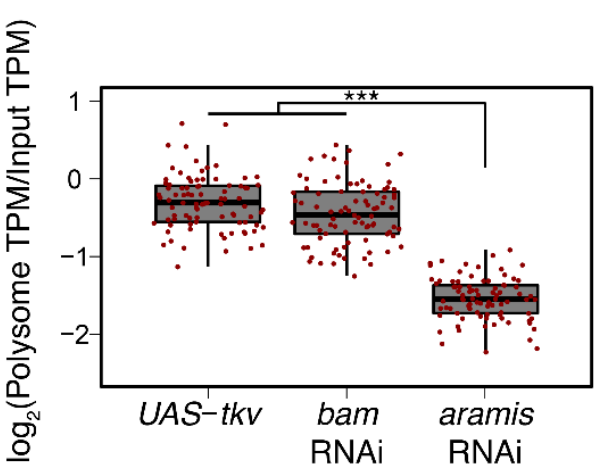

C

\begin{tabular}{|lr|}
\hline Translation Efficiency Targets & 87 \\
\hline Ribosomal Protein Genes & 76 \\
Initiation/Elongation/Termination Genes & 8 \\
\hline Other: & 3 \\
Non1 & p53 interactor \\
CG7414 & putative translation initiation \\
SmydA-1 & histone deacetylase binding \\
\hline
\end{tabular}
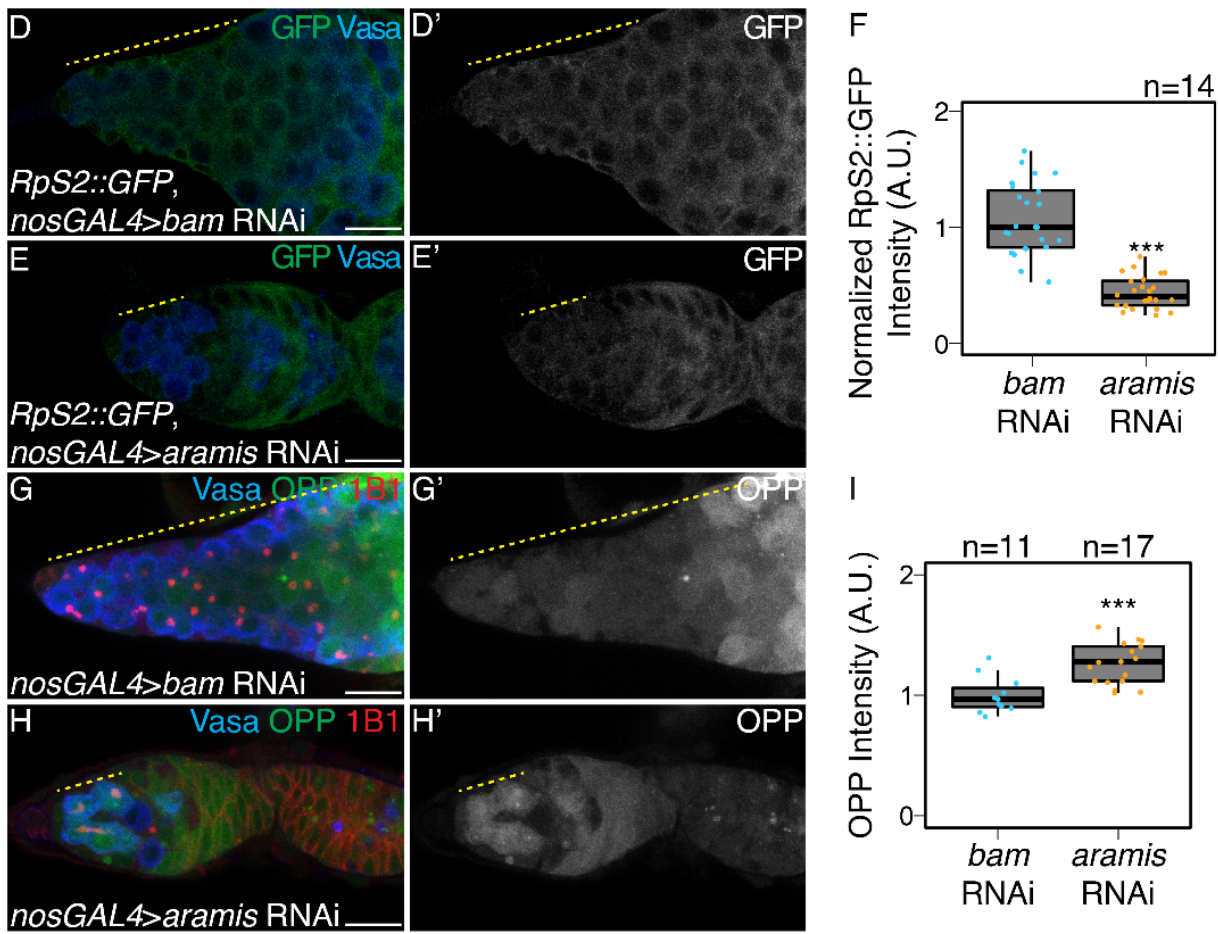

666

667

668

669

670
Figure 4. Aramis is required for efficient translation of a subset of mRNAs. (A-A") Biplots of poly (A)+ mRNA Input versus polysome associated mRNA from (A) ovaries genetically enriched for GSCs (UAS-tkv), (A') Undifferentiated GSC daughter cells (bam RNAi) or (A') germline aramis RNAi ovaries. (B) Boxplot of translation efficiency of target genes in UAS-tkv, bam RNAi, 
671 and aramis RNAi samples (ANOVA p<0.001, post-hoc Welch's t-test, $n=87,{ }^{* * *}=p<0.001$ ). (C) 672 Summary of downregulated target genes identified from polysome-seq. (D-E') Confocal images 673 of germaria stained for 1B1 (red), RpS2::GFP (green, grayscale), and Vasa (blue) in (D-D') bam RNAi control and (E-E') aramis RNAi (yellow dashed line marks approximate region of germline used for quantification). (F) A.U. quantification of germline RpS2::GFP expression normalized to RpS2::GFP expression in the surrounding soma in undifferentiated daughter cells of bam RNAi compared to aramis RNAi. RpS2::GFP expression is significantly lower in aramis RNAi compared to control ( $n=14$ germaria per sample, Welch's t-test, $\left.{ }^{* * *}=p<0.001\right)$. (G-H') Confocal images of germaria stained for 1B1 (red), OPP (green, grayscale), and Vasa (blue) in (G-G') bam RNAi and (H-H') aramis RNAi (yellow dashed line marks approximate region of germline used for quantification). (I) A.U. quantification of OPP intensity in undifferentiated daughter cells in bam RNAi and aramis RNAi ( $n=11-17$ germaria per genotype, Welch's t-test, $\left.{ }^{* * *}=p<0.001\right)$. OPP intensity is not downregulated in aramis RNAi compared to the control. Scale bar for all images is 15 micron. 

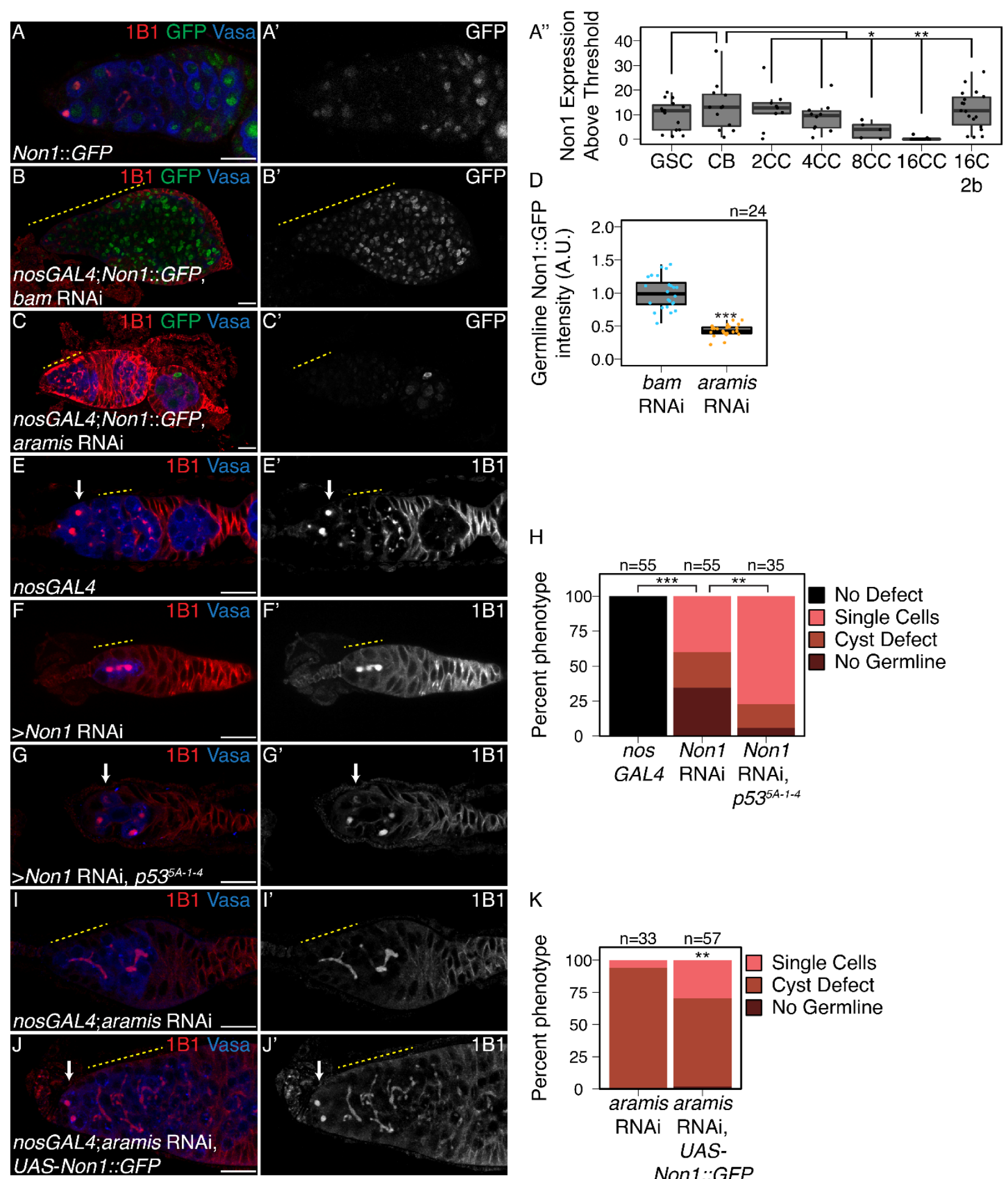

Figure 5. Non1 represses p53 expression to allow for GSC differentiation. (A-A') Confocal images of Non1::GFP germaria stained for 1B1 (red), GFP (green, grayscale), and Vasa (blue). (A") Boxplot of Non1::GFP expression over germline development in GSCs, CBs and Cyst (CC) stages ( $n=5-25$ cysts of each type, ${ }^{*}=p<0.05,{ }^{* *}=p<0.01$, ANOVA with Welch's post-hoc 691 tests). (B-C') Confocal images of (B-B') bam RNAi and (C-C') aramis RNAi germaria both carrying 692 Non1::GFP transgene stained for 1B1 (red), Vasa (blue), and Non1::GFP (green, grayscale). 
693 Yellow dashed line marks region of germline used for quantification. (D) Boxplot of Non1::GFP 694 expression in the germline normalized to somatic Non1::GFP expression in bam RNAi and aramis 695 RNAi ( $n=24$ germaria per genotype, Welch's t-test, $\left.{ }^{* * *}=p<0.001\right)$. Non1 expression is 696 significantly lower in the germline of aramis RNAi compared to bam RNAi control. (E-G') Confocal 697 images of germaria stained for 1B1 (red, grayscale), and Vasa (blue) in (E-E') nosGAL4, driver 698 control ovaries, (F-F') germline Non1 RNAi, and (G-G') germline Non1 RNAi in a p53 ${ }^{5-A-1-4}$ 699 background. Arrow marks the presence of a single cell $(\mathbf{E}, \mathbf{G})$, yellow dashed line marks a stem 700 cyst emanating from the niche (F-F') or the presence of proper cysts (E-E'). (H) Quantification of percentage of germaria with no defect (black), presence of single cell (salmon), presence of a stem cyst emanating from the niche (brown-red), or germline loss (dark red) demonstrates a significant rescue of stem cyst formation upon of loss of Non1 in $p 53^{5-A-14}$ compared to the $p 53$ wild type control ( $n=35-55$ germaria per genotype, $d f=3$, Fisher's exact test with Holm-Bonferroni correction $^{* *}=p<0.01,{ }^{* * *}=p<0.001$ ). (I-J') Confocal images of germaria stained for 1B1 (red, grayscale), and Vasa (blue) in (I-I') aramis germline RNAi exhibiting stem cyst phenotype (yellow dashed line) and (J-J') aramis germline RNAi with Non1 overexpression exhibiting single cells (arrow). (K) Phenotypic quantification of aramis RNAi with Non1 overexpression demonstrates a

709 significant alleviation of the stem cyst phenotype ( $n=33-57$ germaria per genotype, df=2, Fisher's 710 exact test, $\left.{ }^{* *}=p<0.01\right)$. Scale bar for all images is 15 micron. 

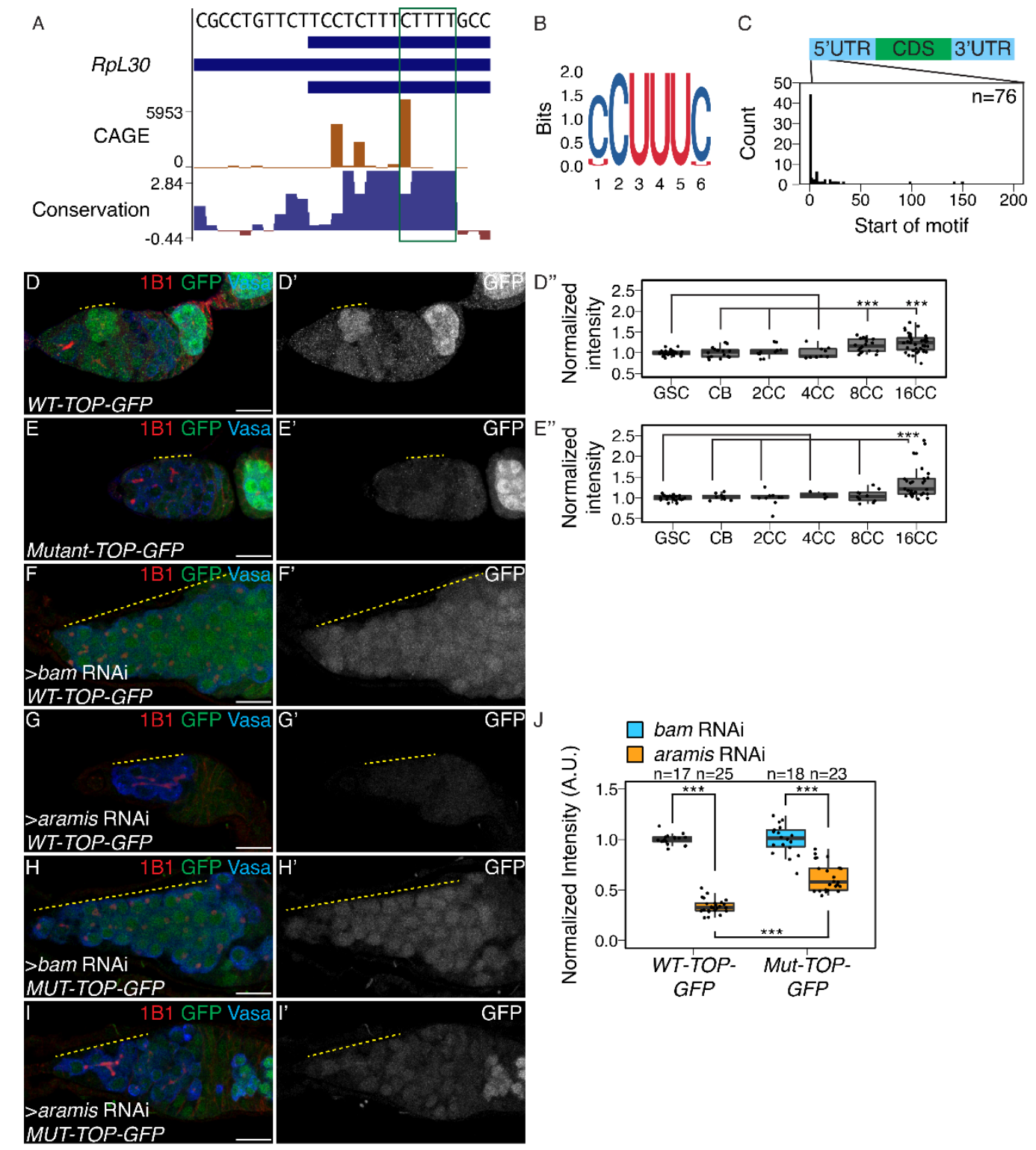

Figure 6. Aramis regulated mRNAs contain a TOP motif. (A) Genome browser tract of $R p L 30$ locus in ovary CAGE-seq data showing the proportion of transcripts that are produced from a given TSS (orange). Predominant TSSs are shown in orange and putative TOP motif indicated with a green box. The bottom blue and red graph represents sequence conservation of the locus across Diptera. The dominant TSS initiates with a canonical TOP motif. (B) Sequence logo generated from de novo motif discovery on the first 200 bases downstream of CAGE derived TSSs of aramis translation target genes resembles a canonical TOP motif. (C) Histogram representing the location of the first 5-mer polypyrimidine sequence from each CAGE based TSS of aramis translation target genes demonstrates that the TOP motifs occur proximal to the TSS ( $\mathrm{n}=76$ targets). (D-E') Confocal images and quantifications of (D-D') WT-TOP-GFP and (E-E') Mut-TOP-GFP reporter expression stained for 1B1 (red), GFP (green, grayscale), and Vasa (blue). Yellow dotted-line marks increased reporter expression in 8-cell cysts of WT-TOP-GFP but not in Mut-TOP-GFP. Reporter expression was quantified over germline development for (D') WT-TOP-GFP and (E') Mut-TOP-GFP reporter expression and normalized to expression in the 
bioRxiv preprint doi: https://doi.org/10.1101/2021.04.04.438367; this version posted April 4, 2021. The copyright holder for this preprint (which was not certified by peer review) is the author/funder, who has granted bioRxiv a license to display the preprint in perpetuity. It is made available under aCC-BY-NC-ND 4.0 International license.

GSC reveals dynamic expression based on the presence of a TOP motif. (F-G') Confocal images of WT-TOP-GFP reporter ovarioles showing 1B1 (red), GFP (green, grayscale), and Vasa (blue) in (F-F') bam germline depletion as a developmental control and (G-G') aramis germline depleted ovaries. Yellow dotted lines indicate germline. (H-l') Confocal images of Mut-TOP-GFP reporter expression showing 1B1 (red), GFP (green, grayscale), and Vasa (blue) in ( $\mathbf{H}^{\left.-\mathbf{H}^{\prime}\right)}$ bam RNAi and (I-I') aramis germline RNAi. Yellow dotted lines indicate germline. (J) A.U. quantification of WT and Mutant TOP reporter expression in undifferentiated daughter cells in bam RNAi compared aramis RNAi demonstrates that the WT-TOP-GFP reporter shows significantly lower expression in aramis RNAi than the Mut-TOP-GFP relative to the expression of the respective reporters in bam RNAi $\left(n=17-25\right.$ germaria per genotype, with Welch's t-test $\left.{ }^{* * *}=p<0.001\right)$. Scale bar for all images is 15 micron. 
A

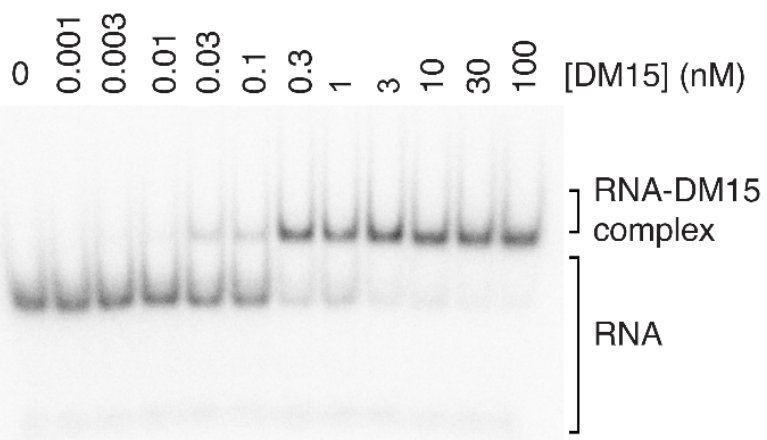

Capped RpL30 5'UTR 42-mer
$A^{\prime}$

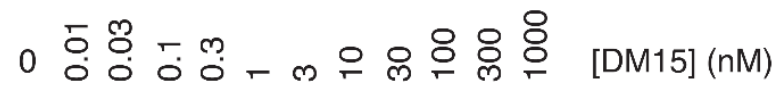
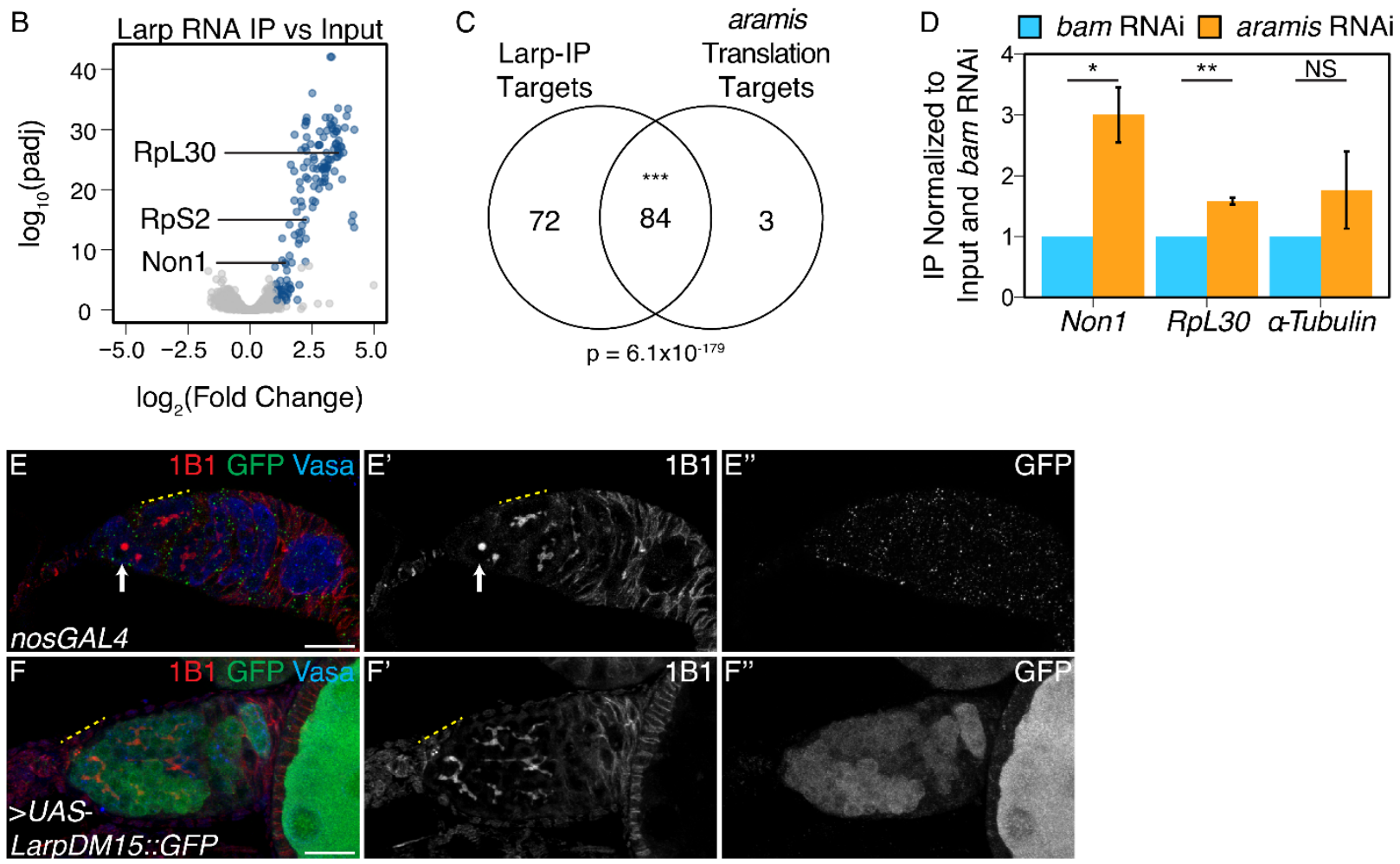

G

Normal

Biogenesis
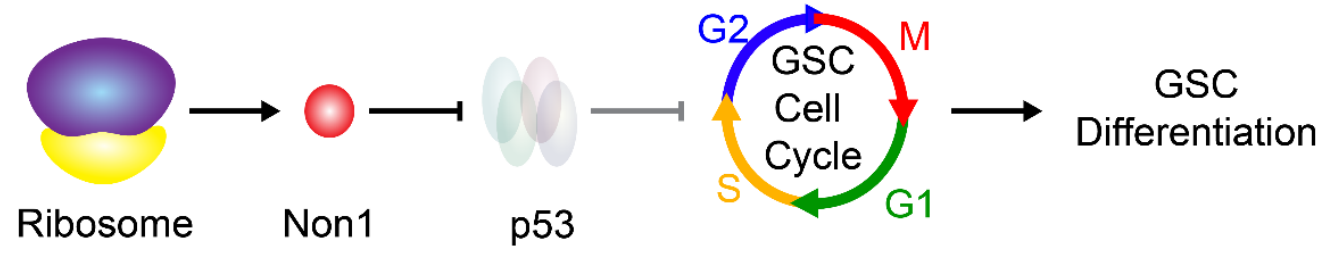

Capped Non1 5'UTR 42-mer

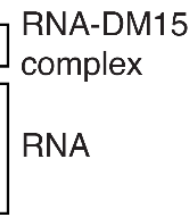


concentrations of Larp-DM15 from left to right indicates that both RNAs bind to Larp-DM15. (B) Volcano plot of mRNAs in Larp::GFP::3xFLAG IP compared to input. Blue points represent mRNAs significantly enriched in Larp::GFP::3xFLAG compared to input, but not enriched in an IgG control compared to input. (C) Venn diagram of overlapping Larp IP targets and aramis RNAi polysome seq targets indicates that Larp physically associates with mRNAs that are translationally downregulated in germline aramis RNAi ( $p<0.001$, Hypergeometric Test). (D) Bar plot representing the fold enrichment of mRNAs from Larp RNA IP in germline aramis RNAi relative to matched bam RNAi ovaries as a developmental control measured with qPCR $(n=3$, * $=p<0.5,{ }^{* *}=p<0.01, \mathrm{NS}=$ nonsignificant, One-sample t-test, mu=1) indicates that more of two aramis translation targets Non1 and RpL30 are bound by Larp in aramis RNAi. (E-F') Confocal images of (E-E') nosGAL4, driver control and (F-F") ovaries overexpressing the DM15 region of Larp in the germline ovaries stained for 1B1 (red, left grayscale), Vasa (blue), and LarpDM15::GFP (green, right grayscale). Overexpression of Larp results in an accumulation of extended 1B1 structures (highlighted with a dotted yellow line), marking interconnected cells when Larp-DM15 is overexpressed compared to nosGAL4, driver control ovaries. (G) In conditions with normal ribosome biogenesis Non1 is efficiently translated, downregulating p53 levels allowing for progression through the cell cycle. When ribosome biogenesis is perturbed Non1 is not translated to sufficient levels, resulting in the accumulation of p53 and cell cycle arrest. Scale bar for all

761 images is 15 micron. 

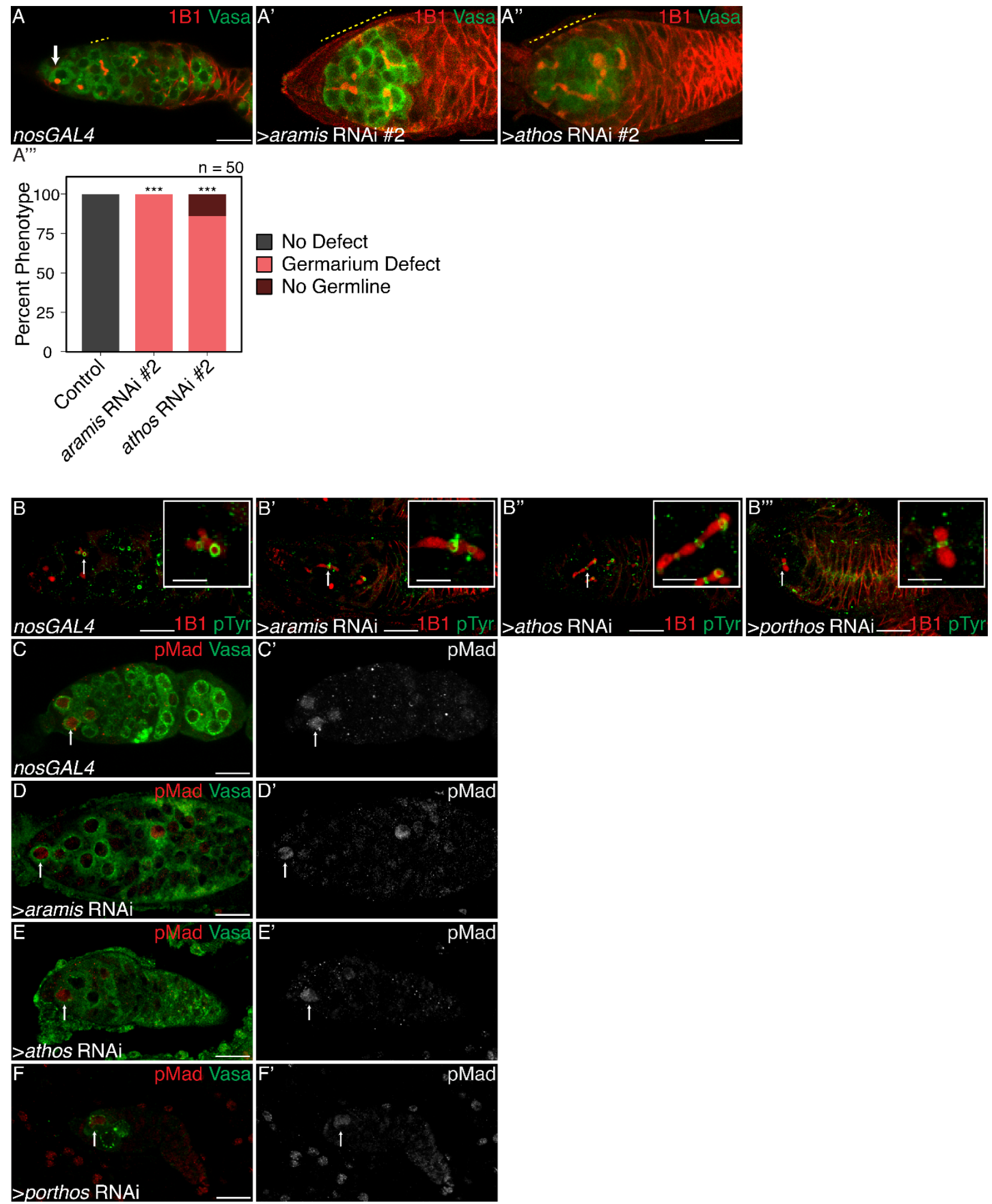

Supplemental Figure 1. Aramis, Athos, and Porthos are required for proper cytokinesis and differentiation, related to Figure 1. (A-A"') Confocal images of (A) nosGAL4, driver control and germline RNAi knockdown using additional RNAi lines for (A') aramis and (A') athos stained for 1B1 (red) and Vasa (green). (A"') Quantification of percentage of germaria with no defect 
bioRxiv preprint doi: https://doi.org/10.1101/2021.04.04.438367; this version posted April 4, 2021. The copyright holder for this preprint (which was not certified by peer review) is the author/funder, who has granted bioRxiv a license to display the preprint in perpetuity. It is made available under aCC-BY-NC-ND 4.0 International license.

(black), stem cysts (salmon), or germline loss (dark red) in ovaries depleted of athos, aramis, or porthos compared to control ovaries recapitulates the phenotypes with independent RNAi lines $\left(n=50, d f=2,{ }^{* * *}=p<0.001\right.$, Fisher's exact test with Holm-Bonferroni correction). (B-B'"') Confocal images of germaria stained for 1B1 (red) and Phospho-tyrosine (green). Ring canals, marked by Phosopho-tyrosine, connect differentiating cysts in (B) control nosGAL4 ovaries and in between the interconnected cells of ovaries depleted of (B') athos, (B') aramis, and (B'"') porthos with 1B1 positive structures going through the ring canals. (C-F') Confocal images of germaria stained for pMad (red, grayscale) and Vasa (green). In (C) control ovaries nuclear pMad staining occurs in cells proximal to the niche marking GSCs. Nuclear pMad staining in ovaries depleted of (D) athos, (E) aramis, and (F) porthos demonstrates that the observed cysts are not composed of GSCs. Scale bar for main images is 15 micron, scale bar for insets is 3.75 micron. 
A

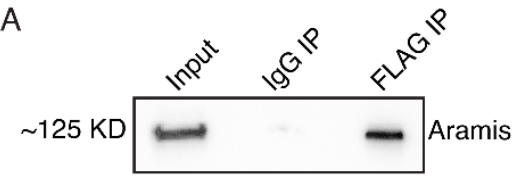

$A^{\prime}$
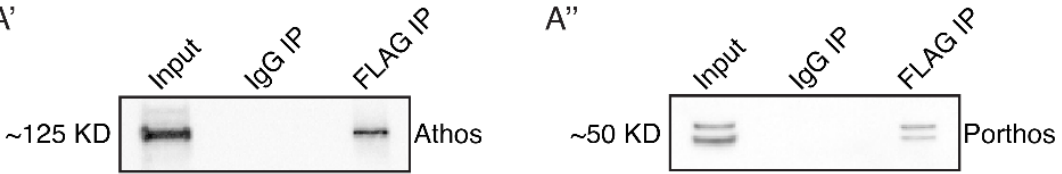
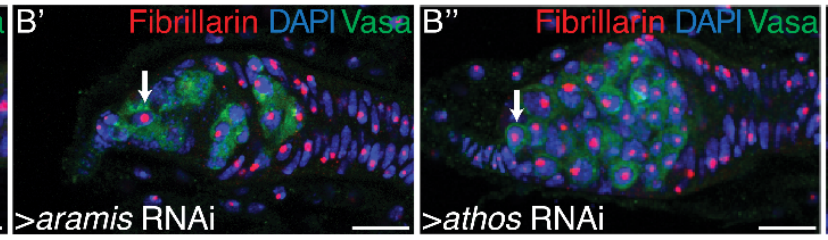

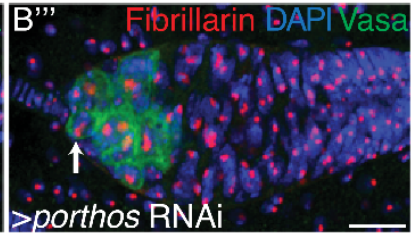

C

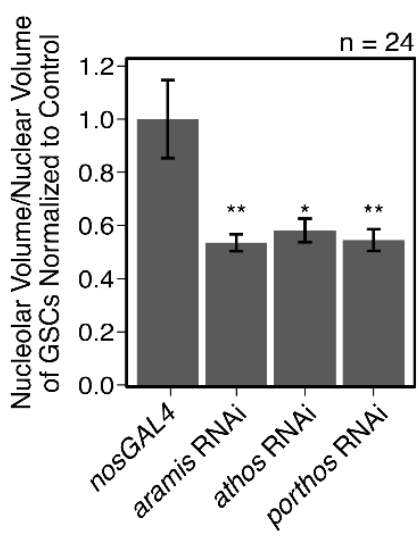

$\mathrm{D}$

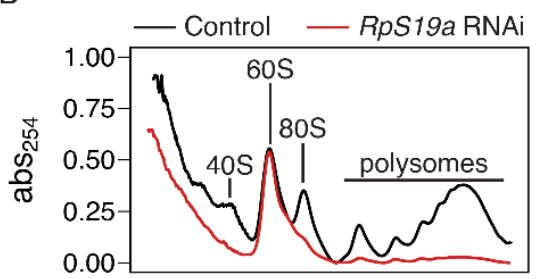

D'

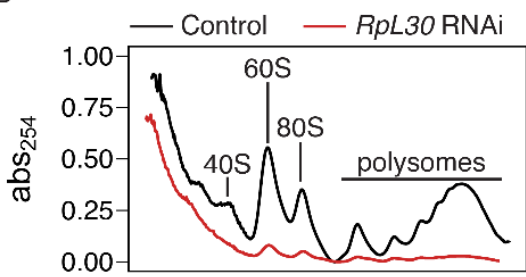

E
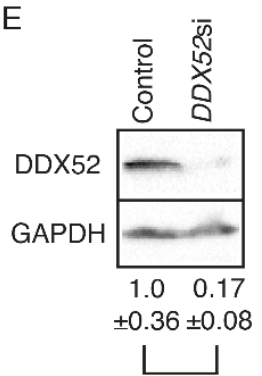

F

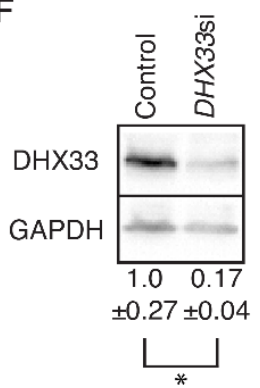

G

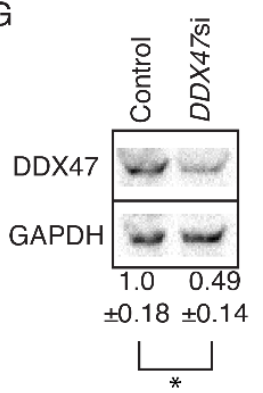

Supplemental Figure 2. Athos, Aramis, and Porthos are required for efficient ribosome biogenesis., related to Figure 2. (A-A') Western blots of immunoprecipitations from ovaries for FLAG-tagged (A) Aramis, (A') Athos, , and (A'") Porthos. (B-B'"') Confocal images of (B) nosGAL4, driver control, (B') aramis (B') athos and (B'"') porthos germline RNAi germaria stained for Fibrillarin (red), DAPI (blue), and Vasa (green). (C) Quantification of nucleolar volume in GSCs of aramis, athos, and porthos RNAi, compared to control normalized to somatic nucleolar volume indicates loss of each helicase results in nucleolar stress ( $n=24$ GSCs per genotype, Oneway ANOVA, $p<0.001$, with Welch's t-test, $\left.{ }^{*}=p<0.05,{ }^{* *}=p<0.01\right)$. (D-D') Polysome preparations 
bioRxiv preprint doi: https://doi.org/10.1101/2021.04.04.438367; this version posted April 4, 2021. The copyright holder for this preprint (which was not certified by peer review) is the author/funder, who has granted bioRxiv a license to display the preprint in perpetuity. It is made available under aCC-BY-NC-ND 4.0 International license.

787 from Drosophila S2 cells in cells treated with dsRNA targeting (D) RpS19a or (D') RpL30. (E-G) 788 Western blot against proteins targeted for depletion by siRNA in HeLa cells. The human homologs 789 of (E) Aramis (DDX52), (F) Athos (DHX33), and (G) Porthos (DDX47) are efficiently depleted with 790 siRNA treatment after 72 hours $\left(n=3\right.$, Welch's t-test, $\left.{ }^{*}=p<0.05\right)$. Scale bar for all images is 15 791 micron. 
A

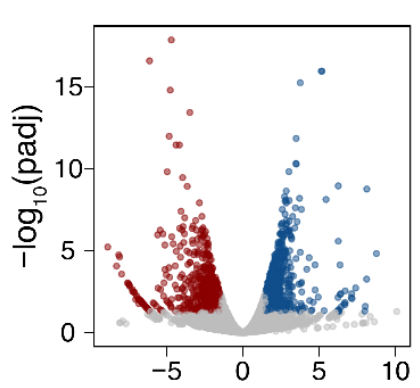

$\log _{2}$ Fold Change aramis $\mathrm{RNAi} /$ bam $\mathrm{RNAi}$

C

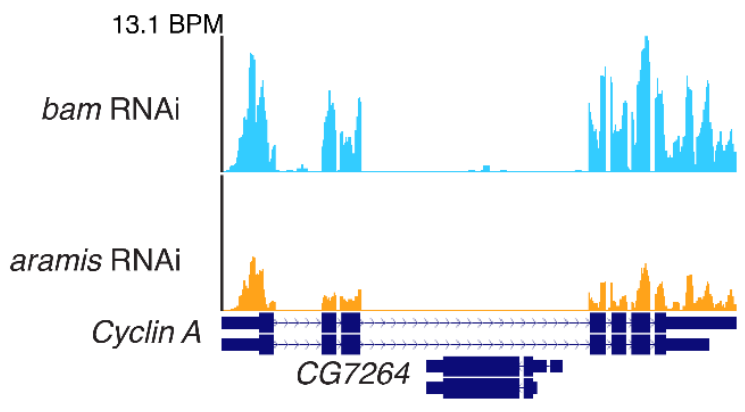

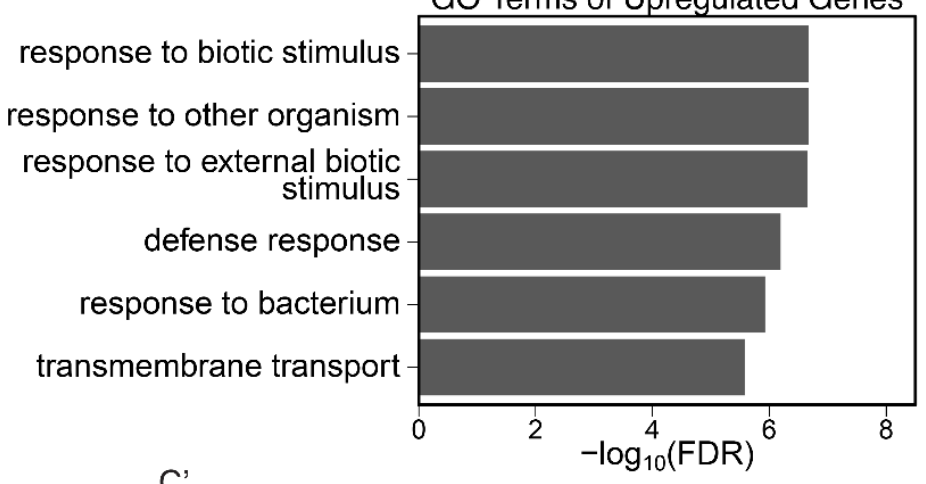

$C^{\prime}$

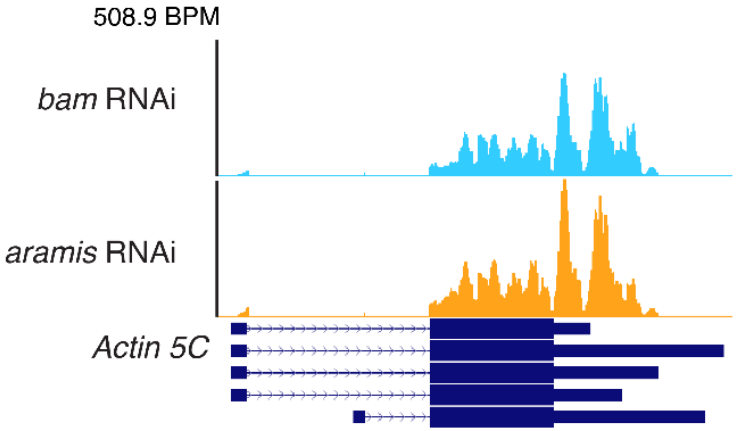

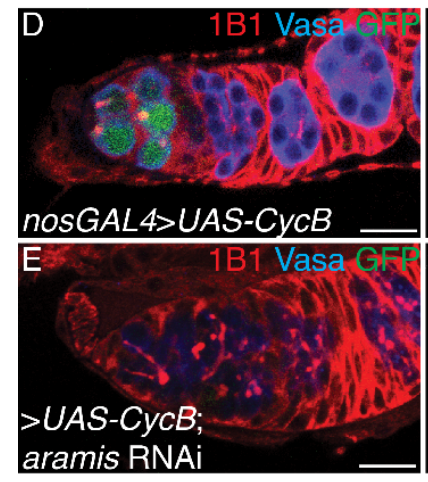
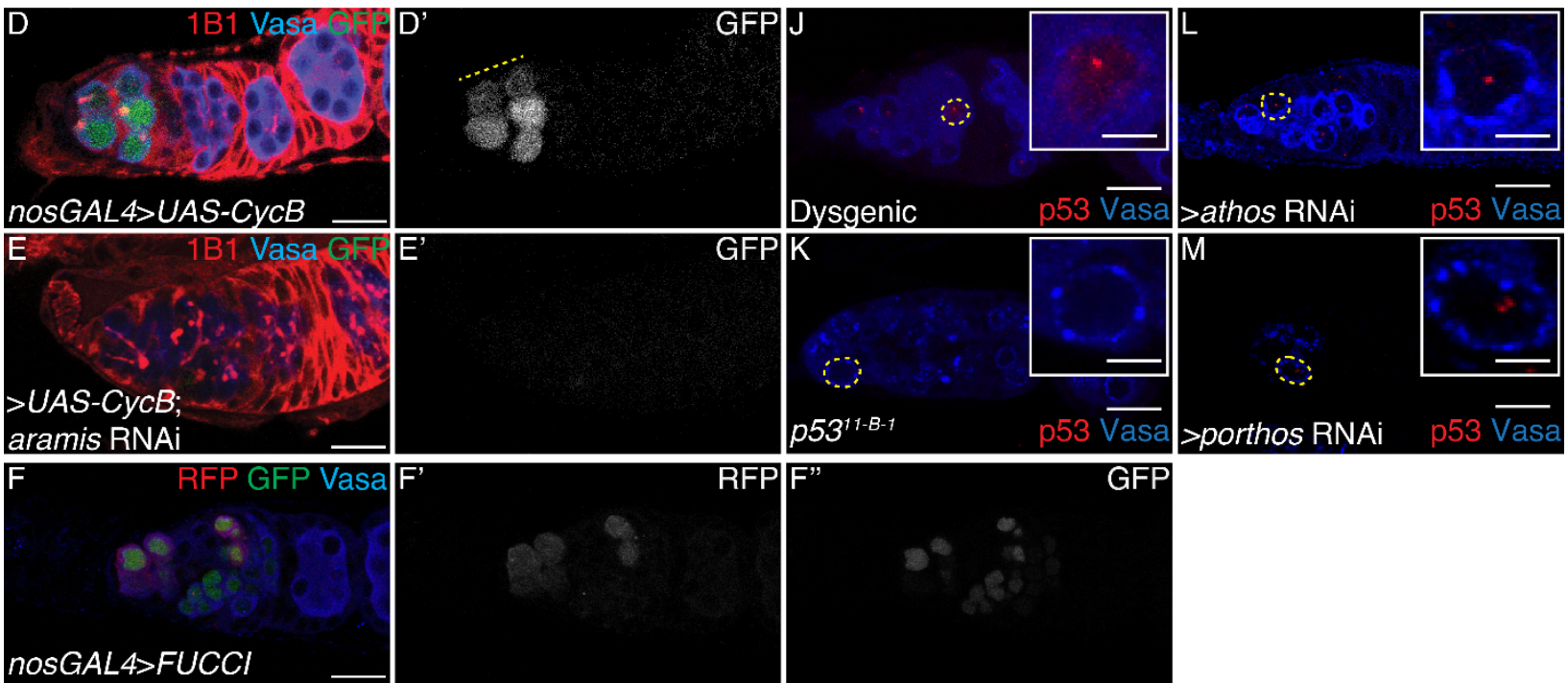

GFP
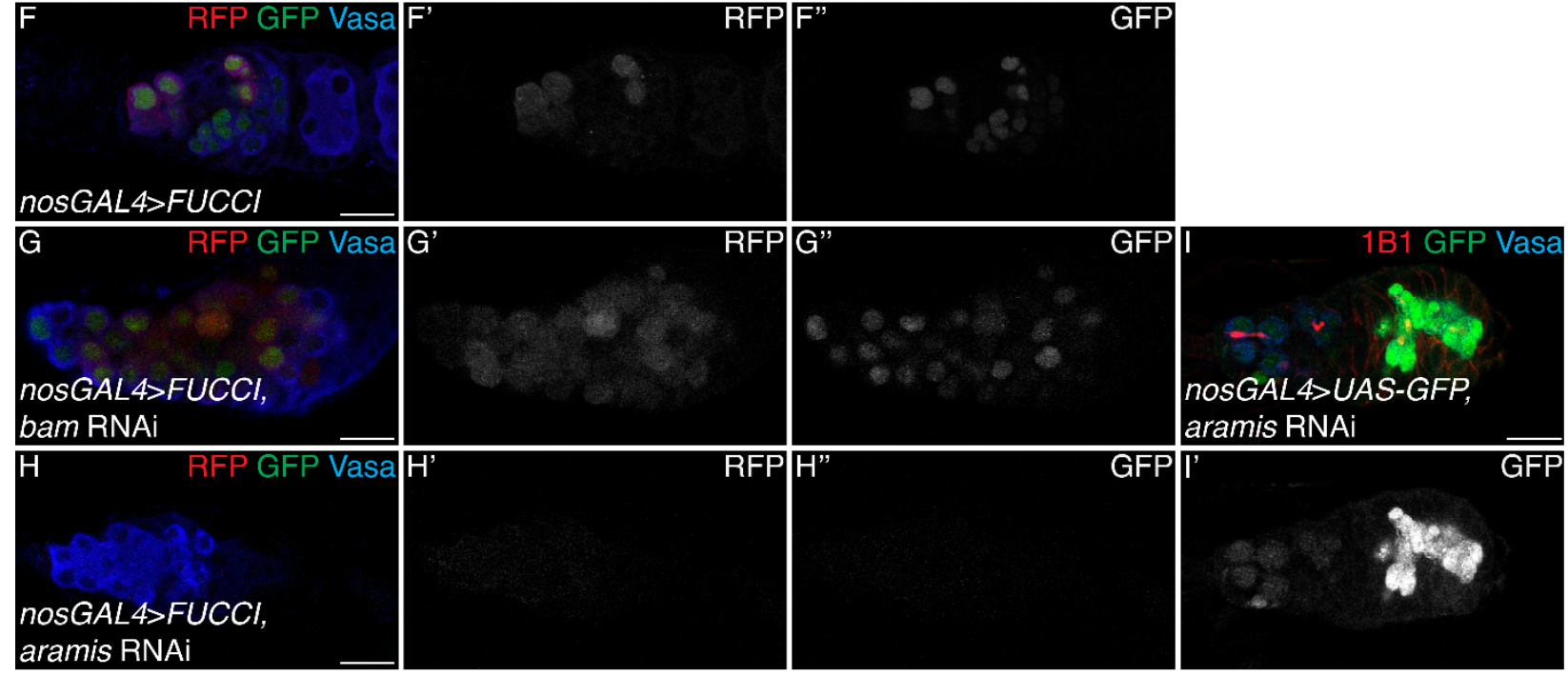
Supplemental Figure 3. Aramis is required for proper cell cycle progression, related to Figure 3. (A) Volcano plot of mRNA expression in aramis RNAi compared to bam RNAi. Blue points represent mRNAs significantly upregulated aramis RNAi compared to bam RNAi, red points represent mRNAs significantly downregulated aramis RNAi compared to bam RNAi. (B) Bar plot representing the most significant Biological Process $G O$ terms of upregulated genes in ovaries depleted of aramis compared to the developmental control, bam RNAi. (C-C') Genome browser tracks of mRNA expression at the (C) Cyclin A and ( $\left.\mathbf{C}^{\prime}\right)$ Actin 5C loci indicate that the RNAseq target gene Cyclin $A$ expression is downregulated, while a non-target, Actin $5 C$ is not downregulated. (D-E') Confocal images of germaria stained for 1B1 (red), Vasa (blue), and Cyclin B::GFP (green, grayscale) in (D-D') control and (E-E') germline depletion of aramis demonstrates that functional Cyclin B::GFP cannot be efficiently expressed in germline depleted of aramis. (FH") Confocal images of germaria that express Fly-FUCCl in the germline stained for Vasa (blue). GFP-E2f1 degron (green, right grayscale) and RFP-CycB ${ }^{\text {degron }}$ (red, left grayscale) in (F-F') nosGAL4, driver control ovaries, (G-G') bam RNAi as a developmental control, and (H-H') ovaries with germline depletion of aramis demonstrates that the germline of aramis RNAi germline depleted ovaries are negative for both G1 and G2 cell cycle markers. (I-I') Confocal images of aramis germline RNAi expressing GFP in the germline, stained for 1B1 (red), Vasa (blue), and GFP (green, grayscale) indicates productive translation of transgenes still occurs. (J-M) Confocal images of germaria stained for p53 (red) and Vasa (blue) in ( $\mathbf{J}$ ) hybrid dysgenic, Harwich, ovaries and (K) p53 $3^{11-B-1}$ ovaries stained for p53 (red) and Vasa (blue) demonstrate the expected p53 staining patterns. (L-M) Confocal images of germaria stained for p53 (red) and Vasa (blue) in ovaries depleted of $(\mathbf{L})$ athos or $(\mathbf{M})$ porthos in the germline exhibit p53 punctate staining. Cells

816 highlighted by a dashed yellow circle represent cells shown in the inset. Scale bar for main images is 15 micron, scale bar for insets is 3.75 micron.
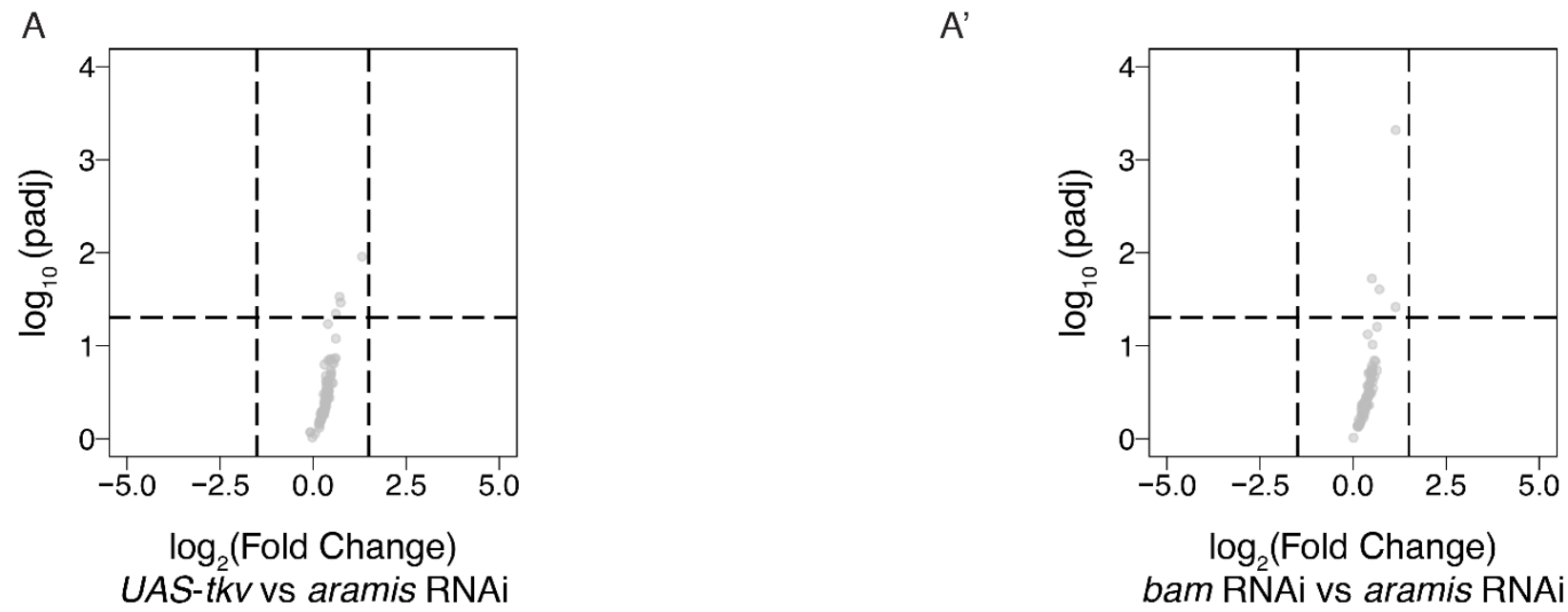

817

818

819

820

821

822

823
Supplemental Figure 4. The mRNA levels of Aramis polysome-seq targets are not significantly changing, related to Figure 4. (A-A') Volcano plot of mRNA expression from poly $(A)+$ mRNA input libraries in germline aramis RNAi compared to (A) germline driven UAS-tkv and (A') bam RNAi of targets identified from polysome-seq. No target genes identified from polysome-seq meet the differential expression cutoff for mRNA in UAS-tkv compared to aramis RNAi or bam RNAi compared to aramis RNAi input libraries. 

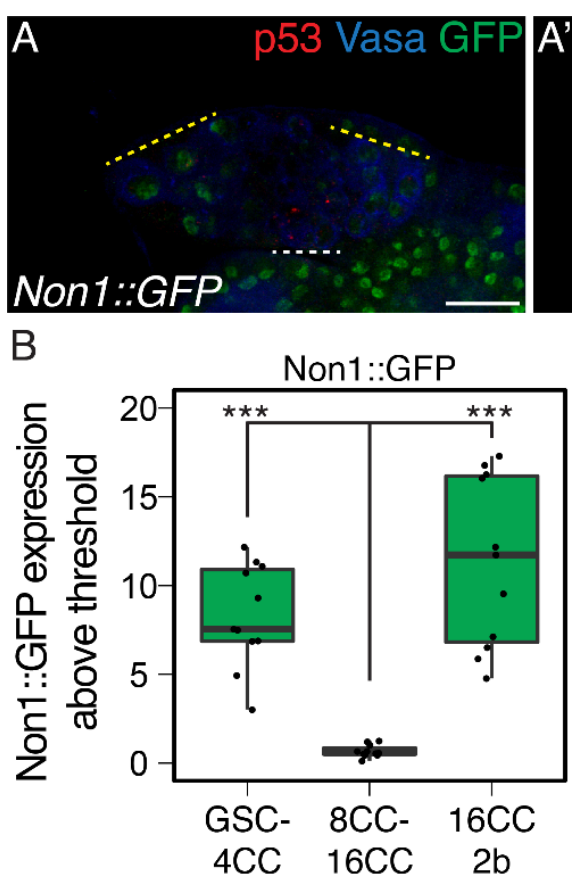
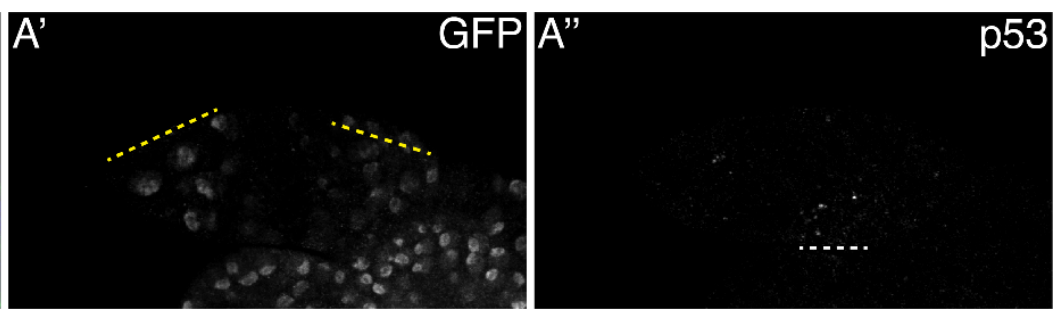

$\mathrm{B}^{\prime}$

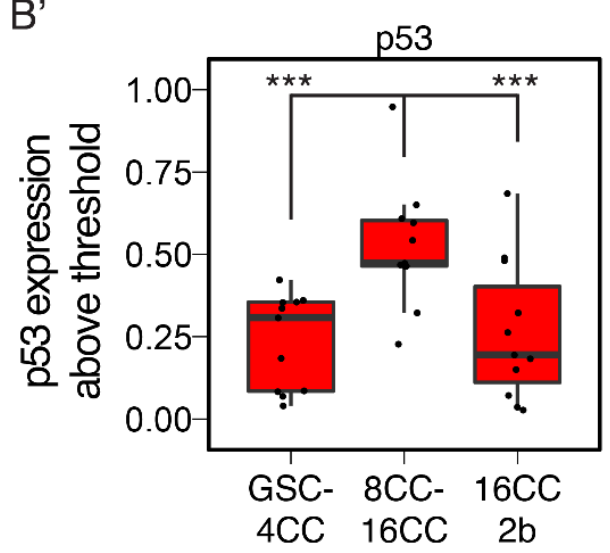

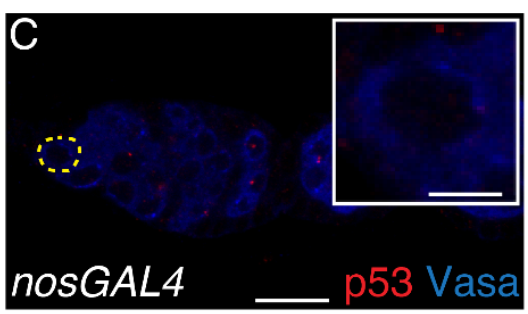
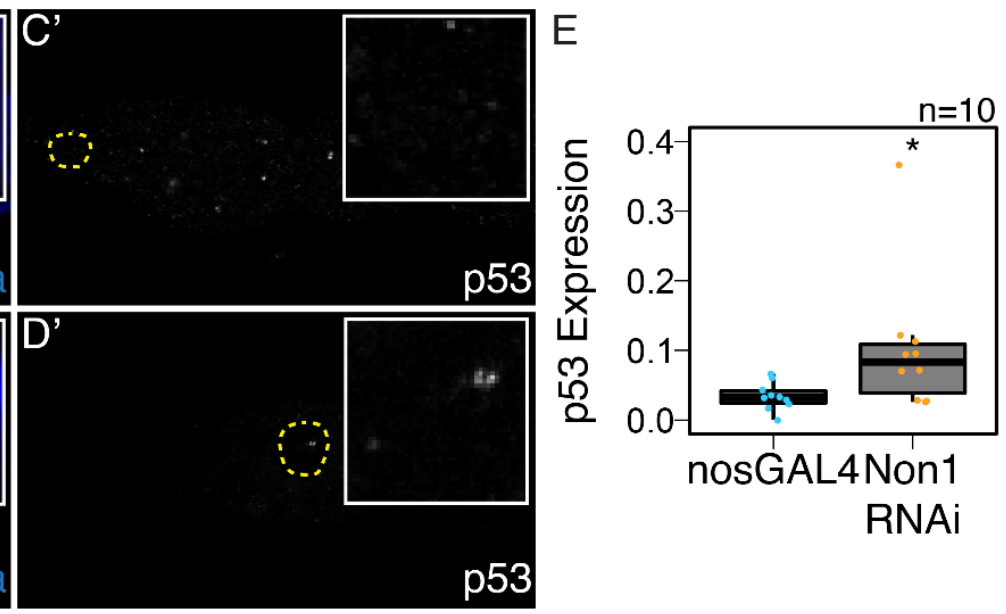
(blue), and Non1::GFP (green, left grayscale). (B-B') Quantifications of staining, (B) peak Non1 expression in control ovaries occurs in GSC-4 cell cyst stages and 16-cell cyst-region $2 \mathrm{~b}$ stages where (B') p53 expression is low. (C-D') Confocal images of nosGAL4, driver control (C-C') and germline Non1 RNAi germaria stained for p53 (red, grayscale) and Vasa (blue). (E) Quantification ovaries compared to the control. Cells highlighted by a dashed yellow circle represent cells shown in the inset. Scale bar for main images is 15 micron, scale bar for insets is 3.75 micron. 
A

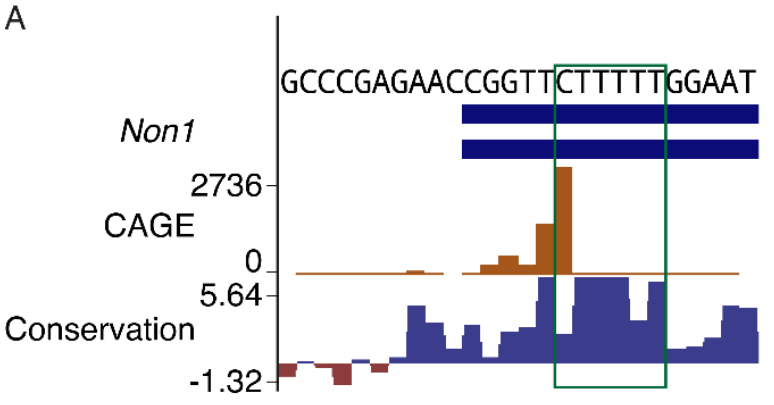

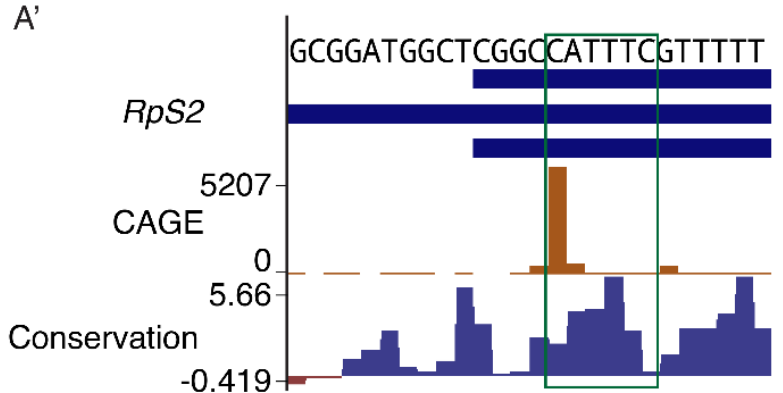

$-0.419$

B

Wildtype-TOP Reporter

Nos Promoter CTTTT-RpL30 5'UTR GFP HA K10-3'UTR

Mutant-TOP Reporter

Nos Promoter AGGGG-RpL30 5'UTR GFP HA K10-3'UTR

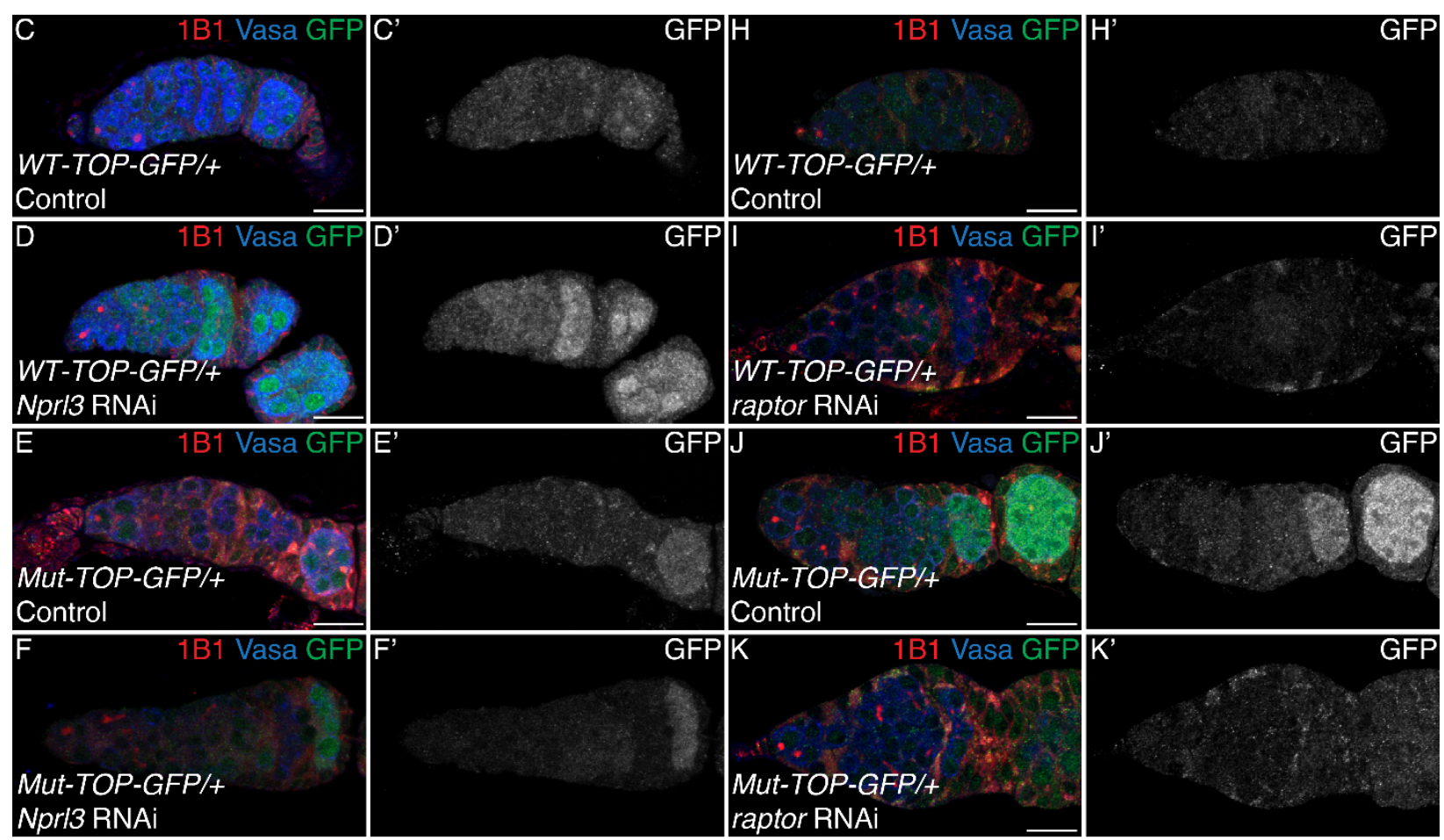

$\mathrm{G}$

$\square$ Control

$\square$ Nprl3 RNAi

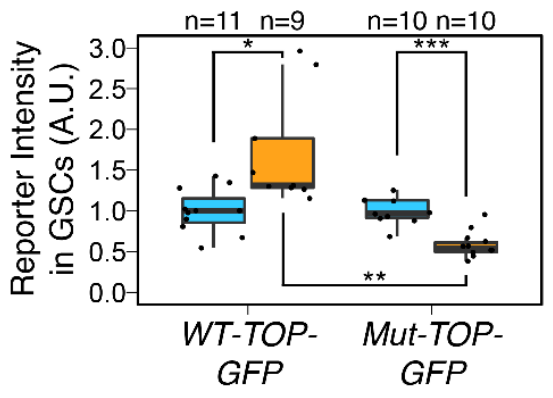

raptor $\mathrm{RNA}$

L $\quad \square$ Control

$\square$ raptor $\mathrm{RNAi}$

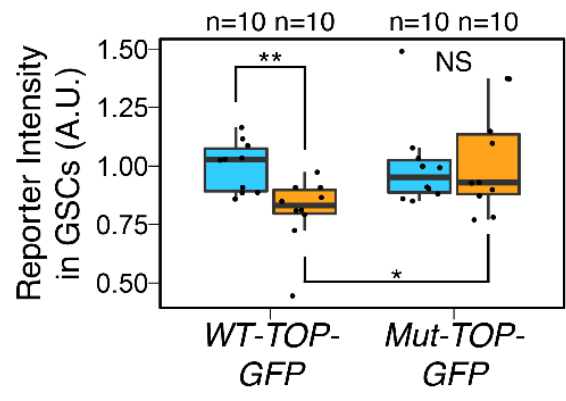



to Figure 6. (A-A') Genome browser tracks of the (A) Non1 and (A') RpS2 loci in ovary CAGEseq data showing the proportion of transcripts that are produced from a given TSS (orange). Predominant TSSs are shown in orange and putative TOP motif beginning at the dominant TSS is indicated with a green box. The bottom blue and red graph represents sequence conservation of the locus across Diptera. The dominant TSS of Non1 initiates with a canonical TOP motif and the RpS2 TSS initiates at a sequence resembling a TOP motif. (B) Diagram of the WT and MutTOP-GFP reporter constructs indicating the TOP sequence that is mutated by transversion in the Mutant reporter (blue). (C-D') Confocal images of WT-TOP reporter expression stained for 1B1 (red), GFP (green, grayscale), and Vasa (blue) in (C-C') nosGAL4, driver control ovaries and (DD') ovaries depleted of Nprl3 in the germline. (E-F') Confocal images of Mut-TOP-GFP reporter expression stained for 1B1 (red), GFP (green, grayscale), and Vasa (blue) in (E-E') nosGAL4, driver control ovaries and (F-F') ovaries depleted of Nprl3 in the germline. (G) A.U. quantification of WT and Mutant TOP reporter expression in GSCs of nosGAL4, driver control ovaries and GSCs of $\mathrm{Nprl3}$ germline depleted ovaries normalized to Vasa expression indicate that the relative expression of the WT-TOP-GFP reporter is higher than the Mut-TOP-GFP reporter ( $n=9-11$ germaria per genotype, Welch's t-test, $\left.{ }^{*}=p<0.05,{ }^{* *}=p<0.01,{ }^{* * *}=p<0.001\right)$. $\left(\mathbf{H}-\mathbf{l}^{\prime}\right)$ Confocal images of WT-TOP reporter expression stained for 1B1 (red), GFP (green, grayscale), and Vasa (blue) in (H-H') nosGAL4, driver control ovaries and (I-I') ovaries depleted of raptor in the germline. (J-K') Confocal images of Mut-TOP-GFP reporter expression stained for 1B1 (red), GFP (green, grayscale), and Vasa (blue) in (J-J') nosGAL4, driver control ovaries and (K-K') ovaries depleted of raptor in the germline. (L) A.U. quantification of WT and Mutant TOP reporter expression in GSCs of nosGAL4, driver control ovaries and GSCs of raptor germline depleted ovaries normalized to Vasa expression indicate that the relative expression of the WT-TOP-GFP reporter is lower than the Mut-TOP-GFP reporter ( $\mathrm{n}=10$ germaria per genotype, Welch's t-test, * $\left.=p<0.05,{ }^{* *}=p<0.01\right)$. Scale bar for images is 15 micron. 


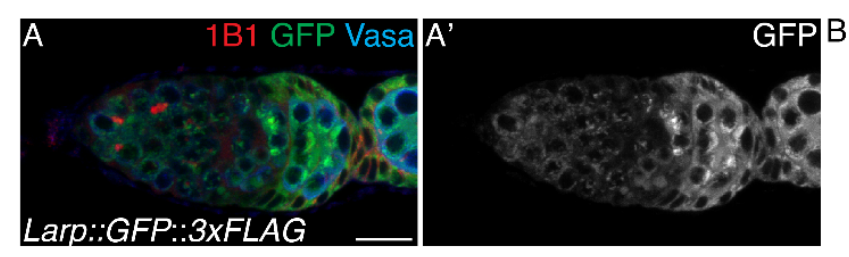

C

$$
\text { 0 }
$$

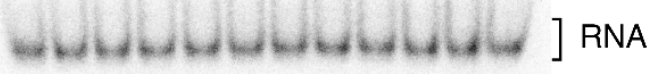

Capped RpL30 purine control 42-mer

$C^{\prime}$

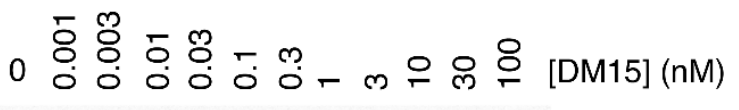

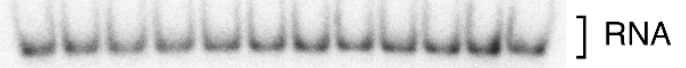

Capped Non1 purine control 42-mer

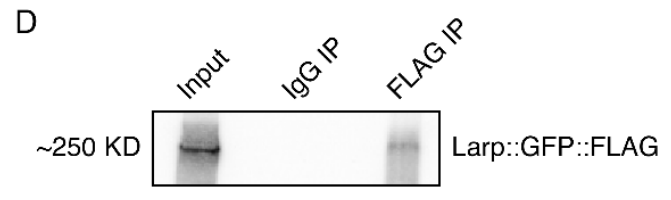

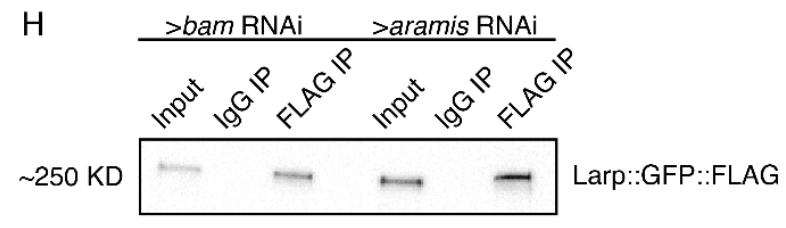

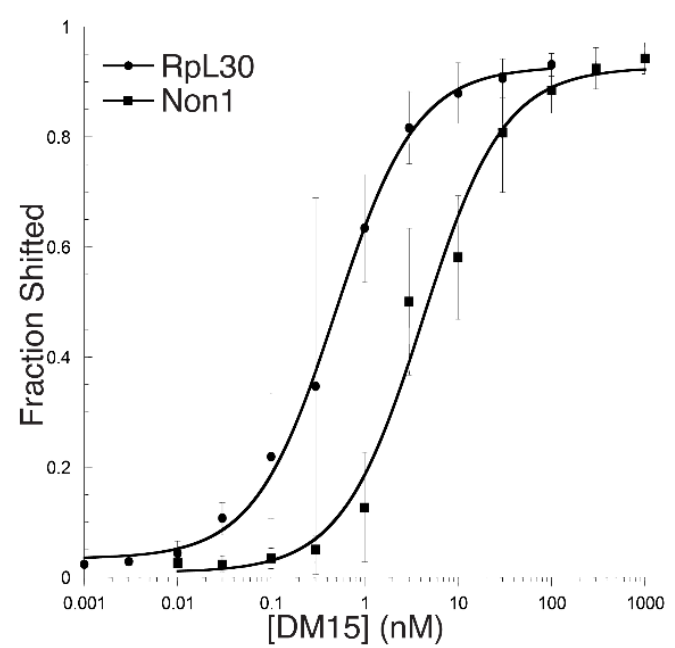

\begin{tabular}{|c|c|l|c|}
\hline RNA & $\mathrm{K}_{\mathrm{d}}$ & Standard Deviation & $\mathrm{R}^{2}$ \\
\hline RpL30 & $487 \mathrm{pM}$ & $\pm 38.3 \mathrm{pM}$ & 0.999 \\
\hline Non1 & $4.2 \mathrm{nM}$ & $\pm 0.87 \mathrm{nM}$ & 0.993 \\
\hline
\end{tabular}

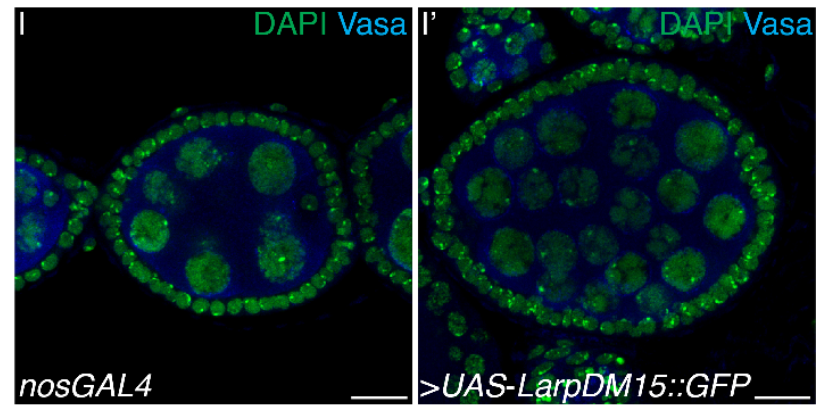

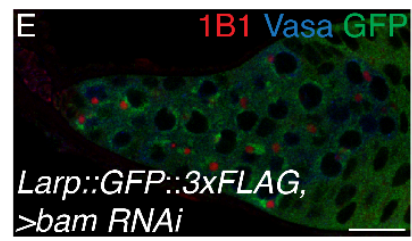
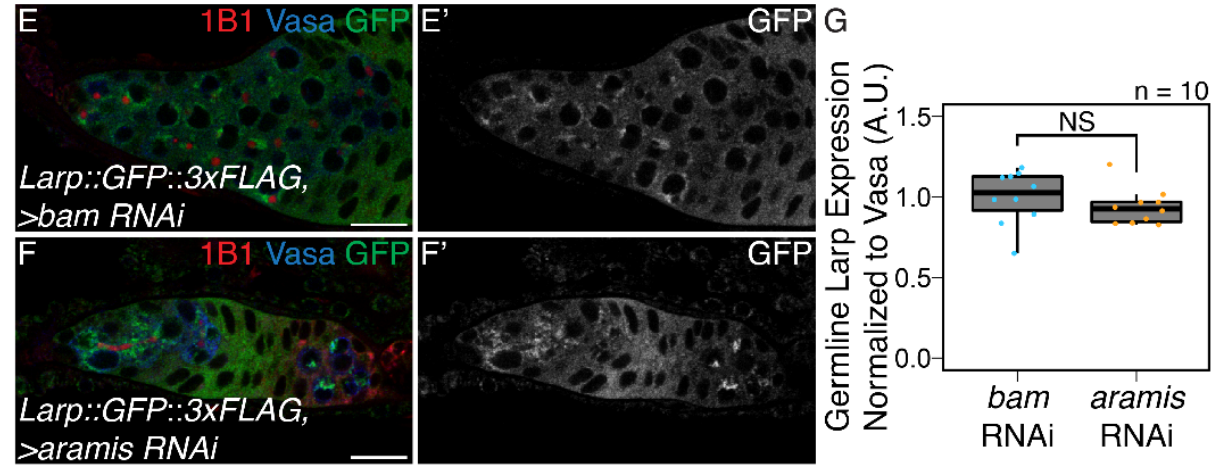
864

865

866

867

868

869

870

871

872

873

874

875

876

877

878

879

880

881

882

883

884

885

886

887

888

889

890

891

892

893

894

895

896

897

898

899

900

901

902

903

904

905

906

907

908

909

910

911

912

913

914

(blue), and Larp GFP-3xFLAG (green, grayscale) indicates Larp is expressed throughout early oogenesis. (B) Quantification of EMSAs and summary of $\mathrm{K}_{d}$ of the protein-RNA interactions. (CC') EMSA of Larp-DM15 and the leading 42 nucleotides of (B) RpL30 and (B') Non1 with their TOP sequence mutated to purines as a negative control with increasing concentrations of LarpDM15 from left to right indicates that Larp-DM15 requires a leading TOP sequence for its binding. (D) Western of representative IP of Larp::GFP::FLAG from ovary tissue used for RNA IP-seq. (EF') Confocal images of Larp::GFP::FLAG reporter expression stained for 1B1 (red), GFP (green, grayscale), and Vasa (blue) in (E-E') bam and (F-F') aramis depleted germaria. (G) A.U. quantification of Larp::GFP::FLAG reporter expression in the germline of bam RNAi and aramis RNAi demonstrates that the germline expression of Larp is not elevated in aramis germline RNAi compared to bam germline RNAi as a developmental control $(n=10, p>0.05$, Welch's t-test). $(\mathbf{H})$ Western of representative IP of Larp::GFP::FLAG from ovary tissue used for RNA IP qPCR. (I-I') Confocal images of (I) nosGAL4, driver control and (I') ovaries overexpressing the DM15 region of Larp in the germline ovaries stained for DAPI (green) and Vasa (blue). Overexpression of LarpDM15 results in the production of 32-cell egg chambers which indicates it causes a cytokinesis defect. Scale bar for all images is 15 micron.

Supplemental Table 1. Results of germline helicase RNAi screen on ovariole morphology. Results of screen of RNA helicases depleted from the germline. Reported is the majority phenotype from $n=50$ ovarioles.

Supplemental Table 2. Differential expression analysis from RNAseq of ovaries depleted of aramis in the germline compared to a developmental control. DEseq2 output from RNAseq of ovaries depleted of aramis in the germline compared to ovaries depleted of bam in the germline as a developmental control. Sheet 1 (Downregulated Genes) contains genes and corresponding DEseq2 output meeting the cutoffs to be considered downregulated in aramis RNAi compared to bam RNAi. Sheet 2 (Upregulated Genes) contains genes and corresponding DEseq2 output meeting the cutoffs to be considered upregulated in aramis RNAi compared to bam RNAi. Sheet 3 (All Genes) contains DEseq2 output for all genes in the dm6 assembly.

Supplemental Table 3. Analysis of polysome-seq of ovaries depleted of aramis in the germline compared to developmental controls. Results of polysome-seq from ovaries depleted of aramis in the germline, ovaries depleted of bam, and ovaries overexpressing tkv in the germline as developmental controls. Sheet 1 (Downregulated Genes) contains genes and corresponding polysome/input ratio values and values representing the difference in the polysome/input ratios between aramis RNAi and the developmental controls meeting the cutoffs to be considered downregulated in aramis RNAi. Sheet 2 (Upregulated Genes) contains genes and corresponding polysome/input ratio values and values representing the difference in the polysome/input ratios between aramis RNAi and the developmental controls meeting the cutoffs to be considered upregulated in aramis RNAi. Sheet 3 (All Genes) contains DEseq2 output for all genes in the dm6 assembly.

Supplemental Table 4. Aramis translation targets contain TOP sequences. List of aramis RNAi polysome downregulated targets and the position and sequence of the first instance of a 5mer pyrimidine sequence downstream of the CAGE-defined TSS of each gene.

Supplemental Table 5. Enrichment analysis of Larp RNA IP mRNA-seq. Results of Larp::GFP::FLAG IP/lgG/Input mRNAseq. Each sheet contains the output of DEseq2. Sheet 1 (Larp Targets) contains Larp IP targets as defined in methods. Sheet 2 (IP vs In Enriched) contains genes significantly enriched in the Larp IP samples compared to the input samples. Sheet 3 (IgG vs In Enriched) contains genes significantly enriched (see methods) in the $\lg G$ 
915

916

917

918

919

920

921

922

923

924

925

926

927

928

929

930

931

932

933

934

935

936

937

938

939

940

941

942

943

944

945

946

947

948

949

950

951

952

953

954

955

956

957

958

959

960

961

962

963

samples compared to the input samples. Sheet 4 (IPvsIn All Genes) contains the DEseq2 output of all genes in the Larp IP samples compared to the input samples. Sheet 5 (IgG vs In All Genes) contains the DEseq2 output of all genes in the IgG samples compared to the input samples.

\section{Materials and Methods}

Fly lines:

The following Bloomington Stock Center lines were used in this study: \#25751 UASDcr2;nosGAL4, \#4442 nosGAL4;MKRS/TM6, \#32334 Aramis RNAi\#1 CG5589 HMS00325, \#56977

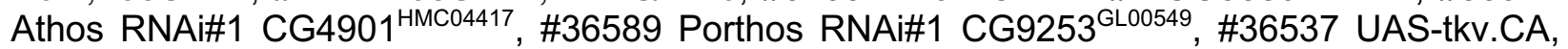
\#33631 bam RNAi ${ }^{\mathrm{HMS00029}}$, \#6815 p53 ${ }^{5 \mathrm{~A}-1-4}$, \#4264 Harwich, \#6816 p53 ${ }^{11-1 \mathrm{~B}-1}$, \#55101 $\mathrm{FUCCl}$ : UASp-GFP.E2f1.1-230, UASp-mRFP1.CycB.1-266/TM6B, \#5431 UAS-EGFP, \#78777 Non1 RNAi P\{TRiP.HMS05872\}, \#61790 Larp::GFP::3xFLAG Mi\{PT-GFSTF.1\}larp ${ }^{\text {Ml06928-GFSTF.1 }, \text { \#8841 }}$ w[1118]; Df(3R)Hsp70A, Df(3R)Hsp70B, \#55384 Nprl3 RNAi P\{TRiP.HMC04072\}attP40, \#34814 raptor RNAi P\{TRiP.HMS00124\}attP2

The following Vienna Stock Center lines were used in this study: Aramis RNAi\#2 CG5589v44322, Athos RNAi\#2 CG4901 344905 , Aramis::GFP PBac\{fTRG01033.sfGFP-TVPTBF\}VK00002, Athos::GFP PBac\{fTRG01233.sfGFP-TVPTBF\}VK00033, Non1::GFP PBac\{fTRG00617.sfGFPTVPTBF\}VK00033

The following additional fly lines were used in the study: UASp-CycB::GFP (Mathieu et al., 2013), UAS-Dcr2;nosGAL4; bamGFP, If/CyO;nosGAL4 (Lehmann Lab), w1118 (Lehmann lab), tjGAL4/CyO (Tanentzapf et al., 2007), RpS2::GFPCB02294 (Buszczak et al., 2007; Zhang et al., 2014), UASp-Non1 (this study), UASp-Larp-DM15 (this study), WT-TOP-Reporter (this study), Mutant-TOP-Reporter (this study).

Antibodies IF

The following antibodies were used for immunoflourenscence: mouse anti-1B1 1:20 (DSHB 1B1), rabbit anti-Vasa 1:833-1:4000 (Rangan Lab), chicken anti-Vasa 1:833-1:4000 (Rangan Lab) (Upadhyay et al., 2016), rabbit anti-pTyr 1:500 (Sigma T1235), rabbit anti-pMad 1:200 (Abcam ab52903), rabbit anti-GFP 1:2000 (abcam, ab6556), mouse anti-p53 1:200 (DSHB 25F4), Rabbit anti-CycB 1:200 (Santa Cruz Biotechnology, 25764), Rabbit anti-Fibrillarin 1:200 (Abcam ab5821), Mouse anti-Fibrillarin 1:50 (Fuchs Lab) (McCarthy et al., 2018). Alexa 488 (Molecular Probes), Cy3 and Cy5 (Jackson Labs) were used at a dilution of 1:500.

Antibodies Western/IP

Mouse anti-FLAG-HRP 1:5000 (Sigma Aldrich, A8592)

Mouse anti-FLAG (Sigma Aldrich, F1804)

Anti-GAPDH-HRP 1:10,000 (Cell Signaling, 14C10)

Rabbit anti-DDX52 1:5000 (Bethyl, A303-053A)

Rabbit anti-DHX33 1:5000 (Bethyl, A300-800A)

Rabbit anti-DDX47 1:1000 (Bethyl, A302-977A)

Protein Domain Analysis:

Protein domain figures were adapted from: The Pfam protein families database in 2019: S. ElGebali et al. Nucleic Acids Research (2019). Protein Similarity values were obtained from the DRSC/TRiP Functional Genomics Resources.

\section{TOP Reporter Cloning}


964

965

966

967

968

969

970

971

972

973

974

975

976

977

978

979

980

981

982

983

984

985

986

987

988

989

990

991

992

993

994

995

996

997

998

999

1000

1001

1002

1003

1004

1005

1006

1007

1008

1009

1010

1011

1012

1013

gBlocks (see primer list for details) were cloned into pCasper2 containing a Nos promoter, HAtag, GFP-tag, and K10 3'UTR. PCR was used in order to amplify the gBlock and to remove the 5'-end of the RpL30 5'UTR in order to generate the 5'-UTR discovered via CAGE-seq. In order to clone the Nos promoter followed by the RpL30 5'UTR without an intervening restriction site, the portion of the plasmid 5' of the 5'UTR consisting of a portion of the plasmid backbone, a Notl restriction site, and the Nos Promoter was amplified from the pCasper plasmid using PCR. HiFi cloning was performed on the amplified fragments. The backbone was cut with Notl and Spel and $\mathrm{HiFi}$ cloning was performed according to the manufactures' instructions except the HiFi incubation was performed for 1 hour to increase cloning efficiency. Colonies were picked and cultured and plasmids were purified using standard techniques. Sequencing was performed by Eton Bioscience Inc. to confirm the correct sequence was present in the final plasmids. Midi-prep scale plasmid was prepared using standard methods and plasmids were sent to BestGene Inc. for microinjection.

\section{Gateway Cloning}

Gateway cloning was performed as described according to the manufacture's manual. Briefly, primers containing the appropriate Gateway attb sequence on the 5'-ends and gene specific sequences on the 3'-ends (see primer list for sequences) were used to PCR amplify each gene of interest. PCR fragments were BP cloned into pEntr221 as detailed in the Thermofisher Gateway Cloning Manual and used to transform Invitrogen One Shot OmniMAX 2 T1 PhageResistant Cells. Resulting clones were picked and used to perform LR cloning into either pPGW or pPWG as appropriate. Cloning was carried out according to the Thermofisher Gateway Cloning Manual except the LR incubation was carried out up to 16 hours. Colonies were picked and cultured and plasmids were purified using standard techniques. Sequencing was performed by Eton Bioscience Inc. to confirm the correct sequence was present in the final plasmids. Midi-prep scale plasmid was prepared using standard methods and plasmids were sent to BestGene Inc. for microinjection.

\section{Egg Laying Test}

Newly eclosed flies were collected and fattened overnight on yeast. Six female flies were crossed to 4 male controls and kept in cages at $25^{\circ} \mathrm{C}$. Flies were allowed to lay for three days, and plates were changed and counted daily. Total number of eggs laid over the three day laying periods were determined and averaged between three replicate crosses for control and experimental crosses.

\section{Immunostaining}

Ovaries were dissected and teased apart with mounting needles in cold PBS and kept on ice for subsequent dissections. All incubations were performed with nutation. Ovaries were fixed for 1015 min in 5\% methanol-free formaldehyde in PBS. Ovaries were washed with PBT (1x PBS, 0.5\% Triton X-100, $0.3 \% \mathrm{BSA}$ ) once quickly, twice for $5 \mathrm{~min}$, and finally for $15 \mathrm{~min}$. Ovaries were incubated overnight, up to 72 hours in PBT with the appropriate primary antibodies. Ovaries were again washed with PBT once quickly, twice for $5 \mathrm{~min}$, and finally for $15 \mathrm{~min}$. Ovaries were then incubated with the appropriate secondary antibodies in PBT overnight up to 72 hours at $4^{\circ} \mathrm{C}$. Ovaries were washed once quickly, twice for $5 \mathrm{~min}$, and finally for $15 \mathrm{~min}$ in PBST (1x PBS, 0.2\% Tween 20 Ovaries). Ovaries were mounted with Vectashield with 4',6-diamidino-2-phenylindole (DAPI) (Vector Laboratories) and imaged on a Zeiss 710. All gain, laser power, and other relevant settings were kept constant for any immunostainings being compared. Image processing was performed in Fiji, gain was adjusted, and images were cropped in Photoshop CC 2018.

\section{Florescent Imaging}


Tissues were visualized and imaged were acquired using a Zeiss LSM-710 confocal microscope under the $20 \times$ and $40 \times$ oil objectives.

1015

1016

1017

1018

1019

1020

1021

1022

1023

1024

1025

1026

1027

1028

1029

1030

1031

1032

1033

1034

1035

1036

1037

1038

1039

1040

1041

1042

1043

1044

1045

1046

1047

1048

1049

1050

1051

1052

1053

1054

1055

1056

1057

1058

1059

1060

1061

1062

1063

1064

\section{Measurement of global protein synthesis}

OPP (Thermo Fisher, C10456) treatment was performed as in McCarthy (2019). Briefly, ovaries were dissected in Schneider's media (Thermo Fisher, 21720024) and incubated in $50 \mu \mathrm{M}$ of OPP reagent for 30 minutes. Tissue was washed in 1x PBS and fixed for 10 minutes in 1x PBS plus $5 \%$ methanol-free formaldehyde. Tissue was permeabilized with $1 \%$ Triton X-100 in $1 \mathrm{x}$ PBST (1x PBS, $0.2 \%$ Tween 20) for 30 minutes. Samples were washed with 1x PBS and incubated with Click-iT reaction cocktail, washed with Click-iT reaction rinse buffer according to manufacturer's instructions. Samples were then immunostained according to previously described procedures.

\section{Image Quantifications}

All quantifications were performed on images using the same confocal settings.

A.U. quantifications were performed in Fiji on images taken with identical settings using the "Measure" function. Intensities were normalized as indicated in the figure legends, boxplots of A.U. measurements were plotted using $R$ and statistics were calculated using $R$.

Quantification of nucleolar size was measured in Fiji by measuring the diameter of the nucleolus using the measure tool in Fiji. Volumes were calculated using the formula for a sphere.

Quantification of p53 area of expression was performed from control, nosGAL4 and nosGAL4>aramis RNAi germaria. A manual threshold was set based off of qualitative assessment of a "punctate". For control ovaries, cells proximal to the niche consisting of GSCs/CBs were outlined and for aramis RNAi the entire germline proximal to the niche was outlined and a Fiji script was used to determine the number of pixels above the threshold and the total number of pixels. Data from each slice for each replicate was summed prior to plotting and statistical analysis.

Colocalization analysis of helicases with Fibrillarin was performed in Fiji using the Plot Profile tool. A selection box was drawn over a Fibrillarin punctate of interest (indicated with a box in the images) and Plot Profiles was acquired for each channel of interest. Data was plotted and Spearman correlations calculated using $\mathrm{R}$.

Quantification of Non1-GFP expression and p53 expression over development was calculated in Fiji using the Auto Threshold tool with the Yen method (Sezgin and Sankur, 2004) to threshold expression. Quantifications were performed on 3 merged slices and egg chambers were cropped out of quantified images prior to thresholding to prevent areas outside of the germarium from influencing the thresholding algorithm. Areas of germline with "high" and "low" expression of Non1-GFP were outlined manually and a custom Fiji script was used in order to quantify the proportion of pixels in the selected marked as positive for expression for either Non1-GFP or p53, staging was inferred from the results of the Non1-GFP quantification performed using $1 \mathrm{~B} 1$ to determine the stages of peak Non1 expression. Percent area was plotted with ggplot2 as boxplots in a custom $R$ script.

\section{RNA Extraction from Ovaries}

RNA extraction was performed using standard methods. Ovaries were dissected into PBS and transferred to microcentrifuge tubes. PBS was removed and $100 \mathrm{ul}$ of Trizol was added and ovaries were flash frozen and stored at $-80^{\circ} \mathrm{C}$. Ovaries were lysed in the microcentrifuge tube using a plastic disposable pestle. Trizol was added to $1 \mathrm{~mL}$ total volume and sample was vigorously shaken and incubated for $5 \mathrm{~min}$ at RT. The samples were centrifuged for $x$ min at $>13,000 \mathrm{~g}$ at $4{ }^{\circ} \mathrm{C}$ and the supernatant was transferred to a fresh microcentrifuge tube. $500 \mathrm{ul}$ of chloroform was added and the samples were vigorously shaken and incubated for 5 minutes at RT. Samples were spun at max speed for 10 minutes at $4{ }^{\circ} \mathrm{C}$. The supernatant was transferred to a fresh microcentrifuge tube and ethanol precipitated. Sodium acetate was added equaling 
1065

1066

1067

1068

1069

1070

1071

1072

1073

1074

1075

1076

1077

1078

1079

1080

1081

1082

1083

1084

1085

1086

1087

1088

1089

1090

1091

1092

1093

1094

1095

1096

1097

1098

1099

1100

1101

1102

1103

1104

1105

1106

1107

1108

1109

1110

1111

1112

1113

1114

1115

$10 \%$ of the volume transferred and $2-2.5$ volumes of $100 \%$ ethanol were added. The samples were shaken thoroughly and left to precipitate at $-20^{\circ} \mathrm{C}$ overnight. The samples were centrifuged at max speed at $4{ }^{\circ} \mathrm{C}$ for 15 min to pellet the RNA. The supernatant was discarded and 500 ul of $75 \%$ ethanol was added to wash the pellet. The samples were vortexed to dislodge the pellet to ensure thorough washing. The samples were spun at $4{ }^{\circ} \mathrm{C}$ for $5 \mathrm{~min}$ and the supernatant was discarded. The pellets were left for 10-20 min until dry. The pellets were resuspended in $20-50 \mathrm{ul}$ of RNAse free water and the absorbance at 260 was measured on a nanodrop to measure the concentration of each sample.

\section{S2 Cell RNAi}

DRSC-S2 cells (Stock \#181, DGRC) were cultured according to standard methods in M3+BPYE media supplemented with 10\% heat-inactivated FBS. dsRNA for RNAi was prepared as described by the SnapDragon manual. Briefly, template was prepared from S2 cell cDNA using the appropriate primers (see primer list) designed using SnapDragon (https://www.flyrnai.org/snapdragon). For in-vitro transcription the T7 Megascript kit (AM1334) was used following manufacturer's instructions and in-vitro transcriptions were incubated overnight at $37^{\circ} \mathrm{C}$. The RNA was treated with DNAse according to the T7 Megascript manual and the RNA was purified using acid-phenol chloroform extraction and ethanol precipitated. The resulting RNA was annealed by heating at $65^{\circ} \mathrm{C}$ for 5 minutes and slow cooling to $37^{\circ} \mathrm{C}$ for an hour. S2 cell RNAi was performed essentially as previously described using Effectine (Zhou et al., 2013). $1.0 \times 10^{6}$ cells were seeded 30 minutes prior to transfection and allowed to attach. After 30 minutes, just prior to transfection, the media was changed for $500 \mu \mathrm{l}$ of fresh media. $500 \mu \mathrm{l}$ of transfection complexes using $1 \mu \mathrm{g}$ of dsRNA was prepared per well of a 6 -well plate and pipetted dropwise onto seeded cells. After 24 hours an additional $1 \mathrm{~mL}$ of media was added to each well. After an additional 24 hours cells were passaged to $10 \mathrm{~cm}$ dishes. After an additional 3 days cells were harvested for further analysis.

\section{HeLa Cell RNAi}

HeLa cells were cultured under standard conditions in DMEM (Gibco) supplemented with 10\% FBS, and $2 \mathrm{mM} \mathrm{L-glutamine} \mathrm{at} 37^{\circ} \mathrm{C}$ and $5 \% \mathrm{CO}_{2}$. RNAi was performed in HeLa cells using the siRNAs in the primer list. $5 \%$ of cells from a $10 \mathrm{~cm}$ dishes with cells between $70-85 \%$ confluency were seeded to 6-well plates. Transfection was performed the following day using Dharmafect (PerkinElmer T-2001-03) according to the manufacture's procedure. Briefly, per well to be transfected Transfection Master Mix was prepared by mixing $5 \mu \mathrm{l}$ of Dharmafect with $200 \mu \mathrm{l}$ of OptiMEM (ThermoFisher 31985070) and incubated for 5 minutes at RT. $50 \mu$ l of OptiMEM was mixed with the given $3.75 \mu \mathrm{l}$ of $20 \mu \mathrm{M}$ siRNA and added to $100 \mu \mathrm{l}$ of Transfection Master Mix and incubated for 20-30 minutes at RT. Each transfection reaction was added to $600 \mu \mathrm{l}$ of DMEM. Media from the previous day was removed from the cells and replaced with the transfection mix. Cells were incubated at $37^{\circ} \mathrm{C}$ for one day, then passaged to $10 \mathrm{~cm}$ dishes and cultured for an additional two days. Cells were subsequently prepared for Western Blotting or Polysome Profiling (see respective sections).

\section{Polysome-profiling}

Polysome-profiling in S2 and HeLa cells was performed as in Fuchs et al. (2011) with minor modifications. HeLa cells were washed in cold PBS and lysed on the plate by scraping under 400 $\mu \mathrm{l}$ lysis buffer $(300 \mathrm{mM} \mathrm{NaCl}, 15 \mathrm{mM}$ Tris-HCl, $\mathrm{pH}$ 7.5, $15 \mathrm{mM}$ EDTA, $100 \mu \mathrm{g} / \mathrm{mL}$ cycloheximide, $1 \%$ Triton X-100). S2 cells were resuspended by pipetting, pelleted by centrifugation at $800 \mathrm{~g}$ for one minute, and washed in cold PBS. S2 cells were again pelleted and resuspended in $400 \mu$ of lysis buffer. HeLa and S2 cells were then allowed to continue to lyse for 15 min on ice. Lysate was cleared by centrifugation at $8500 \mathrm{~g}$ for $5 \mathrm{~min}$ at $4^{\circ} \mathrm{C}$. Cleared lysate was loaded onto $10 \%-$ $50 \%$ sucrose gradients $(300 \mathrm{mM} \mathrm{NaCl}, 15 \mathrm{mM}$ Tris- $\mathrm{HCl}, \mathrm{pH} 7.5,15 \mathrm{mM} \mathrm{MgCl} 2,100 \mathrm{~g} / \mathrm{mL}$ 
1116 cycloheximide) and centrifuged in an SW41 rotor at 35,000 RPM, for 3 hours. Gradients were

1117

1118

1119

1120

1121

1122

1123

1124

1125

1126

1127

1128

1129

1130

1131

1132

1133

1134

1135

1136

1137

1138

1139

1140

1141

1142

1143

1144

1145

1146

1147

1148

1149

1150

1151

1152

1153

1154

1155

1156

1157

1158

1159

1160

1161

1162

1163

1164

1165

1166

fractionated on a Density Gradient Fractionation System (Brandel, \#621140007) at $0.75 \mathrm{~mL} / \mathrm{min}$. Data generated from gradients were plotted using $\mathrm{R}$.

\section{Western Blot}

HeLa cells were harvested for Western by in RIPA buffer by scraping. Western blotting were performed according to standard methods, briefly, each sample was loaded onto a $4-20 \%$ commercial, precast gels and run at $100 \mathrm{~V}$ for $60-90 \mathrm{~m}$ depending on the size of the protein of interest. Gels were transferred to nitrocellulose membranes at $100 \mathrm{~V}$ for $1 \mathrm{hr}$ at $4^{\circ} \mathrm{C}$. Blot was blocked in 1\% milk in PBS and washed 3 times with PBS-T for 5 minutes. Primary antibodies were diluted in PBS-T+5\% BSA and incubated overnight. Blot was washed once quickly, once for $5 \mathrm{~m}$, and once for $10 \mathrm{~m}$ in PBS-T. Blot was subsequently imaged with ECL for conjugated primaries. For unconjugated primaries, the appropriate secondary was diluted $1: 10,000$ in $5 \%$ milk and incubated for 2-4 hours at RT. Blot was washed once quickly, once for $5 \mathrm{~m}$, and once for $10 \mathrm{~m}$ in PBS-T and imaged. Images were quantified using Fiji.

mRNAseq Library Preparation and Analysis

Libraries were prepared with the Biooscientific kit (Bioo Scientific Corp., NOVA-5138-08) according to manufacturer's instructions with minor modifications. Briefly, RNA was prepared with Turbo DNAse according to manufacturer's instructions (TURBO DNA-free Kit, Life Technologies, AM1907), and incubated at $37^{\circ} \mathrm{C}$ for $30 \mathrm{~min}$. DNAse was inactivated using the included DNAse Inactivation reagent and buffer according to manufactures instructions. The RNA was centrifuged at $1000 \mathrm{~g}$ for $1.5 \mathrm{~min}$ and $19 \mu \mathrm{l}$ of supernatant was transferred into a new $1.5 \mathrm{~mL}$ tube. This tube was again centrifuged at $1000 \mathrm{~g}$ for $1.5 \mathrm{~min}$ and $18 \mu \mathrm{l}$ of supernatant was transferred to a new tube to minimize any Inactivation reagent carry-over. RNA concentration was measured on a nanodrop. Poly-A selection was performed on a normalized quantity of RNA dependent on the lowest amount of RNA in a sample, but within the manufacturer's specifications for starting material. Poly-A selection was performed according to manufacturer's instructions (Bioo Scientific Corp., 710 NOVA-512991). Following Poly-A selection mRNA libraries were generated according to manufactures instructions (Bioo Scientific Corp., NOVA-5138-08) except RNA was incubated for $13 \mathrm{~min}$ at $95^{\circ} \mathrm{C}$ to generate optimal fragment sizes. Library quantity was assessed via Qubit according to manufacturer's instructions and library quality was assessed with a Bioanalyzer or Fragment Analyzer according to manufacturer's instructions to assess the library size distribution. Sequencing was performed on biological duplicates from each genotype on an Illumina NextSeq500 by the Center for Functional Genomics (CFG) to generate single end 75 base pair reads. Reads were aligned to the dm6.01 assembly of the Drosophila genome using HISAT v2.1.0. Reads were counted using featureCounts v1.4.6.p5. UCSC genome browser tracks were generated using the bam coverage module of deeptools v3.1.2.0.0. Differential expression analysis was performed using DEseq2 (v1.24.0) and data was plotted using R. Differentially expressed genes were those with $\log _{2}$ (foldchange) $>|1.5|$ and FDR $<0.05$. GO-term analysis of GO biological processes was performed on differentially expressed genes using PANTHER via http://geneontology.org/. Fisher's exact test was used to calculate significance and FDR was used to correct for multiple testing. GO-term analysis results were plotted using $\mathrm{R}$.

\section{Polysome-seq}

Polysome-seq was performed as in Flora et al. (2018b) with minor modifications. Ovaries were dissected in PBS and transferred to a microcentrifuge tube in liquid nitrogen. Ovaries were lysed in $300 \mu \mathrm{l}$ of lysis buffer $(300 \mathrm{mM} \mathrm{NaCl}, 15 \mathrm{mM}$ Tris- $\mathrm{HCl}, \mathrm{pH} 7.5,15 \mathrm{mM}$ EDTA, $100 \mu \mathrm{g} / \mathrm{mL}$ cycloheximide, $1 \%$ Triton X-100) and allowed to lyse for $15 \mathrm{~min}$ on ice. Lysate was cleared by centrifugation at $8500 \mathrm{~g}$ for $5 \mathrm{~min}$ at $4^{\circ} \mathrm{C}$. $20 \%$ of the lysate was reserved as input, $1 \mathrm{~mL}$ of Trizol (Invitrogen, 15596026 ) was added and RNA was stored at $-80^{\circ} \mathrm{C}$. Cleared lysate was loaded onto 
$10 \%-50 \%$ sucrose gradients $(300 \mathrm{mM} \mathrm{NaCl}, 15 \mathrm{mM}$ Tris- $\mathrm{HCl}, \mathrm{pH} 7.5,15 \mathrm{mM} \mathrm{MgCl} 2,100 \mathrm{~g} / \mathrm{mL}$ cycloheximide) and centrifuged in an SW41 rotor at 35,000 RPM, for 3 hours. Gradients were fractionated on a Density Gradient Fractionation System (Brandel, \#621140007) at $0.75 \mathrm{~mL} / \mathrm{min}$, $20 \mu \mathrm{l}$ of $20 \%$ SDS, $8 \mu \mathrm{l}$ of $0.5 \mathrm{M} \mathrm{pH} 8 \mathrm{EDTA}$, and $16 \mu \mathrm{l}$ of proteinase K (NEB, P8107S) was added to each polysome fraction. Fractions were incubated for $30 \mathrm{~m}$ at $37^{\circ} \mathrm{C}$. Standard acid phenol chloroform purification followed by ethanol precipitation was performed on each fraction. The RNA from polysome fractions was pooled and RNAseq libraries were prepared.

\section{S2 Polysome-seq Data Analysis}

Reads were checked for quality using FastQC. Reads were mapped to the Drosophila genome (dm6.01) using Hisat version 2.1.0. Mapped reads were assigned to features using featureCount version v1.6.4. Translation efficiency was calculated as in (Flora et al., 2018) using a custom $R$ script. Briefly, CPMs (counts per million) values were calculated. Any gene having zero reads in any library was discarded from further analysis. The $\log _{2}$ ratio of CPMs between the polysome fraction and total mRNA was calculated and averaged between replicates. This ratio represents TE, TE of each replicate was averaged and delta TE was calculated (Porthos RNAi TE)/(GFP RNAi TE). This ratio represents delta TE. The group of highly expressed targets was defined as transcripts falling greater or less than one standard deviation from the median of delta TE with $\log _{2}($ TPM) expression greater than five.

\section{CAGE-seq Tracks}

CAGE-seq tracks were visualized using the UCSC Genome Browser after adding the publicly available track hub 'EPD Viewer Hub'.

\section{CAGE-seq Data Reanalysis}

Publicly available genome browser tracks were obtained of CAGE-seq data (generated by Chen et al. (2014) and viewed through the UCSC Genome Browser. The original CAGE-seq data from ovaries was obtained from SRA under the accession number SRR488282. Reads were aligned to the dm6.01 assembly of the Drosophila genome using HISAT v2.1.0. cageFightR was used to determine the dominant TSS for every gene with sufficient expression in from the aligned dataset according to its documentation with default parameters excepting the following: For getCTSS, a mappingQualityThreshold of 10 was used. For normalizeTagCount the method used was "simpleTPM". For clusterCTSS the following parameters were used; threshold $=1$, thresholdlsTpm $=$ TRUE, nrPassThreshold $=1$, method $=$ "paraclu", $\operatorname{maxDist~}=20$, removeSingletons $=$ TRUE, keepSingletonsAbove $=5$. Custom Rcripts were used in order to obtain genome sequence information downstream of the TSS of each gene identified.

\section{Motif Enrichment Analysis}

Motif enrichment analysis was performed using Homer (Heinz et al., 2010) using the findmotifs.pl module, supplying Homer with the first 200 nucleotides downstream of the TSS as determined by CAGE-seq for polysome-seq targets and non-targets as a background control with the following parameters "-rna -nogo -p 6 -len 6". Only motifs not marked as potential false positives were considered. The position of the putative TOP motifs was determined using a custom $\mathrm{R}$ script by searching for the first instance of any five pyrimidines in a row within the first 200 nucleotides of the TSS using the Biostrings package (Pagès et al., 2019). Results were plotted as a histogram in R.

\section{RNA Immunoprecipitation (RNA IP)}

All RIPs were performed with biological triplicates. 50-60 ovary pairs were dissected for each sample in RNase free PBS and dissected ovaries were kept on ice during subsequent dissections. After dissection, ovaries were washed with $500 \mu \mathrm{l}$ of PBS to remove any debris. This PBS was 
1218

1219

1220

1221

1222

1223

1224

1225

1226

1227

1228

1229

1230

1231

1232

1233

1234

1235

1236

1237

1238

1239

1240

1241

1242

1243

1244

1245

1246

1247

1248

1249

1250

1251

1252

1253

1254

1255

1256

1257

1258

1259

1260

1261

1262

1263

1264

1265

1266

1267

removed, and ovaries were lysed in $100 \mu$ l of RIPA buffer (10 mM Tris-Cl Buffer ( $\mathrm{pH}$ 8.0), $1 \mathrm{mM}$ EDTA, 1\% Triton X-100,0.1\% Sodium deoxycholate, 0.1\% SDS, $140 \mathrm{mM} \mathrm{NaCl}, 1 \mathrm{mM}$ PMSF, 1 cOmplete, EDTA-free Protease Inhibitor/10mLbuffer (Roche, 11873580001), RNase free H2O) supplemented with $8 \mu \mathrm{l}$ of RNase Out. Following lysis an additional $180 \mu \mathrm{l}$ of RIPA was added to each sample. Lysate was cleared with centrifugation at $14,000 \mathrm{~g}$ for $20 \mathrm{~m}$ at $4^{\circ} \mathrm{C}$. Cleared lysate was transferred to a new $1.5 \mathrm{~mL}$ tube. $10 \%$ of this lysate was reserved for RNA input and $5 \%$ was reserved as a protein input. To the RNA input $100 \mu$ of Trizol was added and the input was stored at $-80^{\circ} \mathrm{C}$. To the protein input SDS loading buffer was added to a $1 \mathrm{X}$ working concentration and the sample was heated at $95^{\circ} \mathrm{C}$ for $5 \mathrm{~m}$ and stored at $-20^{\circ} \mathrm{C}$. The remaining lysate was equally divided into two new $1.5 \mathrm{~mL}$ tubes. To one tube $3 \mu \mathrm{g}$ of mouse anti-FLAG antibody was added and to the other tube $3 \mu \mathrm{g}$ of mouse IgG was added. These samples were incubated for 3 hours with nutation at $4^{\circ} \mathrm{C}$. NP40 buffer was diluted to a $1 \mathrm{X}$ working concentration from a $10 \mathrm{X}$ stock (10x NP40 Buffer: $50 \mathrm{mM}$ Tris-Cl Buffer (pH 8.0), $150 \mathrm{mM} \mathrm{NaCl}, 10 \%$ NP-40, 1 cOmplete, EDTA-free Protease Inhibitor Cocktail Pill/10mL buffer, RNase free H2O). $30 \mu$ l of Protein-G beads per RIP were pelleted on a magnetic stand and supernatant was discarded. $500 \mu$ of 1X NP40 buffer was used to resuspend Protein-G beads by nutation. Once beads were resuspended, they were again pelleted on the magnetic stand. This washing process was repeated a total of 5 times. Washed Protein-G beads were added to each lysate and incubated overnight. The next day fresh 1X NP40 buffer was prepared. Lysates were pelleted on a magnetic stand at $4^{\circ} \mathrm{C}$ and supernatant was discarded. $300 \mu \mathrm{l}$ of $1 \mathrm{XNP} 40$ buffer was added to each sample and samples were resuspended by nutation at $4^{\circ} \mathrm{C}$. Once samples were thoroughly resuspended, they were pelleted on a magnetic stand. These washing steps were repeated 6 times. Following the final washing steps, beads were resuspended in $25 \mathrm{ul}$ of 1 X NP40 Buffer. $5 \mu$ of beads were set aside for Western and the remaining beads were stored at $-80^{\circ} \mathrm{C}$ in $100 \mu \mathrm{l}$ of Trizol. SDS loading buffer was added was added to a $1 \mathrm{X}$ working concentration and the sample was heated at $95^{\circ} \mathrm{C}$ for $5 \mathrm{~m}$ and stored at $-20^{\circ} \mathrm{C}$ or used for Western (refer to Western Blot section).

\section{Helicase RNA IPseq}

RNA was purified as previously described. RNA yield was quantified using Qubit or nanodrop according to manufactures instructions. RNA was run on a Fragment Analyzer according to manufactures instructions to assess quality. Inputs were diluted 1:50 to bring them into a similar range as the IgG and IP samples. To each sample $0.5 \mathrm{ng}$ of Promega Luciferase Control RNA was added as a spike-in. Libraries were prepared as previously described except Poly(A) selection steps were skipped and library preparation was started with between 1-100 $\mathrm{ng}$ of total RNA. Reads were mapped to the M21017.1 NCBI Drosophila rRNA sequence record and the sequence of Luciferase obtained from Promega. All further analysis was performed using custom $R$ scripts. Reads were assigned to features using featureCounts based off of a custom GTF file assembled based off of the Flybase record of rRNA sequences. Reads mapping to rRNA were normalized to reads mapping to the Luciferase spike-in control. Reads were further normalized to the reads from the corresponding input library to account for differences in input rRNA concentration between replicates and replicates were subsequently averaged. Tracks were visualized using the $\mathrm{R}$ package 'ggplot', with additional formatting performed using 'scales' and 'egg'. The rRNA GTF was read into R using 'rtracklayer' and visualized using 'gggenes'. Average reads mapping to rRNA from IgG control and IP was plotted and a one-sided bootstrapped paired t-test for was performed on regions on rRNA that appeared to be enriched in the IP samples compared to the IgG control as it is a non-parametic test suitable for use with low $n$ using $R$ with 100,000 iterations.

\section{Larp Gel Shifts}

Cloning, Protein expression and purification 
The Larp-DM15 protein expression construct (amino acids 1330-1481 corresponding to isoform D) was cloned into a modified $\mathrm{pET} 28$ a vector by PCR using cDNA corresponding to accession ID NP_733244.5. The resulting fusion protein has an $\mathrm{N}$-fHis (10 $_{10}$-maltose binding protein (MBP)tobacco etch virus (TEV) protease recognition site tag. Protein expression and purification were performed as described previously (Lahr et al., 2015). Briefly, plasmid was transformed into BL21(DE3) E. coli cells and plated onto kanamycin-supplemented agar plates. A confluent plate was used to inoculate $500 \mathrm{~mL}$ of autoinduction media (Studier, 2005). Cells were grown for three hours at $37^{\circ} \mathrm{C}$ and induced overnight at $18^{\circ} \mathrm{C}$. Cells were harvested, flash frozen, and stored at $80^{\circ} \mathrm{C}$.

Cells were resuspended in lysis buffer (50 mM Tris, $\mathrm{pH} 8,400 \mathrm{mM} \mathrm{NaCl}, 10 \mathrm{mM}$ imidazole, $10 \%$ glycerol) supplemented with aprotinin (Gold Bio), leupeptin (RPI Research), and PMSF (Sigma) protease inhibitors. Cells were lysed via homogenization. Lysate was clarified by centrifugation and incubated with Ni-NTA resin (ThermoScientific) for batch purification. Resin was washed with lysis buffer supplemented with $35 \mathrm{mM}$ imidazole to remove non-specific interactions. His 10-MBP- $_{\text {- }}$ DM15 was eluted with $250 \mathrm{mM}$ imidazole. The tag was removed via proteolysis using TEV protease and simultaneously dialyzed overnight (3 mg TEV to $40 \mathrm{~mL}$ protein elution). Larp-DM15 was further purified by tandem anion (GE HiTrap Q) and cation exchange (GE HiTrap SP) chromatography using an AKTA Pure (GE) to remove nucleic acid and protein contaminants. The columns were washed with in buffer containing $50 \mathrm{mM}$ Tris, pH 7, $175 \mathrm{mM} \mathrm{NaCl}, 0.5 \mathrm{mM}$ EDTA, and $10 \%$ glycerol and eluted with a gradient of the same buffer containing higher salt $(1 \mathrm{M} \mathrm{NaCl})$. Fractions containing Larp-DM15 were pooled, and $3 \mathrm{M}$ ammonium sulfate was added to a final concentration of $1 \mathrm{M}$. A butyl column (GE HiTrap Butyl HP) was run to remove TEV contamination. The wash buffer contained $50 \mathrm{mM}$ Tris, $\mathrm{pH} 7,1 \mathrm{M}$ ammonium sulfate, and $5 \%$ glycerol, and the elution buffer contained $50 \mathrm{mM}$ Tris pH 7 and $2 \mathrm{mM}$ DTT. Fractions containing Larp-DM15 were buffer exchanged into storage buffer $(50 \mathrm{mM}$ Tris pH, 7.5, $250 \mathrm{mM} \mathrm{NaCl}, 2 \mathrm{mM}$ DTT, $25 \%$ glycerol), flash frozen in liquid nitrogen, and stored at $-80^{\circ} \mathrm{C}$. The purification scheme and buffer conditions were the same as with HsDM15 (Lahr et al., 2015), except cation and anion exchange buffers were at $\mathrm{pH} 7$, as noted above.

\section{RNA preparation}

5'-triphosphorylated RpL30 and Non1 42-mers were synthesized (ChemGenes). Purinesubstituted controls were synthesized by in vitro transcription using homemade P266L T7 RNAP polymerase (Guillerez et al., 2005). The transcription reaction containing $40 \mathrm{mM}$ Tris, pH 8, 10 mM DTT, $5 \mathrm{mM}$ spermidine, $2 \mathrm{mM} \mathrm{NTPs}$, and $10-15 \mathrm{mM} \mathrm{MgCl}_{2}$ was incubated at $37^{\circ} \mathrm{C}$ for 4 hours. Transcripts were subsequently purified from an $8 \%$ polyacrylamide/6M urea/1XTBE denaturing gel, eluted passively using $10 \mathrm{mM}$ sodium cacodylate, $\mathrm{pH}$ 6.5, and concentrated using spin concentrators (Millipore Amicon). All oligos were radioactively capped using Vaccinia virus capping system (NEB) and [a- ${ }^{32}$ P]-GTP (Perkin-Elmer). Labelled oligos were purified using a $10 \%$ polyacrylamide/6M urea/1XTBE denaturing gel, eluted with $10 \mathrm{mM}$ sodium cacodylate, $\mathrm{pH} 6.5$, and concentrated by ethanol precipitation.

The RNA sequences used were:

RpL30: CUUUUGCCAUUGUCAGCCGACGAAGUGCUUUAACCCAAACUA

Non1: CUUUUUGGAAUACGAAGCUGACACCGCGUGGUGUUUUUGCUU

*Purine-substituted RPL30

control: GAAAAGCCAUUGUCAGCCGACGAAGUGCUUUAACCCAAACUA

${ }^{*}$ Purine-substituted Non1 control: 


\begin{tabular}{|l|l|}
\hline DNA oligo & Sequence (5' to 3') \\
\hline $\begin{array}{l}\text { **RpL30 } \\
\text { control gene } \\
\text { block (with 3' } \\
\text { HDV) }\end{array}$ & $\begin{array}{l}\text { GCGCGCGAATTCTAATACGACTCACTATAGAAAAGCCATTGTCAGCC } \\
\text { GACGAGTGCTTTAACCCAACTAGGGTCGGCATGGCATCTCCACCT } \\
\text { TGGCACTGGCCGTCGTTT }\end{array}$ \\
\hline $\begin{array}{l}\text { Non1 control } \\
\text { Forward }\end{array}$ & $\begin{array}{l}\text { GCGCGCGAATTCTAATACGACTCACTATAGGAAAAAGGAATACGAAG } \\
\text { CTGACA }\end{array}$ \\
\hline $\begin{array}{l}\text { Non1 control } \\
\text { Reverse }\end{array}$ & AAGCAAAAACACCACGCGGTGTCAGCTTCGTATTCCTTTTTCCTATAG \\
\hline $\begin{array}{l}\text { 5' GEN amp } \\
\text { TGLA30 amp } \\
\text { Reverse }\end{array}$ & TAGTTTGGGTTAAAGCACTTCGTCGGC \\
\hline $\begin{array}{l}\text { Non1 amp } \\
\text { Reverse }\end{array}$ & AAGCAAAAACACCACGCGGTGTCA \\
\hline
\end{tabular}

* These RNAs were synthesized using run-off transcription.

Electrophoretic mobility shift assays (EMSAs) $\mathrm{mM}$ Tris- $\mathrm{HCl}, \mathrm{pH} 8,150 \mathrm{mM} \mathrm{NaCl}, 10 \%$ glycerol, $1 \mathrm{mM}$ DTT, $0.5 \mu \mathrm{g}$ tRNA (Ambion), $1 \mu \mathrm{g}$ BSA (Invitrogen), and $<90$ pM RNA. To anneal RNA, oligos were snap-cooled by heating at $95^{\circ} \mathrm{C}$ for 1 min and cooled on ice for 1 hour. For capped RpL30 shifts and capped purine-substituted controls, final concentrations of $0,0.001,0.003,0.01,0.03,0.1,0.3,1,3,10,30$, and $100 \mathrm{nM}$ Larp-DM15 were titrated. For capped Non1 shifts, final concentrations of $0,0.01,0.03,0.1,0.3$, $1,3,10,30,100,300$, and $1000 \mathrm{nM}$ Larp-DM15 were titrated. Native 7\% polyacrylamide $0.5 \mathrm{X}$ TBE gels were pre-run on ice at $120 \mathrm{~V}$ for $30 \mathrm{~min}$. Binding reactions were run at $120 \mathrm{~V}$ on ice for 45-52 $\mathrm{min}$. Gels were dried for $30 \mathrm{~min}$ and allowed to expose overnight using a phosphor screen (GE). Screens were imaged using GE Amersham Typhoon. Bands were quantified using ImageQuant TL (GE). Background subtraction was first done using the rolling ball method and then subtracting the signal from the zero-protein lane from each of the shifted bands. Fraction shifted was determined by dividing the background-corrected intensity of the shifted band by total intensity of bands in each lane. Three independent experiments were done for each oligo, with the average plotted and standard deviation shown.

\section{Larp RNA IPseq}

Larp IP was performed as described in the RNA IP-seq section above in triplicate. mRNA libraries were prepared as described in mRNAseq Library Preparation and Data Processing using a constant volume of RNA from each sample with input samples having been diluted 1:50. Data was processed as described as in the mRNAseq Library Preparation and Data Processing section. Targets are defined as genes with $>2$ fold enrichment and an adjusted $p$-value $<0.05$ in the Larp-IP libraries compared to input libraries, but not meeting those criteria in the IgG libraries compared to input.

\section{Larp RNA IP qPCR}

Larp RNA IP was performed as described in the Larp RNA IPseq section with the following modifications. As the ovaries used were small, they were flash frozen in order to accumulate 40- 
1351

1352

1353

1354

1355

1356

1357

1358

1359

1360

1361

1362

1363

1364

1365

1366

1367

1368

1369

1370

1371

1372

1373

1374

1375

1376

1377

1378

1379

1380

1381

1382

1383

1384

1385

1386

1387

1388

1389

1390

1391

1392

1393

1394

1395

1396

1397

1398

1399

1400

samples. Once RNA was purified all of the RNA was treated with Turbo DNAse as in the mRNAseq Library Preparation and Analysis section. Reverse transcription (RT) was performed using Superscript II according to the manufacture's protocol with equivalent volumes of RNA for each sample. CDNA was diluted 1:8 before performing PPCR using Syber Green. Each reaction consisted of 5ul Syber Green master mix, 0.4 ul water, 0.3 ul of each primer, and 4 ul of diluted cDNA. For each sample 3 biological and 3 technical replicates were performed. Oulier values of technical replicates were removed using a Dixon test with a cutoff of $p<0.05$. Remaining technical replicates were averaged, and the IP Input Ct value, the $\log _{2}$ of the Input dilution (20) was also subtracted to account for the Input being $5 \%$ of the total sample as follows:

$\Delta \mathrm{Ct}\left[\right.$ normalized IP] $=\left(\right.$ Average $\mathrm{Ct}[\mathrm{IP}]-\left(\right.$ Average $\mathrm{Ct}[$ Input $]-\log _{2}($ Input Dilution Factor $\left.\left.)\right)\right)$

Next, RNA recovery was normalized using the spike-in control for each sample as follows:

$\Delta \Delta \mathrm{Ct}=\Delta \mathrm{Ct}[$ normalized IP] $-\Delta \mathrm{Ct}[$ Luciferase $]$

Next, Each sample was normalized to it's matched bam RNAi control as follows:

bam RNAi normalized $\mathrm{Ct}=\Delta \Delta \mathrm{Ct}[$ aramis RNAi IP] $-\Delta \Delta \mathrm{Ct}[[$ bam RNAi IP]

Finally, fold increase of IP from aramis RNAi over bam RNAi was calculated as follows:

Fold Enrichment $=2^{(- \text {bam RNAi normalized } \mathrm{Ct} \text { ) }}$

Fold enrichment was plotted and One-sample t-test performed on aramis RNAi samples in R using a mu of 1 .

\section{References}

Agarwal, M.L., Agarwal, A., Taylor, W.R., Stark, G.R., 1995. p53 controls both the G2/M and the G1 cell cycle checkpoints and mediates reversible growth arrest in human fibroblasts.

Proc. Natl. Acad. Sci. 92, 8493-8497.

Anthony, J.C., Anthony, T.G., Kimball, S.R., Vary, T.C., Jefferson, L.S., 2000. Orally Administered Leucine Stimulates Protein Synthesis in Skeletal Muscle of Postabsorptive Rats in Association with Increased elF4F Formation. J. Nutr. 130, 139-145. https://doi.org/10.1093/jn/130.2.139

Aoki, K., Adachi, S., Homoto, M., Kusano, H., Koike, K., Natsume, T., 2013. LARP1 specifically recognizes the $3^{\prime}$ terminus of poly(A) mRNA. FEBS Lett. 587, 2173-2178. https://doi.org/10.1016/j.febslet.2013.05.035

Arabi, A., Wu, S., Ridderstråle, K., Bierhoff, H., Shiue, C., Fatyol, K., Fahlén, S., Hydbring, P., Söderberg, O., Grummt, I., Larsson, L.-G., Wright, A.P.H., 2005. c-Myc associates with ribosomal DNA and activates RNA polymerase I transcription. Nat. Cell Biol. 7, 303-310. https://doi.org/10.1038/ncb1225

Armistead, J., Triggs-Raine, B., 2014. Diverse diseases from a ubiquitous process: The ribosomopathy paradox. FEBS Lett. 588, 1491-1500. https://doi.org/10.1016/j.febslet.2014.03.024

Barlow, J.L., Drynan, L.F., Trim, N.L., Erber, W.N., Warren, A.J., Mckenzie, A.N.J., 2010. Cell Cycle New insights into 5q-syndrome as a ribosomopathy. Cell Cycle 9, 4286-4293. https://doi.org/10.4161/cc.9.21.13742

Baxter-Roshek, J.L., Petrov, A.N., Dinman, J.D., 2007. Optimization of ribosome structure and function by rRNA base modification. PLoS ONE 2, e174. https://doi.org/10.1371/journal.pone.0000174

Berman, A.J., Thoreen, C.C., Dedeic, Z., Chettle, J., Roux, P.P., Blagden, S.P., 2020. Controversies around the function of LARP1. RNA Biol. 1-11. https://doi.org/10.1080/15476286.2020.1733787 
1401

1402

1403

1404

1405

1406

1407

1408

1409

1410

1411

1412

1413

1414

1415

1416

1417

1418

1419

1420

1421

1422

1423

1424

1425

1426

1427

1428

1429

1430

1431

1432

1433

1434

1435

1436

1437

1438

1439

1440

1441

1442

1443

1444

1445

1446

1447

1448

1449

1450

1451

Bernardini, L., Gimelli, S., Gervasini, C., Carella, M., Baban, A., Frontino, G., Barbano, G., Divizia, M., Fedele, L., Novelli, A., Béna, F., Lalatta, F., Miozzo, M., Dallapiccola, B., 2009. Recurrent microdeletion at $17 q 12$ as a cause of Mayer-Rokitansky-Kuster-Hauser (MRKH) syndrome: two case reports. Orphanet J. Rare Dis. 4, 25. https://doi.org/10.1186/1750-1172-4-25

Blagden, S.P., Gatt, M.K., Archambault, V., Lada, K., Ichihara, K., Lilley, K.S., Inoue, Y.H., Glover, D.M., 2009. Drosophila Larp associates with poly (A)-binding protein and is required for male fertility and syncytial embryo development. Dev. Biol. 334, 186-197. https://doi.org/10.1016/J.YDBIO.2009.07.016

Blatt, P., Martin, E.T., Breznak, S.M., Rangan, P., 2020a. Post-transcriptional gene regulation regulates germline stem cell to oocyte transition during Drosophila oogenesis, in: Current Topics in Developmental Biology. Elsevier, pp. 3-34.

Blatt, P., Wong-Deyrup, S.W., McCarthy, A., Breznak, S., Hurton, M.D., Upadhyay, M., Bennink, B., Camacho, J., Lee, M.T., Rangan, P., 2020b. RNA degradation sculpts the maternal transcriptome during Drosophila oogenesis. bioRxiv 2020.06.30.179986. https://doi.org/10.1101/2020.06.30.179986

Boamah, E.K., Kotova, E., Garabedian, M., Jarnik, M., Tulin, A.V., 2012. Poly(ADP-Ribose) Polymerase 1 (PARP-1) Regulates Ribosomal Biogenesis in Drosophila Nucleoli. PLoS Genet. 8. https://doi.org/10.1371/journal.pgen.1002442

Bohnsack, M.T., Kos, M., Tollervey, D., 2008. Quantitative analysis of snoRNA association with pre-ribosomes and release of snR30 by Rok1 helicase. EMBO Rep. 9, 1230-1236. https://doi.org/10.1038/embor.2008.184

Boley, N., Wan, K.H., Bickel, P.J., Celniker, S.E., 2014. Navigating and Mining modENCODE Data. Methods San Diego Calif 68, 38-47. https://doi.org/10.1016/j.ymeth.2014.03.007

Bousquet-Antonelli, C.C., Vanrobays, E., Gélugne, J.-P., Caizergues-Ferrer, M., Henry, Y., 2000. Rrp8p is a yeast nucleolar protein functionally linked to Gar1p and involved in prerRNA cleavage at site A2. Rna 6, 826-843.

Bowen, M.E., Attardi, L.D., 2019. The role of p53 in developmental syndromes. J. Mol. Cell Biol. 11, 200-211. https://doi.org/10.1093/jmcb/mjy087

Brooks, S.S., Wall, A.L., Golzio, C., Reid, D.W., Kondyles, A., Willer, J.R., Botti, C., Nicchitta, C.V., Katsanis, N., Davis, E.E., 2014. A novel ribosomopathy caused by dysfunction of RPL10 disrupts neurodevelopment and causes X-linked microcephaly in humans. Genetics 198, 723-33. https://doi.org/10.1534/genetics.114.168211

Burrows, C., Abd Latip, N., Lam, S.-J., Carpenter, L., Sawicka, K., Tzolovsky, G., Gabra, H., Bushell, M., Glover, D.M., Willis, A.E., Blagden, S.P., 2010. The RNA binding protein Larp1 regulates cell division, apoptosis and cell migration. Nucleic Acids Res. 38, 55425553. https://doi.org/10.1093/nar/gkq294

Buszczak, M., Paterno, S., Lighthouse, D., Bachman, J., Planck, J., Owen, S., Skora, A.D., Nystul, T.G., Ohlstein, B., Allen, A., Wilhelm, J.E., Murphy, T.D., Levis, R.W., Matunis, E., Srivali, N., Hoskins, R.A., Spradling, A.C., 2007. The Carnegie Protein Trap Library: A Versatile Tool for Drosophila Developmental Studies. Genetics 175, 1505-1531. https://doi.org/10.1534/genetics.106.065961

Calo, E., Gu, B., Bowen, M.E., Aryan, F., Zalc, A., Liang, J., Flynn, R.A., Swigut, T., Chang, H.Y., Attardi, L.D., 2018. Tissue-selective effects of nucleolar stress and rDNA damage in developmental disorders. Nature 554, 112.

Chen, D., McKearin, D.M., 2003. A discrete transcriptional silencer in the bam gene determines asymmetric division of the Drosophila germline stem cell. Development 130, 1159-1170. https://doi.org/10.1242/dev.00325

Chen, T., Steensel, B. van, 2017. Comprehensive analysis of nucleocytoplasmic dynamics of mRNA in Drosophila cells. PLOS Genet. 13, e1006929.

https://doi.org/10.1371/journal.pgen.1006929 
1452

1453

1454

1455

1456

1457

1458

1459

1460

1461

1462

1463

1464

1465

1466

1467

1468

1469

1470

1471

1472

1473

1474

1475

1476

1477

1478

1479

1480

1481

1482

1483

1484

1485

1486

1487

1488

1489

1490

1491

1492

1493

1494

1495

1496

1497

1498

1499

1500

1501

1502

Chen, Z.-X., Sturgill, D., Qu, J., Jiang, H., Park, S., Boley, N., Suzuki, A.M., Fletcher, A.R., Plachetzki, D.C., FitzGerald, P.C., Artieri, C.G., Atallah, J., Barmina, O., Brown, J.B., Blankenburg, K.P., Clough, E., Dasgupta, A., Gubbala, S., Han, Y., Jayaseelan, J.C., Kalra, D., Kim, Y.-A., Kovar, C.L., Lee, S.L., Li, M., Malley, J.D., Malone, J.H., Mathew, T., Mattiuzzo, N.R., Munidasa, M., Muzny, D.M., Ongeri, F., Perales, L., Przytycka, T.M., Pu, L.-L., Robinson, G., Thornton, R.L., Saada, N., Scherer, S.E., Smith, H.E., Vinson, C., Warner, C.B., Worley, K.C., Wu, Y.-Q., Zou, X., Cherbas, P., Kellis, M., Eisen, M.B., Piano, F., Kionte, K., Fitch, D.H., Sternberg, P.W., Cutter, A.D., Duff, M.O., Hoskins, R.A., Graveley, B.R., Gibbs, R.A., Bickel, P.J., Kopp, A., Carninci, P., Celniker, S.E., Oliver, B., Richards, S., 2014. Comparative validation of the D. melanogaster modENCODE transcriptome annotation. Genome Res. 24, 1209-1223. https://doi.org/10.1101/gr.159384.113

Cheng, Z., Mugler, C.F., Keskin, A., Hodapp, S., Chan, L.Y.-L., Weis, K., Mertins, P., Regev, A., Jovanovic, M., Brar, G.A., 2019. Small and Large Ribosomal Subunit Deficiencies Lead to Distinct Gene Expression Signatures that Reflect Cellular Growth Rate. Mol. Cell 73, 36-47.e10. https://doi.org/10.1016/j.molcel.2018.10.032

Corsini, N.S., Peer, A.M., Moeseneder, P., Roiuk, M., Burkard, T.R., Theussl, H.-C., Moll, I., Knoblich, J.A., 2018. Coordinated Control of mRNA and rRNA Processing Controls Embryonic Stem Cell Pluripotency and Differentiation. Cell Stem Cell 22, 543-558.e12. https://doi.org/10.1016/j.stem.2018.03.002

De Cuevas, M., Spradling, A.C., 1998. Morphogenesis of the Drosophila fusome and its implications for oocyte specification. Development 125, 2781 LP - 2789.

de la Cruz, J., Karbstein, K., Woolford, J.L., 2015. Functions of ribosomal proteins in assembly of eukaryotic ribosomes in vivo. Annu. Rev. Biochem. 84, 93-129. https://doi.org/10.1146/annurev-biochem-060614-033917

Decatur, W.A., Fournier, M.J., 2002. rRNA modifications and ribosome function. Trends Biochem. Sci. 27, 344-351. https://doi.org/10.1016/S0968-0004(02)02109-6

Deisenroth, C., Zhang, Y., 2010. Ribosome biogenesis surveillance: Probing the ribosomal protein-Mdm2-p53 pathway. Oncogene 29, 4253-4260. https://doi.org/10.1038/onc.2010.189

DeLuca, S.Z., Spradling, A.C., 2018. Efficient Expression of Genes in the Drosophila Germline Using a UAS Promoter Free of Interference by Hsp70 piRNAs. Genetics 209, 381-387. https://doi.org/10.1534/genetics.118.300874

dos Santos, G., Schroeder, A.J., Goodman, J.L., Strelets, V.B., Crosby, M.A., Thurmond, J., Emmert, D.B., Gelbart, W.M., 2015. FlyBase: introduction of the Drosophila melanogaster Release 6 reference genome assembly and large-scale migration of genome annotations. Nucleic Acids Res. 43, D690-D697. https://doi.org/10.1093/nar/gku1099

Draptchinskaia, N., Gustavsson, P., Andersson, B., Pettersson, M., Willig, T.-N., Dianzani, I., Ball, S., Tchernia, G., Klar, J., Matsson, H., Tentler, D., Mohandas, N., Carlsson, B., Dahl, N., 1999. The gene encoding ribosomal protein S19 is mutated in DiamondBlackfan anaemia. Nat. Genet. 21, 169-175. https://doi.org/10.1038/5951

Emtenani, S., Martin, E.T., Gyoergy, A., Bicher, J., Genger, J.-W., Hurd, T.R., Köcher, T., Bergthaler, A., Rangan, P., Siekhaus, D.E., 2021. A genetic program boosts mitochondrial function to power macrophage tissue invasion. bioRxiv 2021.02.18.431643. https://doi.org/10.1101/2021.02.18.431643

Fan, Y., Lee, T.V., Xu, D., Chen, Z., Lamblin, A.-F., Steller, H., Bergmann, A., 2010. Dual roles of Drosophila p53 in cell death and cell differentiation. Cell Death Differ. 17, 912-921. https://doi.org/10.1038/cdd.2009.182

Fichelson, P., Moch, C., Ivanovitch, K., Martin, C., Sidor, C.M., Lepesant, J.-A., Bellaiche, Y., Huynh, J.-R., 2009. Live-imaging of single stem cells within their niche reveals that a 
1503

1504

1505

1506

1507

1508

1509

1510

1511

1512

1513

1514

1515

1516

1517

1518

1519

1520

1521

1522

1523

1524

1525

1526

1527

1528

1529

1530

1531

1532

1533

1534

1535

1536

1537

1538

1539

1540

1541

1542

1543

1544

1545

1546

1547

1548

1549

1550

1551

1552

U3snoRNP component segregates asymmetrically and is required for self-renewal in Drosophila. Nat. Cell Biol. 11, 685.

Flora, P., Schowalter, S., Wong-Deyrup, S., DeGennaro, M., Nasrallah, M.A., Rangan, P., 2018a. Transient transcriptional silencing alters the cell cycle to promote germline stem cell differentiation in Drosophila. Dev. Biol. 434, 84-95. https://doi.org/10.1016/j.ydbio.2017.11.014

Flora, P., Wong-Deyrup, S.W., Martin, E.T., Palumbo, R.J., Nasrallah, M., Oligney, A., Blatt, P., Patel, D., Fuchs, G., Rangan, P., 2018b. Sequential Regulation of Maternal mRNAs through a Conserved cis-Acting Element in Their 3' UTRs. Cell Rep. 25, 3828-3843.e9. https://doi.org/10.1016/j.celrep.2018.12.007

Fonseca, B.D., Jia, J.-J., Hollensen, A.K., Pointet, R., Hoang, H.-D., Niklaus, M.R., Pena, I.A., Lahr, R.M., Smith, E.M., Hearnden, J., Wang, X.-D., Yang, A.-D., Celucci, G., Graber, T.E., Dajadian, C., Yu, Y., Damgaard, C.K., Berman, A.J., Alain, T., 2018. LARP1 is a major phosphorylation substrate of mTORC1 (preprint). Biochemistry.

Fonseca, B.D., Zakaria, C., Jia, J.-J., Graber, T.E., Svitkin, Y., Tahmasebi, S., Healy, D., Hoang, H.-D., Jensen, J.M., Diao, I.T., 2015. La-related protein 1 (LARP1) represses terminal oligopyrimidine (TOP) mRNA translation downstream of mTOR complex 1 (mTORC1). J. Biol. Chem. 290, 15996-16020.

Fortier, S., MacRae, T., Bilodeau, M., Sargeant, T., Sauvageau, G., 2015. Haploinsufficiency screen highlights two distinct groups of ribosomal protein genes essential for embryonic stem cell fate. Proc. Natl. Acad. Sci. 112, 2127-2132. https://doi.org/10.1073/pnas.1418845112

Fuchs, G., Diges, C., Kohlstaedt, L.A., Wehner, K.A., Sarnow, P., 2011. Proteomic Analysis of Ribosomes: Translational Control of mRNA Populations by Glycogen Synthase GYS1. J. Mol. Biol. 410, 118-130. https://doi.org/10.1016/J.JMB.2011.04.064

Gabut, M., Bourdelais, F., Durand, S., 2020. Ribosome and Translational Control in Stem Cells. Cells 9, 497. https://doi.org/10.3390/cells9020497

Gentilella, A., Morón-Duran, F.D., Fuentes, P., Zweig-Rocha, G., Riaño-Canalias, F., Pelletier, J., Ruiz, M., Turón, G., Castaño, J., Tauler, A., Bueno, C., Menéndez, P., Kozma, S.C., Thomas, G., 2017. Autogenous Control of 5'TOP mRNA Stability by 40 S Ribosomes. Mol. Cell 67, 55-70.e4. https://doi.org/10.1016/j.molcel.2017.06.005

Gilboa, L., Forbes, A., Tazuke, S.I., Fuller, M.T., Lehmann, R., 2003. Germ line stem cell differentiation in Drosophila requires gap junctions and proceeds via an intermediate state. Development 130, 6625-6634. https://doi.org/10.1242/dev.00853

Glotzer, M., Murray, A.W., Kirschner, M.W., 1991. Cyclin is degraded by the ubiquitin pathway. Nature 349, 132-138. https://doi.org/10.1038/349132a0

Grandori, C., Gomez-Roman, N., Felton-Edkins, Z.A., Ngouenet, C., Galloway, D.A., Eisenman, R.N., White, R.J., 2005. c-Myc binds to human ribosomal DNA and stimulates transcription of rRNA genes by RNA polymerase I. Nat. Cell Biol. 7, 311-318. https://doi.org/10.1038/ncb1224

Granneman, S., Bernstein, K.A., Bleichert, F., Baserga, S.J., 2006. Comprehensive Mutational Analysis of Yeast DEXD/H Box RNA Helicases Required for Small Ribosomal Subunit Synthesis Downloaded from. Mol. Cell. Biol. 26, 1183-1194. https://doi.org/10.1128/MCB.26.4.1183-1194.2006

Granneman, S., Petfalski, E., Tollervey, D., Hurt, E.C., 2011. A cluster of ribosome synthesis factors regulate pre-rRNA folding and 5.8S rRNA maturation by the Rat1 exonuclease. EMBO J. 30, 4006-19. https://doi.org/10.1038/emboj.2011.256

Guillerez, J., Lopez, P.J., Proux, F., Launay, H., Dreyfus, M., 2005. A mutation in T7 RNA polymerase that facilitates promoter clearance. Proc. Natl. Acad. Sci. 102, 5958-5963. https://doi.org/10.1073/pnas.0407141102 
1553

1554

1555

1556

1557

1558

1559

1560

1561

1562

1563

1564

1565

1566

1567

1568

1569

1570

1571

1572

1573

1574

1575

1576

1577

1578

1579

1580

1581

1582

1583

1584

1585

1586

1587

1588

1589

1590

1591

1592

1593

1594

1595

1596

1597

1598

1599

1600

1601

1602

Heinz, S., Benner, C., Spann, N., Bertolino, E., Lin, Y.C., Laslo, P., Cheng, J.X., Murre, C., Singh, H., Glass, C.K., 2010. Simple combinations of lineage-determining transcription factors prime cis-regulatory elements required for macrophage and B cell identities. Mol. Cell 38, 576-589. https://doi.org/10.1016/j.molcel.2010.05.004

Hendrix, N.W., Clemens, M., Canavan, T.P., Surti, U., Rajkovic, A., 2012. Prenatally Diagnosed $17 q 12$ Microdeletion Syndrome with a Novel Association with Congenital Diaphragmatic Hernia. Fetal Diagn. Ther. 31, 129-133. https://doi.org/10.1159/000332968

Henras, A.K., Soudet, J., Gérus, M., Lebaron, S., Caizergues-Ferrer, M., Mougin, A., Henry, Y., 2008. The post-transcriptional steps of eukaryotic ribosome biogenesis. Cell. Mol. Life Sci. 65, 2334-2359. https://doi.org/10.1007/s00018-008-8027-0

Higa-Nakamine, S., Suzuki, T.T., Uechi, T., Chakraborty, A., Nakajima, Y., Nakamura, M., Hirano, N., Suzuki, T.T., Kenmochi, N., 2012. Loss of ribosomal RNA modification causes developmental defects in zebrafish. Nucleic Acids Res. 40, 391-398. https://doi.org/10.1093/nar/gkr700

Hinnant, T.D., Alvarez, A.A., Ables, E.T., 2017. Temporal remodeling of the cell cycle accompanies differentiation in the Drosophila germline. Dev. Biol. 429, 118-131. https://doi.org/10.1016/j.ydbio.2017.07.001

Hong, S., Freeberg, M.A., Han, T., Kamath, A., Yao, Y., Fukuda, T., Suzuki, T., Kim, J.K., Inoki, K., 2017. LARP1 functions as a molecular switch for mTORC1-mediated translation of an essential class of mRNAs. Elife 6, e25237.

Hong, S., Mannan, A.M., Inoki, K., 2012. Evaluation of the Nutrient-Sensing mTOR Pathway, in: Weichhart, T. (Ed.), MTOR: Methods and Protocols, Methods in Molecular Biology. Humana Press, Totowa, NJ, pp. 29-44.

Hornstein, E., Tang, H., Meyuhas, O., 2001. Mitogenic and nutritional signals are transduced into translational efficiency of TOP mRNAs, in: Cold Spring Harbor Symposia on Quantitative Biology. Cold Spring Harbor Laboratory Press, pp. 477-484.

Hsu, H.-J., LaFever, L., Drummond-Barbosa, D., 2008. Diet controls normal and tumorous germline stem cells via insulin-dependent and -independent mechanisms in Drosophila. Dev. Biol. 313, 700-712. https://doi.org/10.1016/j.ydbio.2007.11.006

Hu, Y., Flockhart, I., Vinayagam, A., Bergwitz, C., Berger, B., Perrimon, N., Mohr, S.E., 2011. An integrative approach to ortholog prediction for disease-focused and other functional studies. BMC Bioinformatics 12, 357. https://doi.org/10.1186/1471-2105-12-357

ladevaia, V., Liu, R., Proud, C.G., 2014. mTORC1 signaling controls multiple steps in ribosome biogenesis. Semin. Cell Dev. Biol., Development of the urogenital system \& mTOR Signalling \& Tight Junctions in Health and Disease 36, 113-120. https://doi.org/10.1016/j.semcdb.2014.08.004

Ichihara, K., Shimizu, H., Taguchi, O., Yamaguchi, M., Inoue, Y.H., 2007. A Drosophila orthologue of larp protein family is required for multiple processes in male meiosis. Cell Struct. Funct. 710190003.

Jefferies, H.B.J., Fumagalli, S., Dennis, P.B., Reinhard, C., Pearson, R.B., Thomas, G., 1997. Rapamycin suppresses 5'TOP mRNA translation through inhibition of p70s6k. EMBO J. 16, 3693-3704. https://doi.org/10.1093/emboj/16.12.3693

Jia, J.-J., Lahr, R.M., Solgaard, M.T., Moraes, B.J., Pointet, R., Yang, A.-D., Celucci, G., Graber, T.E., Hoang, H.-D., Niklaus, M.R., Pena, I.A., Hollensen, A.K., Smith, E.M., Chaker-Margot, M., Anton, L., Dajadian, C., Livingstone, M., Hearnden, J., Wang, X.-D., Yu, Y., Maier, T., Damgaard, C.K., Berman, A.J., Alain, T., Fonseca, B.D., 2021. mTORC1 promotes TOP mRNA translation through site-specific phosphorylation of LARP1. Nucleic Acids Res. https://doi.org/10.1093/nar/gkaa1239

Jones, N.C., Lynn, M.L., Gaudenz, K., Sakai, D., Aoto, K., Rey, J.-P., Glynn, E.F., Ellington, L., Du, C., Dixon, J., Dixon, M.J., Trainor, P.A., 2008. Prevention of the neurocristopathy 
1603

1604

1605

1606

1607

1608

1609

1610

1611

1612

1613

1614

1615

1616

1617

1618

1619

1620

1621

1622

1623

1624

1625

1626

1627

1628

1629

1630

1631

1632

1633

1634

1635

1636

1637

1638

1639

1640

1641

1642

1643

1644

1645

1646

1647

1648

1649

1650

1651

Treacher Collins syndrome through inhibition of p53 function. Nat. Med. 14, 125-133. https://doi.org/10.1038/nm1725

Kai, T., Spradling, A., 2003. An empty Drosophila stem cell niche reactivates the proliferation of ectopic cells.

Kai, T., Williams, D., Spradling, A.C., 2005. The expression profile of purified Drosophila germline stem cells. Dev. Biol. 283, 486-502.

Karpen, G.H., Schaefer, J.E., Laird, C.D., 1988. A Drosophila rRNA gene located in euchromatin is active in transcription and nucleolus formation. Genes Dev. 2, 17451763.

Khajuria, R.K., Munschauer, M., Ulirsch, J.C., Fiorini, C., Ludwig, L.S., McFarland, S.K., Abdulhay, N.J., Specht, H., Keshishian, H., Mani, D.R.R., Jovanovic, M., Ellis, S.R., Fulco, C.P., Engreitz, J.M., Schütz, S., Lian, J., Gripp, K.W., Weinberg, O.K., Pinkus, G.S., Gehrke, L., Regev, A., Lander, E.S., Gazda, H.T., Lee, W.Y., Panse, V.G., Carr, S.A., Sankaran, V.G., 2018. Ribosome levels selectively regulate translation and lineage commitment in human hematopoiesis. Cell 173, 90-103. https://doi.org/10.1016/J.CELL.2018.02.036

Khoshnevis, S., Askenasy, I., Johnson, M.C., Dattolo, M.D., Young-Erdos, C.L., Stroupe, M.E., Karbstein, K., 2016. The DEAD-box Protein Rok1 Orchestrates 40S and 60S Ribosome Assembly by Promoting the Release of Rrp5 from Pre-40S Ribosomes to Allow for $60 \mathrm{~S}$ Maturation. PLOS Biol. 14, e1002480. https://doi.org/10.1371/journal.pbio.1002480

Kim, E., Goraksha-Hicks, P., Li, L., Neufeld, T.P., Guan, K.-L., 2008. Regulation of TORC1 by Rag GTPases in nutrient response. Nat. Cell Biol. 10, 935.

Kim, W., Jang, Y.-G., Yang, J., Chung, J., 2017. Spatial Activation of TORC1 Is Regulated by Hedgehog and E2F1 Signaling in the Drosophila Eye. Dev. Cell 42, 363-375.e4. https://doi.org/10.1016/j.devcel.2017.07.020

Kimball, S.R., 2002. Regulation of Global and Specific mRNA Translation by Amino Acids. J. Nutr. 132, 883-886. https://doi.org/10.1093/jn/132.5.883

Koš, M., Tollervey, D., 2010. Yeast pre-rRNA processing and modification occur cotranscriptionally. Mol. Cell 37, 809-820.

Lahr, R.M., Fonseca, B.D., Ciotti, G.E., Al-Ashtal, H.A., Jia, J.-J., Niklaus, M.R., Blagden, S.P., Alain, T., Berman, A.J., 2017. La-related protein 1 (LARP1) binds the mRNA cap, blocking elF4F assembly on TOP mRNAs. Elife 6, e24146.

Lahr, R.M., Mack, S.M., Héroux, A., Blagden, S.P., Bousquet-Antonelli, C., Deragon, J.-M., Berman, A.J., 2015. The La-related protein 1-specific domain repurposes HEAT-like repeats to directly bind a 5'TOP sequence. Nucleic Acids Res. 43, 8077-8088. https://doi.org/10.1093/nar/gkv748

Li, L., Pang, X., Zhu, Z., Lu, L., Yang, J., Cao, J., Fei, S., 2018. GTPBP4 Promotes Gastric Cancer Progression via Regulating P53 Activity. Cell. Physiol. Biochem. 45, 667-676.

Lipton, J.M., Kudisch, M., Gross, R., Nathan, D.G., 1986. Defective Erythroid Progenitor Differentiation System in Congenital Hypoplastic (Diamond-Blackfan) Anemia. Blood 67, 962-968. https://doi.org/10.1182/blood.V67.4.962.962

Loewith, R., Hall, M.N., 2011. Target of Rapamycin (TOR) in Nutrient Signaling and Growth Control. Genetics 189, 1177-1201. https://doi.org/10.1534/genetics.111.133363

Lu, W.-J., Chapo, J., Roig, I., Abrams, J.M., 2010. Meiotic Recombination Provokes Functional Activation of the p53 Regulatory Network. Science 328, 1278-1281. https://doi.org/10.1126/science.1185640

Lunardi, A., Di Minin, G., Provero, P., Dal Ferro, M., Carotti, M., Del Sal, G., Collavin, L., 2010. A genome-scale protein interaction profile of Drosophila p53 uncovers additional nodes of the human p53 network. Proc. Natl. Acad. Sci. 107, 6322-6327. 
1652

1653

1654

1655

1656

1657

1658

1659

1660

1661

1662

1663

1664

1665

1666

1667

1668

1669

1670

1671

1672

1673

1674

1675

1676

1677

1678

1679

1680

1681

1682

1683

1684

1685

1686

1687

1688

1689

1690

1691

1692

1693

1694

1695

1696

1697

1698

1699

1700

1701

Ma, X., Han, Y., Song, X., Do, T., Yang, Z., Ni, J., Xie, T., 2016. DNA damage-induced Lok/CHK2 activation compromises germline stem cell self-renewal and lineage differentiation. Development 143, 4312-4323. https://doi.org/10.1242/dev.141069

Martin, R., Hackert, P., Ruprecht, M., Simm, S., Brüning, L., Mirus, O., Sloan, K.E., Kudla, G., Schleiff, E., Bohnsack, M.T., 2014. A pre-ribosomal RNA interaction network involving snoRNAs and the Rok1 helicase. RNA 20, 1173-1182. https://doi.org/10.1261/rna.044669.114

Mathieu, J., Cauvin, C., Moch, C., Radford, S.J.J., Sampaio, P., Perdigoto, C.N., Schweisguth, F., Bardin, A.J., Sunkel, C.E., McKim, K., Echard, A., Huynh, J.-R., 2013. Aurora B and cyclin B have opposite effects on the timing of cytokinesis abscission in Drosophila germ cells and in vertebrate somatic cells. Dev. Cell 26, 250-265.

https://doi.org/10.1016/J.DEVCEL.2013.07.005

Matias, N.R., Mathieu, J., Huynh, J.-R., 2015. Abscission is regulated by the ESCRT-III protein shrub in Drosophila germline stem cells. PLoS Genet. 11, e1004653. https://doi.org/10.1371/journal.pgen.1004653

Mayer, C., Grummt, I., 2006. Ribosome biogenesis and cell growth: mTOR coordinates transcription by all three classes of nuclear RNA polymerases. Oncogene 25, 6384 .

McCarthy, A., Deiulio, A., Martin, E.T., Upadhyay, M., Rangan, P., 2018. Tip60 complex promotes expression of a differentiation factor to regulate germline differentiation in female Drosophila. Mol. Biol. Cell 29, 2933-2945. https://doi.org/10.1091/mbc.E18-060385

McCarthy, A., Sarkar, K., Martin, E.T., Upadhyay, M., James, J.R., Lin, J.M., Jang, S., Williams, N.D., Forni, P.E., Buszczak, M., Rangan, P., 2019. MSL3 coordinates a transcriptional and translational meiotic program in female Drosophila. bioRxiv 2019.12.18.879874. https://doi.org/10.1101/2019.12.18.879874

McGowan, K.A., Pang, W.W., Bhardwaj, R., Perez, M.G., Pluvinage, J.V., Glader, B.E., Malek, R., Mendrysa, S.M., Weissman, I.L., Park, C.Y., Barsh, G.S., 2011. Reduced ribosomal protein gene dosage and p53 activation in low-risk myelodysplastic syndrome. Blood 118, 3622-3633. https://doi.org/10.1182/blood-2010-11-318584

McKearin, D., Ohlstein, B., 1995. A role for the Drosophila bag-of-marbles protein in the differentiation of cystoblasts from germline stem cells. Development 121, 2937 LP 2947.

McKearin, D.M., Spradling, A.C., 1990. bag-of-marbles: a Drosophila gene required to initiate both male and female gametogenesis. Genes Dev. 4, 2242-2251. https://doi.org/10.1101/gad.4.12b.2242

Meyuhas, O., 2000. Synthesis of the translational apparatus is regulated at the translational level. Eur. J. Biochem. 267, 6321-6330. https://doi.org/10.1046/j.14321327.2000.01719.x

Meyuhas, O., Kahan, T., 2015. The race to decipher the top secrets of TOP mRNAs. Biochim. Biophys. Acta BBA - Gene Regul. Mech. 1849, 801-811. https://doi.org/10.1016/j.bbagrm.2014.08.015

Mills, E.W., Green, R., 2017. Ribosomopathies: There's strength in numbers. Science 358, eaan2755. https://doi.org/10.1126/science.aan2755

Moon, S., Cassani, M., Lin, Y.A., Wang, L., Dou, K., Zhang, Z.Z.Z., 2018. A Robust Transposon-Endogenizing Response from Germline Stem Cells. Dev. Cell 47, 660-671.

Nerurkar, P., Altvater, M., Gerhardy, S., Schütz, S., Fischer, U., Weirich, C., Panse, V.G., 2015. Eukaryotic ribosome assembly and nuclear export. Int. Rev. Cell Mol. Biol. 319, 107-40. https://doi.org/10.1016/bs.ircmb.2015.07.002

Neumüller, R.A., Betschinger, J., Fischer, A., Bushati, N., Poernbacher, I., Mechtler, K., Cohen, S.M., Knoblich, J.A., 2008. Mei-P26 regulates microRNAs and cell growth in the 
1702

1703

1704

1705

1706

1707

1708

1709

1710

1711

1712

1713

1714

1715

1716

1717

1718

1719

1720

1721

1722

1723

1724

1725

1726

1727

1728

1729

1730

1731

1732

1733

1734

1735

1736

1737

1738

1739

1740

1741

1742

1743

1744

1745

1746

1747

1748

1749

1750

1751

Drosophila ovarian stem cell lineage. Nature 454, 241-5. https://doi.org/10.1038/nature07014

'day, C.L., Chavanikamannil, F., Abelson, J., 1996. 18S rRNA processing requires the RNA helicase-like protein Rrp3. Nucleic Acids Res. 24.

Ochs, R.L., Lischwe, M.A., Spohn, W.H., Busch, H., 1985. Fibrillarin: a new protein of the nucleolus identified by autoimmune sera. Biol. Cell 54, 123-133. https://doi.org/10.1111/j.1768-322X.1985.tb00387.x

Ogami, K., Oishi, Y., Nogimori, T., Sakamoto, K., Hoshino, S., 2020. LARP1 facilitates translational recovery after amino acid refeeding by preserving long poly(A)-tailed TOP mRNAs. bioRxiv 716217. https://doi.org/10.1101/716217

Ohlstein, B., McKearin, D., 1997. Ectopic expression of the Drosophila Bam protein eliminates oogenic germline stem cells. Development 124, 3651-3662.

Õunap, K., Käsper, L., Kurg, A., Kurg, R., 2013. The Human WBSCR22 Protein Is Involved in the Biogenesis of the 40S Ribosomal Subunits in Mammalian Cells. PLoS ONE 8. https://doi.org/10.1371/journal.pone.0075686

Pagès, H., Aboyoun, P., Gentleman, R., DebRoy, S., 2019. Biostrings: Efficient manipulation of biological strings.

Pallares-Cartes, C., Cakan-Akdogan, G., Teleman, A.A., 2012. Tissue-specific coupling between insulin/IGF and TORC1 signaling via PRAS40 in Drosophila. Dev. Cell 22, 172182.

Pereboom, T.C., van Weele, L.J., Bondt, A., Maclnnes, A.W., 2011. A zebrafish model of dyskeratosis congenita reveals hematopoietic stem cell formation failure resulting from ribosomal protein-mediated p53 stabilization. Blood 118, 5458-5465.

Philippe, L., van den Elzen, A.M.G., Watson, M.J., Thoreen, C.C., 2020. Global analysis of LARP1 translation targets reveals tunable and dynamic features of $5^{\prime}$ TOP motifs. Proc. Natl. Acad. Sci. 117, 5319-5328. https://doi.org/10.1073/pnas.1912864117

Philippe, L., Vasseur, J.-J., Debart, F., Thoreen, C.C., 2018. La-related protein 1 (LARP1) repression of TOP mRNA translation is mediated through its cap-binding domain and controlled by an adjacent regulatory region. Nucleic Acids Res. 46, 1457-1469. https://doi.org/10.1093/nar/gkx1237

Powers, T., Walter, P., 1999. Regulation of ribosome biogenesis by the rapamycin-sensitive TOR-signaling pathway in Saccharomyces cerevisiae. Mol. Biol. Cell 10, 987-1000.

Qiao, H., Li, Y., Feng, C., Duo, S., Ji, F., Jiao, J., 2018. Nap1/1 Controls Embryonic Neural Progenitor Cell Proliferation and Differentiation in the Developing Brain. Cell Rep. 22, 2279-2293. https://doi.org/10.1016/j.celrep.2018.02.019

Qin, X., Ahn, S., Speed, T.P., Rubin, G.M., 2007. Global analyses of mRNA translational control during early Drosophila embryogenesis. Genome Biol. 8, R63. https://doi.org/10.1186/gb-2007-8-4-r63

Rørth, P., 1998. Gal4 in the Drosophila female germline. Mech. Dev. 78, 113-118. https://doi.org/10.1016/S0925-4773(98)00157-9

Sanchez, C.G., Teixeira, F.K., Czech, B., Preall, J.B., Zamparini, A.L., Seifert, J.R.K., Malone, C.D., Hannon, G.J., Lehmann, R., 2016. Regulation of ribosome biogenesis and protein synthesis controls germline stem cell differentiation. Cell Stem Cell 18, 276-290. https://doi.org/10.1016/J.STEM.2015.11.004

Sarov, M., Barz, C., Jambor, H., Hein, M.Y., Schmied, C., Suchold, D., Stender, B., Janosch, S., KJ, V.V., Krishnan, R., Krishnamoorthy, A., Ferreira, I.R., Ejsmont, R.K., Finkl, K., Hasse, S., Kämpfer, P., Plewka, N., Vinis, E., Schloissnig, S., Knust, E., Hartenstein, V., Mann, M., Ramaswami, M., VijayRaghavan, K., Tomancak, P., Schnorrer, F., 2016. A genome-wide resource for the analysis of protein localisation in Drosophila. eLife 5, e12068. https://doi.org/10.7554/eLife.12068 
1752

1753

1754

1755

1756

1757

1758

1759

1760

1761

1762

1763

1764

1765

1766

1767

1768

1769

1770

1771

1772

1773

1774

1775

1776

1777

1778

1779

1780

1781

1782

1783

1784

1785

1786

1787

1788

1789

1790

1791

1792

1793

1794

1795

1796

1797

1798

1799

1800

1801

Sekiguchi, T., Hayano, T., Yanagida, M., Takahashi, N., Nishimoto, T., 2006. NOP132 is required for proper nucleolus localization of DEAD-box RNA helicase DDX47. Nucleic Acids Res. 34, 4593-4608. https://doi.org/10.1093/nar/gkl603

Senturk, E., Manfredi, J.J., 2013. p53 and Cell Cycle Effects After DNA Damage. Methods Mol. Biol. Clifton NJ 962, 49-61. https://doi.org/10.1007/978-1-62703-236-0_4

Serano, T.L., Cheung, H.-K., Frank, L.H., Cohen, R.S., 1994. P element transformation vectors for studying Drosophila melanogaster oogenesis and early embryogenesis. Gene 138, 181-186. https://doi.org/10.1016/0378-1119(94)90804-4

Sezgin, M., Sankur, B., 2004. Survey over image thresholding techniques and quantitative performance evaluation. J. Electron. Imaging 13, 146-166.

Shu, X.E., Swanda, R.V., Qian, S.-B., 2020. Nutrient Control of mRNA Translation. Annu. Rev. Nutr. 40, 51-75. https://doi.org/10.1146/annurev-nutr-120919-041411

Sloan, K.E., Warda, A.S., Sharma, S., Entian, K.D., Lafontaine, D.L.J., Bohnsack, M.T., 2017. Tuning the ribosome: The influence of rRNA modification on eukaryotic ribosome biogenesis and function. RNA Biol. 14, 1138-1152. https://doi.org/10.1080/15476286.2016.1259781

Studier, F.W., 2005. Protein production by auto-induction in high-density shaking cultures. Protein Expr. Purif. 41, 207-234. https://doi.org/10.1016/j.pep.2005.01.016

Tafforeau, L., Zorbas, C., Langhendries, J.-L., Mullineux, S.-T., Stamatopoulou, V., Mullier, R., Wacheul, L., Lafontaine, D.L.J., 2013. The Complexity of Human Ribosome Biogenesis Revealed by Systematic Nucleolar Screening of Pre-rRNA Processing Factors. Mol. Cell 51, 539-551. https://doi.org/10.1016/J.MOLCEL.2013.08.011

Tanentzapf, G., Devenport, D., Godt, D., Brown, N.H., 2007. Integrin-dependent anchoring of a stem-cell niche. Nat. Cell Biol. 9, 1413-1418. https://doi.org/10.1038/ncb1660

Tang, H., Hornstein, E., Stolovich, M., Levy, G., Livingstone, M., Templeton, D., Avruch, J., Meyuhas, O., 2001. Amino Acid-Induced Translation of TOP mRNAs Is Fully Dependent on Phosphatidylinositol 3-Kinase-Mediated Signaling, Is Partially Inhibited by Rapamycin, and Is Independent of S6K1 and rpS6 Phosphorylation. Mol. Cell. Biol. 21, 8671-8683. https://doi.org/10.1128/MCB.21.24.8671-8683.2001

Tasnim, S., Kelleher, E.S., 2018. p53 is required for female germline stem cell maintenance in P-element hybrid dysgenesis. Dev. Biol. 434, 215-220.

Tcherkezian, J., Cargnello, M., Romeo, Y., Huttlin, E.L., Lavoie, G., Gygi, S.P., Roux, P.P., 2014. Proteomic analysis of cap-dependent translation identifies LARP1 as a key regulator of 5'TOP mRNA translation. Genes Dev. 28, 357-371. https://doi.org/10.1101/gad.231407.113

Thomas, P.D., Campbell, M.J., Kejariwal, A., Mi, H., Karlak, B., Daverman, R., Diemer, K., Muruganujan, A., Narechania, A., 2003. PANTHER: A Library of Protein Families and Subfamilies Indexed by Function. Genome Res. 13, 2129-2141. https://doi.org/10.1101/gr.772403

Thoreen, C.C., Chantranupong, L., Keys, H.R., Wang, T., Gray, N.S., Sabatini, D.M., 2012. A unifying model for mTORC1-mediated regulation of mRNA translation. Nature 485, 109 113. https://doi.org/10.1038/nature11083

Twombly, V., Blackman, R.K., Jin, H., Graff, J.M., Padgett, R.W., Gelbart, W.M., 1996. The TGF-beta signaling pathway is essential for Drosophila oogenesis. Development 122, 1555 LP - 1565.

Tye, B.W., Commins, N., Ryazanova, L.V., Wühr, M., Springer, M., Pincus, D., Churchman, L.S., 2019. Proteotoxicity from aberrant ribosome biogenesis compromises cell fitness. eLife 8, e43002. https://doi.org/10.7554/eLife.43002

Upadhyay, M., Martino Cortez, Y., Wong-Deyrup, S., Tavares, L., Schowalter, S., Flora, P., Hill, C., Nasrallah, M.A., Chittur, S., Rangan, P., 2016. Transposon Dysregulation Modulates 
1802

1803

1804

1805

1806

1807

1808

1809

1810

1811

1812

1813

1814

1815

1816

1817

1818

1819

1820

1821

1822

1823

1824

1825

1826

1827

1828

1829

1830

1831

1832

1833

1834

1835

1836

1837

1838

1839

1840

1841

1842

1843

1844

1845

1846

1847

1848

1849

1850

dWnt4 Signaling to Control Germline Stem Cell Differentiation in Drosophila. PLOS Genet. 12, e1005918. https://doi.org/10.1371/journal.pgen.1005918

Valdez, B.C., Henning, D., So, R.B., Dixon, J., Dixon, M.J., 2004. The Treacher Collins syndrome (TCOF1) gene product is involved in ribosomal DNA gene transcription by interacting with upstream binding factor. Proc. Natl. Acad. Sci. 101, 10709-10714. https://doi.org/10.1073/pnas.0402492101

Venema, J., Cile Bousquet-Antonelli, C., Gelugne, J.-P., Le Caizergues-Ferrer, M., Tollervey, D., 1997. Rok1p Is a Putative RNA Helicase Required for rRNA Processing 17, 33983407.

Venema, J., Tollervey, D., 1995. Processing of pre-ribosomal RNA inSaccharomyces cerevisiae. Yeast 11, 1629-1650. https://doi.org/10.1002/yea.320111607

Vincent, N.G., Charette, J.M., Baserga, S.J., 2017. The SSU processome interactome in Saccharomyces cerevisiae reveals potential new protein subcomplexes. RNA rna.062927.117. https://doi.org/10.1261/rna.062927.117

Warren, A.J., 2018. Molecular basis of the human ribosomopathy Shwachman-Diamond syndrome. Adv. Biol. Regul. 67, 109-127. https://doi.org/10.1016/j.jbior.2017.09.002

Watanabe-Susaki, K., Takada, H., Enomoto, K., Miwata, K., Ishimine, H., Intoh, A., Ohtaka, M., Nakanishi, M., Sugino, H., Asashima, M., 2014. Biosynthesis of ribosomal RNA in nucleoli regulates pluripotency and differentiation ability of pluripotent stem cells. Stem Cells 32, 3099-3111.

Watkins, N.J., Bohnsack, M.T., 2012. The box C/D and H/ACA snoRNPs: Key players in the modification, processing and the dynamic folding of ribosomal RNA. Wiley Interdiscip. Rev. RNA 3, 397-414. https://doi.org/10.1002/wrna.117

Wei, Y., Reveal, B., Reich, J., Laursen, W.J., Senger, S., Akbar, T., lida-Jones, T., Cai, W., Jarnik, M., Lilly, M.A., 2014. TORC1 regulators Iml1/GATOR1 and GATOR2 control meiotic entry and oocyte development in Drosophila. Proc. Natl. Acad. Sci. 111, E5670E5677.

Woolnough, J.L., Atwood, B.L., Liu, Z., Zhao, R., Giles, K.E., 2016. The Regulation of rRNA Gene Transcription during Directed Differentiation of Human Embryonic Stem Cells. PLOS ONE 11, e0157276. https://doi.org/10.1371/journal.pone.0157276

Xie, T., 2000. A Niche Maintaining Germ Line Stem Cells in the Drosophila Ovary. Science 290, 328-330. https://doi.org/10.1126/science.290.5490.328

Xie, T., Li, L., 2007. Stem cells and their niche: an inseparable relationship. Development 134, 2001 LP - 2006. https://doi.org/10.1242/dev.002022

Xie, T., Spradling, A.C., 1998. decapentaplegic Is Essential for the Maintenance and Division of Germline Stem Cells in the Drosophila Ovary. Cell 94, 251-260. https://doi.org/10.1016/S0092-8674(00)81424-5

Yelick, P.C., Trainor, P.A., 2015. Ribosomopathies: Global process, tissue specific defects. Rare Dis. 3, e1025185. https://doi.org/10.1080/21675511.2015.1025185

Yu, H., Jin, S., Zhang, N., Xu, Q., 2016. Up-regulation of GTPBP4 in colorectal carcinoma is responsible for tumor metastasis. Biochem. Biophys. Res. Commun. 480, 48-54. https://doi.org/10.1016/j.bbrc.2016.10.010

Zahradkal, P., Larson, DawnE., Sells, BruceH., 1991. Regulation of ribosome biogenesis in differentiated rat myotubes. Mol. Cell. Biochem. 104. https://doi.org/10.1007/BF00229819

Zemp, I., Kutay, U., 2007. Nuclear export and cytoplasmic maturation of ribosomal subunits. FEBS Lett. 581, 2783-2793.

Zhang, Q., Shalaby, N.A., Buszczak, M., 2014. Changes in rRNA transcription influence proliferation and cell fate within a stem cell lineage. Science 343, 298-301. 
Zhang, Y., Forys, J.T., Miceli, A.P., Gwinn, A.S., Weber, J.D., 2011. Identification of DHX33 as a Mediator of rRNA Synthesis and Cell Growth. Mol. Cell. Biol. 31, 4676-4691. https://doi.org/10.1128/MCB.05832-11

Zhang, Y., Lu, H., 2009. Signaling to p53: Ribosomal Proteins Find Their Way. Cancer Cell 16, 369-377. https://doi.org/10.1016/j.ccr.2009.09.024

Zhou, R., Mohr, S., Hannon, G.J., Perrimon, N., 2013. Inducing RNAi in Drosophila Cells by Transfection with dsRNA. Cold Spring Harb. Protoc. 2013, pdb.prot074351pdb.prot074351. https://doi.org/10.1101/pdb.prot074351

Zielke, N., Korzelius, J., van Straaten, M., Bender, K., Schuhknecht, G.F.P., Dutta, D., Xiang, J., Edgar, B.A., 2014. Fly-FUCCl: A versatile tool for studying cell proliferation in complex tissues. Cell Rep. 7, 588-598. 